\title{
METODOLOGIA DE PROJETO DE FUNDAÇÕES POR ESTACAS INCLUINDO PROBABILIDADE DE RUÍNA
}

\author{
Jefferson Lins da Silva \\ Eng $^{\circ}$ Civil, Universidade Federal de Alagoas, 2004
}

Dissertação apresentada à Escola de Engenharia de São Carlos da Universidade de São Paulo, como parte dos requisitos para obtenção do título de Mestre em Geotecnia.

ORIENTADOR: Prof. Dr. Nelson Aoki

São Carlos - SP

2006 
Ficha catalográfica preparada pela Seçã̃o de Tratamento da Informaçẫo do Serviço de Biblioteca - EESC/USP

Silva, Jefferson Lins da

$5586 \mathrm{~m}$ Metodologia de projeto de fundações por estacas incluindo probabilidade de ruína / Jefferson Lins da Silva. -- São Carlos, 2006.

Dissertação (Mestrado) -- Escola de Engenharia de são Carlos-Universidade de são Paulo, 2006.

Área: Geotecnia.

Orientador: Prof. Dr. Nelson Aoki.

1. Fundações por estacas. 2. Probabilidade de ruína. 3. Provas de carga. I. Título. 


\section{FOLHA DE JULGAMENTO}

Candidato: Engenheiro JEFFERSON LINS DA SILVA

Dissertação defendida c julgada em 28-06-2006 perante a Comissão Julgadora:

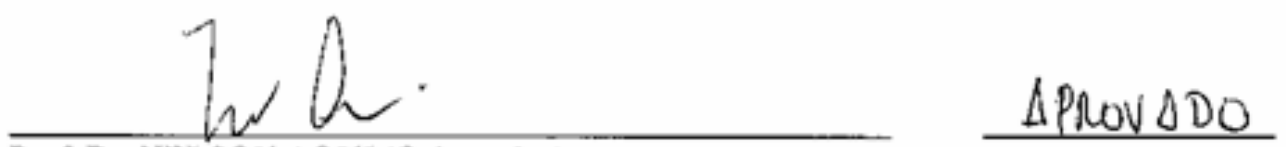

Prof. Dr. NELSON AOKI (Orientador)

(Escola de Engenharia de São Carlos/USP)

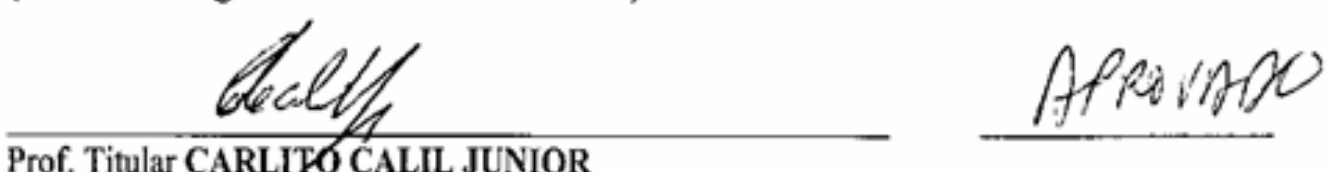

(Escola de Engenharia de São Carlos/USP)
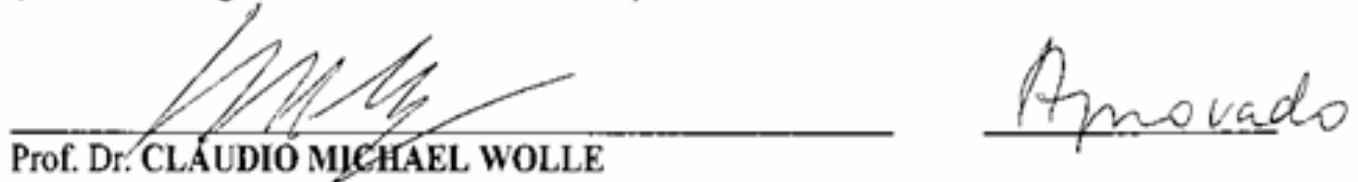

(Escola Politécnica/USP)

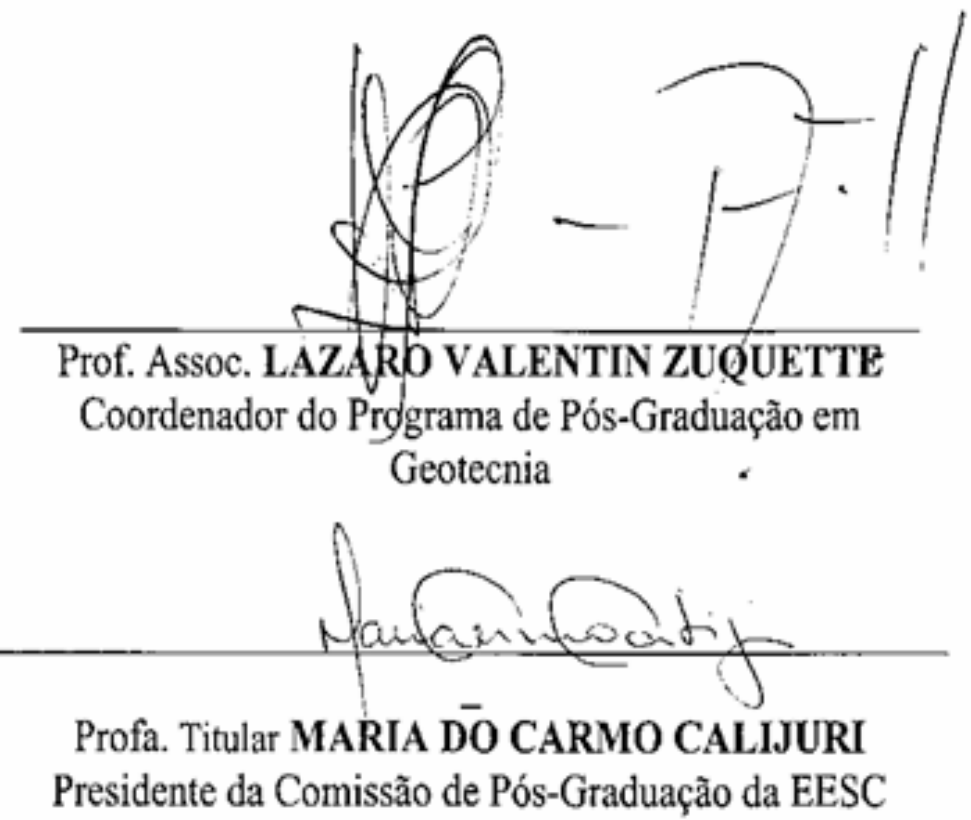


No mundo de hoje, as coisas andam a passos largos. As pessoas estão se tornando cada vez mais intolerantes e sem esperança. Pensando sobre isso, numa das madrugadas em que estive finalizando este trabalho, gostaria de deixar um testemunho pessoal que, quem sabe, possa lhe ajudar:

O maior milagre que aconteceu em minha vida foi quando ainda na infância aceitei a Jesus como Senhor e Salvador. Desde então, tenho visto Deus operar maravilhas no meu caminho. Esta dissertação é uma destas bençãos. Que o Rei Jesus possa abençoar a cada pessoa que se interesse por este texto técnico. Saiba caro leitor, que estarei orando para que você possa ter um encontro com Jesus, aliás, não foi à toa que Ele deu a sua vida na cruz por nós e ressuscitou ao terceiro dia. O bem e o mal existem, basta que nós façamos a opção por Jesus. Tudo que você precisa é secundário, ante a presença de Jesus em sua vida. Ele no Sermão da Montanha falou:

Mas buscai primeiro o Reino de Deus e a sua justiça, e todas estas coisas vos serão acrescentadas. 
Aos meus pais Renê Macêdo da Silva e Sônia Lins da Silva e a minha irmã Naila Lins da Silva: Eu e a minha casa servimos ao Senhor Jesus. 


\section{AGRADECIMENTOS}

À trindade: Deus Pai, Deus Filho e Deus Espírito Santo.

Eu sou fruto da generosidade de muitas pessoas que de bom grado me ajudaram e contribuiram de forma decisiva na minha vida pessoal e profissional até este momento. Dentre estas, não poderia deixar de citar:

Ao Prof. Dr. Nelson Aoki a quem admiro, por sua inteligência e simplicidade, e tenho orgulho de ter sido seu orientado. Obrigado pela excelente orientação, amizade, apoio e conselhos.

À Empresa Mendes Júnior Trading e Engenharia S.A., que por intemédio do Prof. Aoki, cedeu às informações sobre as fundações das obras de ampliação do Porto de Vila do Conde e autorização para publicação.

Ao Conselho Nacional de Desenvolvimento Científico e Tecnológico (CNPq) pela bolsa.

Aos Profs. Dr. José Carlos A. Cintra e Dr. Carlito Calil Júnior pelas sugestões na qualificação.

Ao Prof. Dr. Mário de Castro pela ajuda com a probabilidade e estatística.

Aos Profs. alagoanos Dr. Severino P. C. Marques, Dra. Viviane C. L. Ramos e Dra. Dilze P. C. Marques Coda pela amizade e incentivo nos trabalhos de Iniciação Científica na UFAL.

A todos os professores e funcionários do departamento de Geotecnia da EESC/USP. Em particular aos que mais solicitei ajuda: Profs. Lázaro V. Zuquette, Edmundo R. Esquivel, Gene Stancati, e aos funcionários Maristela, Alvaro, Neiva e Herivelto.

À minha turma de formandos de engenharia da UFAL.

À minha turma de mestrado, além de outros que tive o prazer de conviver no mestrado: André(PE), Angelita(MG), Clébio(PR), Cristina (SP), Fernando(SP), George(CE), Gilmar(SP), Gracinete(BA), Giulliana(SP), Isaura(Portugal), Iván(Perú), Jeselay(RN), Karla(ES), Leonardo(ES), Luiz(PR), Marcilene(PA), Magnólia(CE), Marcos(Uruguai), Nívea(RS), Ovídio(GO), Rafael(SP), Regiane(PR), Ricardo(SP), Silvia(PR), Telma(SP) e Wanessa (PB).

Aos amigos Edson Costa de Assis Júnior e Geilson Márcio Albuquerque de Vasconcelos pela amizade e parceria no convívio na república. Aos demais alagoanos que estiveram na EESC durante minha permanência no mestrado e me ajudaram em muitos momentos: André Dória, Antonio Netto, Eduardo Lucena, Eduardo Toledo, Fábio Lopes, Gustavo Codá, Jerônymo Pereira, Márcio Felix, Rafael Piatti, Saulo Almeida e Walter Oliveira.

A todos os irmãos da Igreja Evangélica Assembléia de Deus, muito especialmente em Maceió (AL) e em São Carlos (SP).

Muito obrigado e que Deus abençoe a todos! 
LISTA DE FIGURAS .........................................................................................................

LISTA DE TABELAS ...................................................................................ii

LISTA DE ABREVIATURAS E SIGLAS................................................................iii

LISTA DE SÍMBOLOS........................................................................................iv

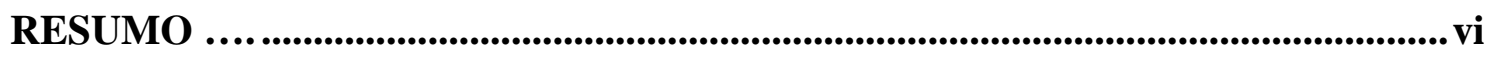

ABSTRACT ....................................................................................................................vii

1 INTRODUÇÃO ............................................................................................ 1

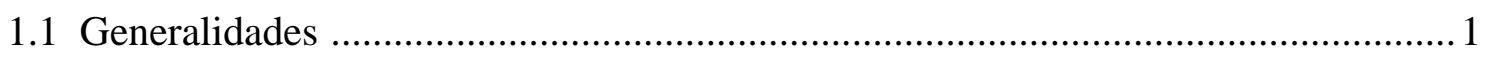

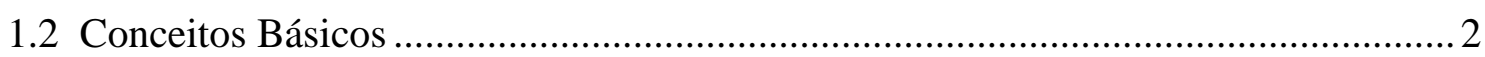

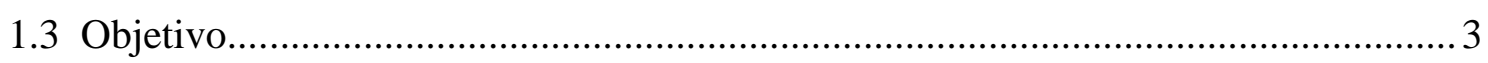

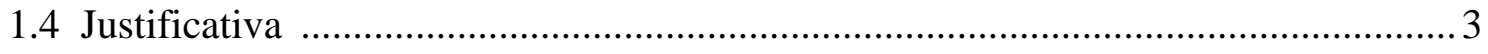

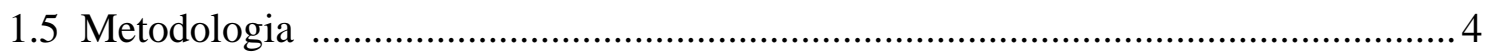

1.6 Organização da Dissertação .................................................................................

2 EVOLUÇÃO BIBLIOGRÁFICA ...................................................................6

2.1 Trabalhos Pesquisados ................................................................................

2.2 Comentários sobre a Bibliografia Pesquisada ........................................................19

3 MÉTODOS DE VERIFICAÇÃO DE SEGURANÇA …………………………...... 21

3.1 Formulações Determinísticas ( $\mathrm{F}_{\mathrm{S}}$ e MTA) ……………………………………...... 23

3.2 Formulações Semi-Probabilísticas ( $F_{S}$ Parciais e MEL) ………………………….... 23

3.3 Formulações Probabilísticas (Probabilidade de Ruína) ............................................ 25

3.4 Verificação de Segurança em Fundações .................................................................... 27

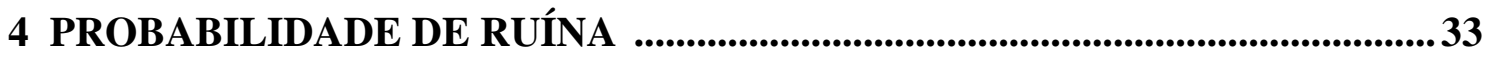

4.1 Função Margem de Segurança ............................................................................. 35

4.2 Função Fator de Segurança ..................................................................................... 37

4.3 Distribuições de Resistências e Solicitações .................................................................38

4.4 O Método de Monte-Carlo .................................................................................... 40 


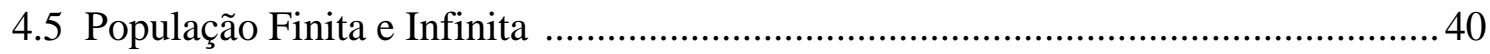

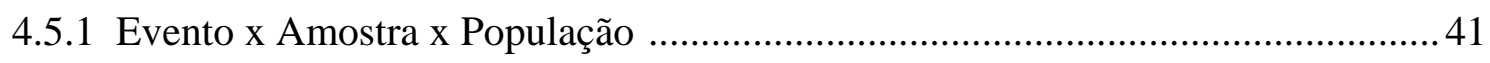

4.5.2 População Finita - Proposição de Aoki (2002) .................................................. 42

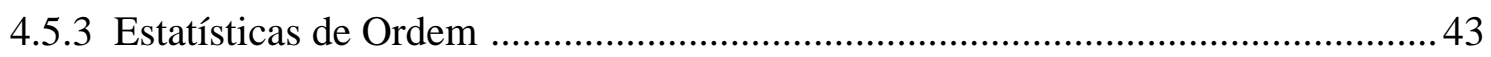

4.5.4 Aplicação 1 - Edifício de Concreto Armado ....................................................... 45

4.5.5 Aplicação 2 - Casos de Fundações ...................................................................... 49

5. PROPOSTA PARA O PROJETO DE FUNDAÇÕES ...................................... 54

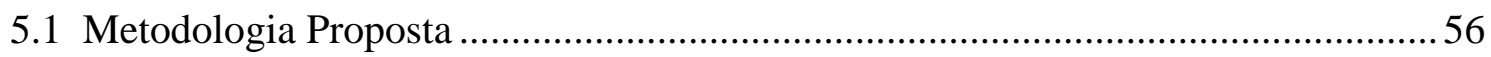

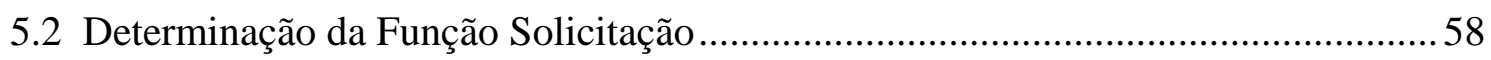

5.3 Determinação da Função Resistência ...................................................................... 59

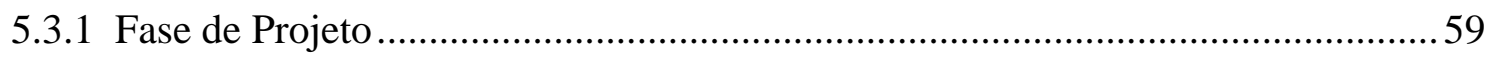

5.3.2 Fase de Execução - Controles Executivos de Campo ............................................62

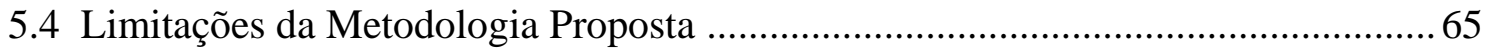

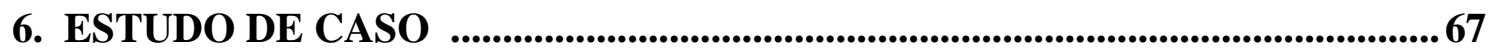

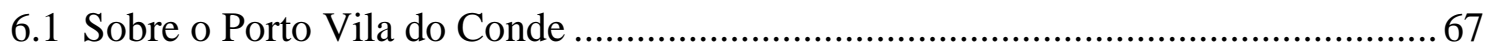

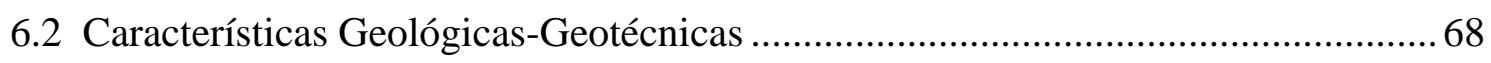

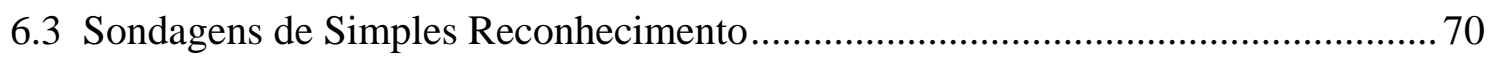

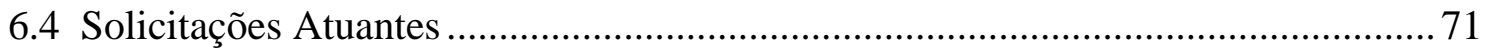

6.5 Resistências dos Elementos Isolados de Fundação................................................... 71

6.5.1 Elemento Estrutural de Fundação ....................................................................... 71

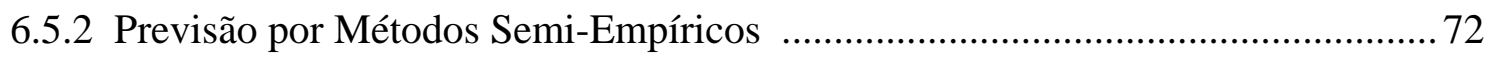

6.5.3 Provas de Carga Dinâmica de Energia Crescente ................................................. 74

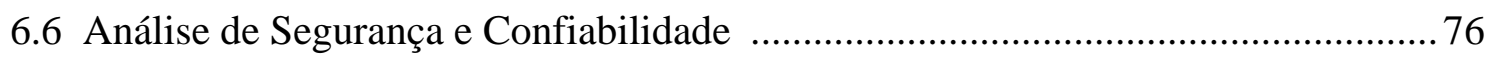

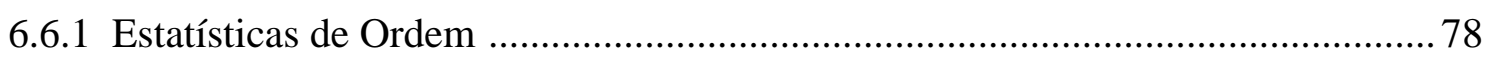

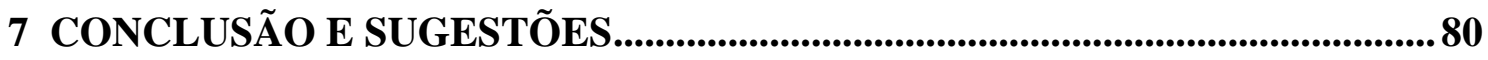

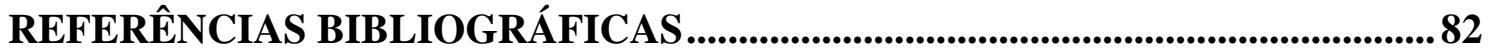

ANEXO A - PERFIS GEOTÉCNICOS ...........................................................99

ANEXO B - SOLICITAÇÕES ATUANTES ........................................................95

ANEXO C - SUPERFÍCIE RESISTENTE PREVISTA......................................... 103 


\section{LISTA DE FIGURAS}

Figura 1.1 - Objeto de estudo da fundação: superfície resistente...................................2

Figura 2.1 - Valores usuais da probabilidade e consequências da ruína ........................ 10

Figura 2.2 - Componentes do projeto da fundação e os códigos de prática ................... 15

Figura 2.3 - Ilustração da análise de custo-benefício ................................................ 18

Figura 3.1 - Métodos de verificação da segurança....................................................22

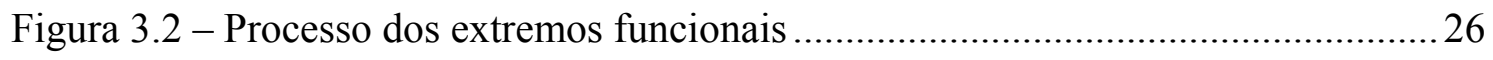

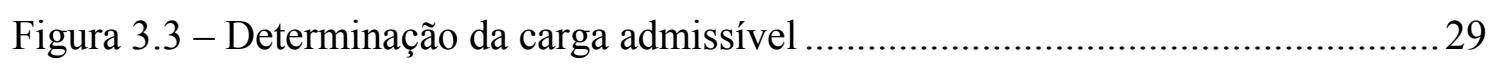

Figura 3.4 - Curvas de solicitações e resistências e fatores de segurança global e

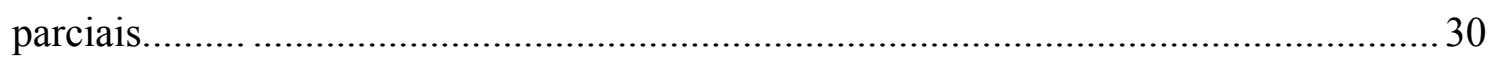

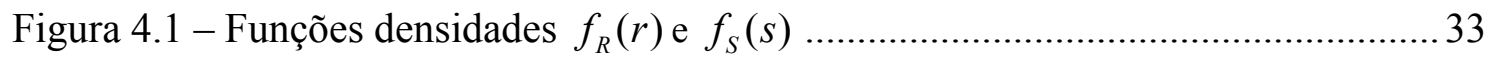

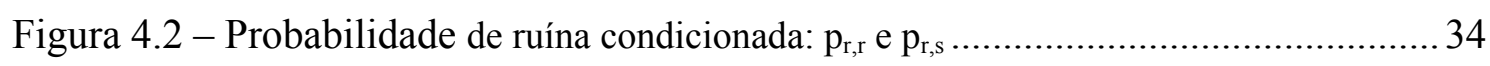

Figura 4.3 - Margem de segurança e respectivo índice de confiabilidade ..................... 35

Figura 4.4 - Fator de segurança e respectivo índice de confiabilidade .......................... 37

Figura 4.5 - Distribuição probabilística do FS considerando duas condições (a) e (b).. 37

Figura 4.6 - Amostra e população de uma fundação ...................................................... 42

Figura 4.7 - Esquema de locação e solicitações nos pilares do andar térreo .................. 45

Figura 4.8 - Seção transversal do pilar: (a) Real e (b) Homogeneizada......................... 46

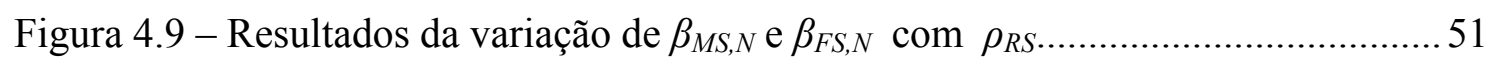

Figura 5.1 - Deslocamento D do topo da estaca (nega S e repique K)..........................65

Figura 6.1 - Vista panorâmica e esquema simplificado do Porto de Vila do Conde...... 68

Figura 6.2 - Localização das sondagens no Píer 3 ....................................................... 70

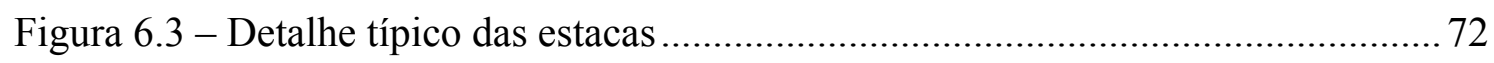

Figura 6.4 - Curvas resistência x deslocamento das provas de carga............................ 75 


\section{LISTA DE TABELAS}

Tabela 3.1 - Fatores de segurança globais mínimos para estacas e tubulões 29

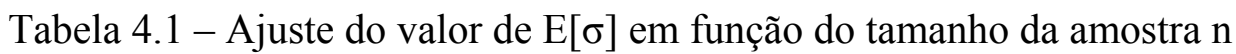
44

Tabela 4.2 - Análise estatística das solicitações nos pilares.......................................... 46

Tabela $4.3-\sigma_{R}$ em função da qualidade de execução do concreto..................................4 47

Tabela 4.4 - Análise estatística das resistências nos pilares.......................................... 47

Tabela $4.5-F_{S}$ para 12 casos de resistência e solicitação .............................................. 48

Tabela 4.6 - $\beta_{M S, N}$ para 12 casos de resistência e solicitação......................................... 48

Tabela $4.7-p_{r}$ para 12 casos de resistência e solicitação............................................. 48

Tabela 4.8 - Resistência e Solicitação das 13 fundações utilizadas ............................... 49

Tabela 4.9 - Obtenção de $\beta_{M S, N}$ a partir da Simulação de Monte-Carlo e Aoki (2002). 50

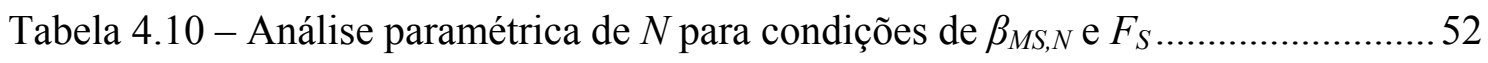

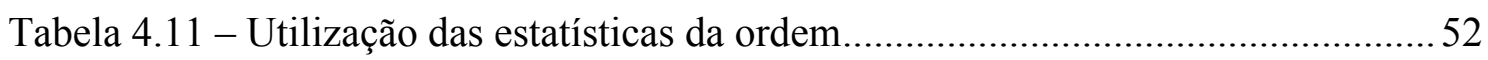

Tabela 6.1 - Condições meteorológicas e hidrográficas do Porto de Vila do Conde...... 68

Tabela 6.2 - Análise estatística das solicitações atuantes $(\mathrm{kN})$...................................... 71

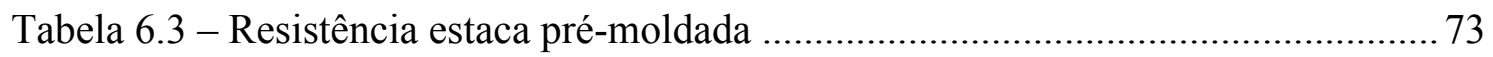

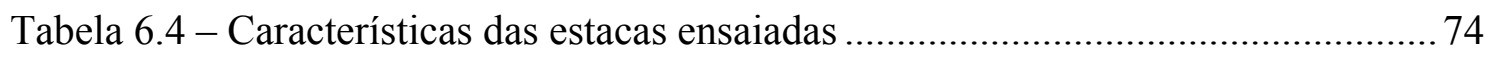

Tabela 6.5 - Análise dos resultados das provas de carga dinâmica................................ 75

Tabela 6.6 - Segurança e confiabilidade da previsão ................................................... 76

Tabela 6.7 - Segurança e confiabilidade da comprovação ........................................... 77

Tabela 6.8 - Segurança e confiabilidade da comprovação ........................................... 77

Tabela 6.9 - Segurança e confiabilidade da comprovação ............................................. 77

Tabela 6.10 - Segurança e confiabilidade usando estatísticas de ordem ....................... 78

Tabela 6.11 - Segurança e confiabilidade usando estatísticas de ordem ....................... 79 


$\begin{array}{ll}\text { ABCP } & \text { Associação Brasileira de Cimento Portland } \\ \text { CASE } & \text { Case institute of technology } \\ \text { CAPWAP } & \text { Case pile wave analysis program } \\ \text { CAPWAPC } & \text { Case pile wave analysis program continuous version } \\ \text { EEF } & \text { Elemento estrutural de fundação } \\ \text { EESC/USP } & \text { Escola de Engenharia de São Carlos - USP } \\ \text { EIF } & \text { Elemento isolado de fundação } \\ \text { MTA } & \text { Método das tensões admissíveis } \\ \text { MEL } & \text { Método dos estados limites } \\ \text { MPC } & \text { Método probabilista condicionado } \\ \text { MPP } & \text { Método probabilista puro } \\ \text { MSP } & \text { Método semi-probabilista } \\ \text { PUC-Rio } & \text { Pontifícia Universidade Católica do Rio de Janeiro }\end{array}$




\section{LISTA DE SÍMBOLOS}

\section{Letras romanas}

$E[X]$ - Valor médio esperado da variável aleatória $\mathrm{X}$

$E_{s}$ - Módulo de elasticidade do solo

$F_{S}-$ Fator de segurança global $\left(F S=m_{F S}=m_{R} / m_{S}\right)$

$F S$ - Função não-linear fator de segurança $(F S=R / S)$

$F_{R}(x)$ - Função distribuição $\mathrm{R}$ acumulada até $\mathrm{x}$

$f_{S}(x)$ - Função distribuição $\mathrm{S}$ em $\mathrm{x}$

$M S$ - Função linear margem de segurança $(M S=R-S)$

$m_{R}$ e $R_{m}$ - Valor médio ou média da variável resitência

$m_{S}$ e $S_{m}$ - Valor médio ou média da variável solicitação

$n$ - Tamanho da amostra e fator proposto por Shigley (1989)

$N$ - Tamanho da população

$P_{a d m}-$ Carga admissível

$p_{r}$ - Probabilidade de ruína

$\mathrm{p}_{\mathrm{r}, \mathrm{r}}$ - Probabilidade de ruína condicionada com resistência crescente

$\mathrm{p}_{\mathrm{r}, \mathrm{s}}$ - Probabilidade de ruína condicionada com solicitação crescente

$R$ - Variável aletória resistência

$R_{d}$ - Resistência de cálculo

$R_{k}$ - Resistência característica

$R_{m, e}-$ Resitência média estrutural

$R_{m, g}-$ Resitência média geotécnica

$S$ - Variável aletória solicitação

$S_{d}$ - Solicitação de cálculo

$S_{k}$ - Solicitação característica

$\operatorname{Var}[X]$ ou $E\left[X^{2}\right]$ - Variância da variável aleatória $\mathrm{X}$ 


\section{LISTA DE SÍMBOLOS}

\section{Letras gregas}

$\beta_{M S}$ ou $\beta_{M S, N}$ - Índice de confiabilidade a partir de $M S$ com $R$ e $S$ apresentando distibuição normal

$\beta_{F S}$ ou $\beta_{F S, N}$ - Índice de confiabilidade a partir de $F S$ com $R$ e $S$ apresentando distibuição normal

$\beta_{M S, L N}$ - Índice de confiabilidade a partir de $M S$ com $R$ e $S$ apresentando distibuição log-normal

$\beta_{F S, L N}$ - Índice de confiabilidade a partir de $F S \operatorname{com} R$ e $S$ apresentando distibuição lognormal

$\phi$ - ângulo de atrito do solo

$\nu_{R}$ - Coeficiente de variação de $R$

$v_{S}$ - Coeficiente de variação de $S$

$\rho_{R S}$ - Coeficiente de correlação entre $R$ e $S$

$\sigma_{R}-$ desvio padrão da variável resistência

$\sigma_{S}$ - desvio padrão da variável solicitação

$\sigma_{M S}-$ desvio padrão da variável $M S$

$\sigma_{F S}$ - desvio padrão da variável $F S$

$\gamma_{i}$ - fator de segurança interno

$\gamma_{S}$ - Fator parcial de segurança função da variabilidade da solicitação

$\gamma_{R}$ - Fator parcial de segurança função da variabilidade da solicitação

$\gamma_{f}$ - Fator parcial de majoração das solicitações

$\gamma_{m}$ - Fator parcial de majoração das resistências

$\gamma_{v}$ - Fator parcial resultante variável $\left(\gamma_{v}=\gamma_{S} \cdot \gamma_{R}\right)$

$\gamma_{k}$ - Fator parcial resultante característico $\left(\gamma_{k}=\gamma_{f} \cdot \gamma_{m}\right)$ 


\section{RESUMO}

SILVA, J. L. (2006). Metodologia de Projeto de Fundações por Estacas incluindo Probabilidade de Ruína. Dissertação (Mestrado) - Escola de Engenharia de São Carlos, Universidade de São Paulo. São Carlos, 2006.

Apresenta-se uma metodologia de projeto de fundações por estacas incluindo probabilidade de ruína. Considera-se que a complexidade do comportamento geológicogeotécnico do maciço de solo e do elemento estrutural de fundação, submetidos às ações aleatórias ambientais e funcionais, pode ser avaliada por meio das variáveis aleatórias resistência e solicitação. Estatisticamente, a metodologia proposta supõe que a população da fundação é finita, e que os estimadores extraídos das sondagens de simples reconhecimento e das provas de carga podem ser representativos da população (Aoki, 2002), também podem ser avaliados pelas estatísticas de ordem. Aplica-se esta metodologia na fundação do Píer 3 do Porto de Vila do Conde localizado no Estado do Pará, tendo como compartimentação geológica a Formação Barreiras. Conclui-se, de modo geral, que esta metodologia pode ser aplicada nas obras de fundações por estacas, especialmente, para auxiliar nas tomadas de decisões.

Palavaras-chave: Fundação por Estacas, Probabilidade de Ruína, Provas de Carga. 


\section{ABSTRACT}

SILVA, J. L. (2006). Application of ruin probability in pile foundation projects. Dissertation (MSc.) - Engineering School of Sao Carlos, University of Sao Paulo. Sao Carlos, 2006.

A methodology of pile foundation projects is presented incorporating ruin probability. It is considered that the complexity of the geological and geotechnical behaviors of the soil mass and the structural element of foundation, subjected to environmental and functional random actions, can be evaluated by strength and solicitation variables. Statistically, the proposed methodology assumes that the population of the foundation is finite, and that the extracted estimators of the standard penetration tests (SPT) and the load tests could be representative of the population (Aoki, 2002). The extracted estimators of the said tests can also be evaluated by the order statistics. This methodology is applied in the Pier 3 foundation of Porto de Vila do Conde, Pará State, which is underlain by the Barreiras Formation. It is concluded that in most cases, this methodology could be applied to pile foundations, especially, in taking decisions.

Key words: Pile Foundations, Ruin Probability, Load Tests. 


\section{Introdução}

\subsection{Generalidades}

Desde a época mais antiga o homem percebeu que suas obras mostravam comportamentos diferentes ao longo do tempo, especialmente pelo procedimento utilizado: tentativa e erro (Bilfinger, 2002). Os construtores recebiam severas penalidades quando a estrutura não apresentava o desempenho desejado na sua concepção. Ainda era cedo para perceber que o comportamento de uma obra dependia da combinação de eventos simples, complexos, dependentes e independentes.

Fundamentado na observação das estruturas o homem, desde a antiguidade, já demonstrava preocupação com questões como segurança e regulamentos para a construção de suas obras. Com o aumento das construções, aliado ao enorme desperdício dos materiais utilizados, também nascia o entendimento popular de que economizar é preciso.

Hoje, é notório que para garantir o sucesso de uma estrutura, seja ela civil, mecânica, aeronáutica, etc; deve-se buscar desvendar a variabilidade das características mecânicas inerentes aos materiais no espaço-tempo. À medida que esta variabilidade se tornava conhecida, a racionalização dos projetos e normas de engenharia foram desenvolvidos a partir de teorias empíricas, modelos físicos e matemáticos.

Considerar a aleatoriedade dos eventos físicos com o uso da estatística é a moderna tendência dos projetos e normas de engenharia. Porém, como comenta Whitman (1984), infelizmente a probabilidade remanesce ainda um mistério para muitos engenheiros, por um lado por causa da barreira linguística e por outro pela falta de exemplos que mostrem como a metodologia pode ser utilizada no processo de tomada de decisão.

Neste sentido, esta dissertação contribui para a utilização da estatística e probabilidade na geotecnia, em particular na engenharia de fundações. 


\subsection{Conceitos Básicos}

A definição de fundação adotada nesta dissertação é a mesma de Cintra \& Aoki (1999): fundação é um sistema formado por elementos estruturais de fundação (EEF) e as diversas camadas de solos que os envolvem. Um EEF com o solo em volta denomina-se elemento isolado de fundação (EIF), logo pode-se definir que uma fundação é um conjunto de EIF.

Com a utilização da definição de Cintra \& Aoki (1999), pode-se dizer que a engenharia de fundações é uma área de pesquisa com cárater multidisciplinar, na qual os parâmetros resistência e solicitação são avaliados, basicamente, a partir da engenharia de estruturas e geotecnia. Portanto, a verificação ao estado limite último deve atender simultâneamente às normas de fundações, basicamente a NBR 6122/1996 (projeto e execução de fundações), e de estruturas, por exemplo: NBR 6118/2003 (estruturas de concreto) e NBR 8681/2003 (ações e segurança nas estruturas).

O objeto de estudo de uma fundação por estacas é a superfície resistente formada pelas áreas das bases dos EEF, conforme Aoki e Cintra (1996). A definição de superfície resistente está vinculada a uma análise global que considera as variabilidades estrutural e geotécnica e a influência da atividade humana no processo, como indica a Figura 1.1a. Em última análise, o problema pode ser condensado no estudo de duas variáveis aleatórias: solicitação e resistência referentes à fundação representada pela superfície resistente (Figura 1.1b).

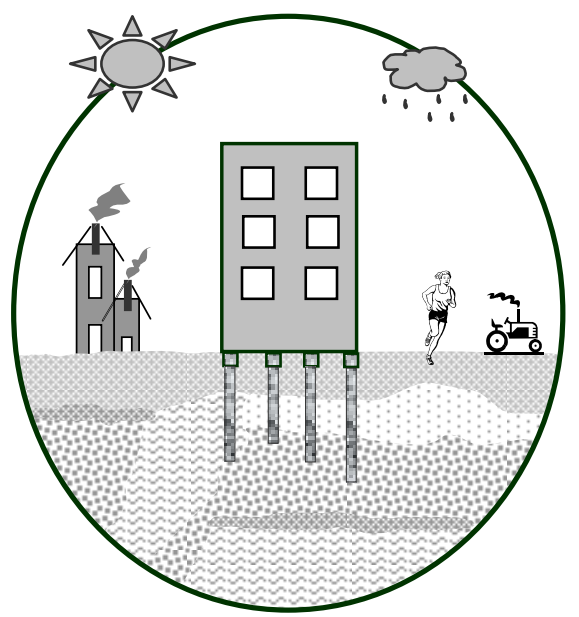

(a) Sistema Global: Obra + Meio Físico

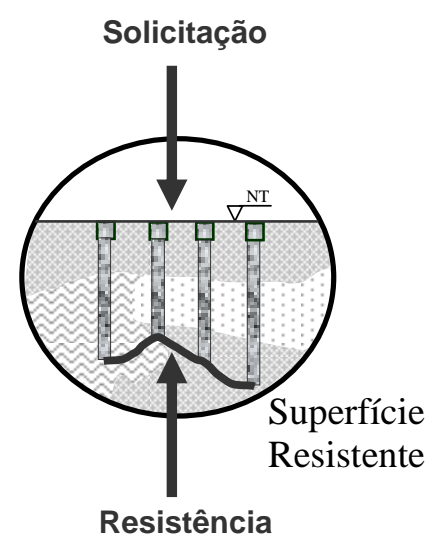

(b) Sub-Sistema: Fundação

Figura 1.1 - Objeto de estudo da fundação: superfície resistente. 


\subsection{Objetivo}

O objetivo deste trabalho é apresentar uma metodologia de projeto de fundações por estacas no estado limite último incluindo probabilidade de ruína, de forma a projetar fundações com segurança e confiabilidade associadas.

O interesse principal é analisar a aleatoriedade das variáveis resistência e solicitação e introduzir o estudo da confiabilidade na engenharia de fundações, que ainda é utilizado aquém de suas possibilidades.

\subsection{Justificativa}

As modificações na filosofia de projeto e execução de fundações no Brasil e no exterior exigem uma nova visão do processo de verificação da segurança de fundações.

A cultura tradicional da carga admissível, baseada num fator de segurança global e obtida pela experiência, foi redirecionada para uma nova cultura da carga característica, baseada na aplicação de fatores de segurança parciais. Todavia, esta mudança foi proposta sem uma devida divulgação dos pressupostos científicos em que foi baseada, gerando resistência na sua adoção.

Não há uma metodologia de projeto de fundações comum no mundo, pois em cada país, e até dentro de um mesmo país, existem conceitos de projeto que não são unânimes para a comunidade técnica, como mostra De Cock e Legrand (1997).

A justificativa desta pesquisa se baseia na necessidade de estudos que apresentem metodologias para projetos de fundação por estacas fundamentadas não somente nos fatores de segurança, mas também na estimativa da probabilidade de ruína associada. A inércia da evolução deste assunto na engenharia de fundações se dá basicamente, pelo excesso de conservadorismo, motivado pela grande responsabilidade envolvida e pelo custo proporcionalmente baixo da fundação em relação à superestrutura.

Esta dissertação é uma extensão dos trabalhos de Oliveira (1998) e Silva, F. (2003), desenvolvidos no Departamento de Geotecnia da EESC/USP.

Oliveira (1998) aborda o modelo de introdução da segurança baseada em métodos probabilísticos, utilizado nos cálculos em estados limites, e apresenta um paralelo entre o cálculo em estados limites e cargas admissíveis, enfatizando a calibração dos fatores utilizados nos dois métodos de cálculo para garantir o bom desempenho das fundações. 
Uma conclusão interessante deste trabalho revela que alguns fatores de segurança parciais são conservadores.

Em Silva, F. (2003) gerou-se um banco de dados do valor do coeficiente de variação da resistência de fundações para diferentes tipos de estacas e formações geológico-geotécnicas, a partir de provas de carga estática e dinâmica.

\subsection{Metodologia}

Na realização do trabalho, procurou-se inicialmente realizar uma ampla revisão bibliográfica para levantar referências sobre o assunto da pesquisa, assim como a revisão de conceitos ligados aos diferentes métodos de introdução da segurança nos projetos de fundação.

A partir da revisão bibliográfica, analisaram-se alguns tópicos relativos à estimativa da probabilidade de ruína na engenharia civil, tais como: população, amostra, proposição de Aoki (2002) e as estatísticas de ordem.

Com base nos itens anteriores, elaborou-se a metodologia proposta considerando, especialmente, a obtenção das solicitações e resistências na engenharia de fundações, dando-se mais ênfase a variabilidade da resistência estrutural-geotécnica.

Para validação da metodologia, utilizou-se dados reais de uma obra situada no Porto de Vila do Conde - PA, com os quais pode-se mostrar a importância do uso dos conceitos probabilísticos nos projetos de fundações ressaltando as suas aplicações práticas.

\subsection{Organização da Dissertação}

Esta dissertação é composta por sete capítulos. A revisão bibliográfica foi dividida nos capítulos 2 e 3. No capítulo 2, apresenta-se uma evolução sintética do conceito da segurança e confiabilidade na engenharia geotécnica e estrutural, enfatizando a engenharia de fundações, onde procurou-se abordar os principais trabalhos.

O capítulo 3 trata dos métodos de verificação de segurança, desde os que se baseiam em formulações determinísticas até os mais avançados, que utilizam formulações probabilísticas. Dentre estes métodos, destacam-se: método da tensão admissível, método dos estados limites e o método do índice de confiabilidade (probabilidade de 
ruína). No final deste capítulo, comenta-se como é avaliada a segurança na engenharia de fundações nos dias atuais.

O capítulo 4 trata da aplicação da matemática estatística no problema. Neste, procurou-se abordar o cálculo da probabilidade de ruína baseada no índice de confiabilidade, levando em consideração duas variáveis aleatórias: resistência e soliciação. A probabilidade de ruína foi formulada analíticamente a partir das funções margem de segurança e fator de segurança.

No final do capítulo 4 discutem-se tópicos relacionados à estimativa da probabilidade de ruína, tais como:

- Evento, amostra e população;

- Proposição de Aoki (2002) para população finita e as estatísticas de ordem;

- A dependência entre resistência e solicitação na probabilidade de ruína;

- O Método de Monte-Carlo e a formulação simplificada do capítulo 4.

Ainda no capítulo 4, foram utilizados dois exemplos para a análise dos tópicos supracitados, o primeiro referente a um edifício de concreto armado e alguns casos de fundações extraídos do banco de dados publicados por Silva, F. (2003).

Com base nas informações dos capítulos anteriores, o capítulo 5 descreve a metodologia de projeto de fundações por estacas no estado limite último incluindo probabilidade de ruína, dando-se ênfase a obtenção das variáveis resistência e solicitação no projeto. A metodologia desta dissertação foi inspirada em Cintra \& Aoki (1999).

O capítulo 6 refere-se à aplicação da metodologia proposta, onde se utilizou os dados da fundação do Porto de Vila do Conde - PA. O capítulo 7 apresenta a conclusão da dissertação e sugestões para futuras pesquisas. 


\section{Evolução Bibliográfica}

O intuito deste capítulo é mostrar a evolução da noção de segurança e confiabilidade na engenharia geotécnica, especialmente em fundações. Porém, devido à menor quantidade de trabalhos sobre este assunto em geotecnia em relação à engenharia estrutural, aliada ao fato desta ser precursora neste assunto, procurou-se pesquisar os principais trabalhos nacionais e internacionais que envolvem a confiabilidade estrutural e geotécnica.

Para uma melhor compreensão da evolução do estudo da segurança e confiabilidade, os trabalhos pesquisados são apresentados em ordem cronológica e de forma resumida.

\subsection{Trabalhos Pesquisados}

O código de Hamurabi (Bouzon, 1976), rei da Babilônia, talvez seja o mais antigo código que trata da segurança estrutural. Este pode ser compilado na seguinte frase: olho por olho, dente por dente. Nas civilizações antigas, os códigos existiam para estabelecer a ordem nos reinados e, de certa forma, proteger os interesses de seus cidadãos.

Conforme Nowak \& Collins (2000), os primeiros trabalhos abordando a segurança na engenharia podem ser atribuídos a Mayer (1926), Wierzbicki (1936) e Streletzki (1947). Estes trabalhos reconhecem que os parâmetros de resistência e solicitação são variáveis aleatórias e que uma estrutura tem probabilidade de ruína finita.

Freudenthal (1947) utiliza a estatística como ferramenta para verificar a segurança de estruturas. Neste trabalho, mostra-se as tendências de evolução da área, define-se a probabilidade de ruína como sendo a integral da distribuição de probabilidade das variáveis dentro de um certo domínio. Afirma-se que as causas que afetam a dispersão 
da solicitação e resistência de uma estrutura são praticamente infinitas e as classifica em três grupos:

Grupo A: Causas de variação da deformação*

I. Incerteza e variabilidade das condições de carregamento

a. Carga permanente

b. Carga acidental (incluindo efeitos dinâmicos)

II. Incerteza e variabilidade das condições externas que são independentes do carregamento

a. Mudança de temperatura

b. Forças do vento

c. Incertezas do comportamento do subsolo

Grupo Intermediário: Causas de incertezas das análises computacionais da

III. Variação da rigidez deformação*

IV. Imperfeição dos métodos e defeito de suposições

a. Precisão de métodos e tolerância da computação numérica

b. Inadequação das suposições concernentes as condições iniciais e de contorno, concentração de tensões, e deformações secundárias.

Grupo B: Causas de variação da resistência

$V$. Incerteza e imprecisão dos mecanismos de resistência adotados

a. Imprecisão ou inadequação dos mecanismos concebidos

b. Variabilidade da resistência limite dos materiais

II. Variabilidade das dimensões estruturais

Ao analisar a influência das incertezas no comportamento do subsolo, Freudenthal (1947) explica que a fundação (neste caso, entenda-se fundação como elemento estrutural de fundação) é uma parte integrante da estrutura, e seu comportamento, que depende principalmente do desempenho do subsolo, exerce considerável influência no estado de deformação de estruturas estaticamente indeterminadas (interação soloestrutura). A deformação resultante do desempenho do subsolo na estrutura é ou inteiramente negligenciada nos projetos convencionais (essencialmente baseado na suposição de apoios indeslocáveis ou uniformemente deslocáveis) ou considerada com importância secundária.

Freudenthal (1956) analisa a probabilidade de ruína envolvendo o estado limite de serviço e o estado limite último e conclui que essas verificações são tão importantes quanto às feitas para as tensões admissíveis.

* No Brasil o efeito das cargas, que é a deformação, é denominado de solicitação. 
Hansen (1956) propõe, na filosofia de projeto de fundação, a substituição do fator de segurança global por fatores de segurança parciais relacionados aos parâmetros que influenciam no projeto, tais como: carregamento, materiais do EEF, etc. Este mesmo autor comenta que um projeto de fundação deve obedecer a duas condições de ruína, relacionadas ao estado limite último e de serviço.

Casagrande (1965) classifica os riscos em risco de engenharia (divididos em risco calculados e desconhecidos) e riscos humanos, que se dividem em organização insatisfatória, incluindo divisão de responsabilidade entre projeto e supervisão da construção, uso insatisfatório do conhecimento disponível, e a corrupção. O autor comenta que nos casos de riscos humanos frequentemente há uma interligação entre as três divisões.

Langejan (1965) relata sobre dois aspectos do fator de segurança na mecânica dos solos considerando como um problema de probabilidade: a relação entre o número de ensaios e a probabilidade de ruína da estrutura e o uso da teoria da decisão econômica estatística na determinação da probabilidade de ruína.

Em Freudenthal et al. (1966) observa-se que as equações da probabilidade de ruína são colocadas na forma em que são utilizadas hoje. O capítulo 4 desta dissertação aborda com mais detalhes este trabalho.

Ang e Amin (1968) descrevem o problema clássico da resistência e solicitação, cuja solução é exata. Conclui-se neste trabalho que o procedimento de cálculo da confiabilidade para sistemas estruturais determinados e indeterminados é o mesmo.

Na engenharia geotécnica, o livro de Benjamim e Cornell (1970) é uma excelente fonte de consulta para assuntos relacionados à segurança, probabilidade e decisões para engenheiros. Estes autores aplicam estes assuntos a diversos problemas da engenharia civil, enfatizando que a probabilidade de ruína pode ser vinculada a uma análise de custo-benefício.

Zagottis (1974) apresenta um histórico dos métodos de introdução da segurança no projeto estrutural, exemplificando com exemplos e avaliando a potencialidade de cada procedimento.

Os recentes trabalhos sobre confiabilidade, como por exemplo: Neves (2004) e Nogueira (2005) destacam o artigo de Hasofer e Lind (1974) como um dos mais importantes. As principais conclusões deste artigo são: 
- Uma medida do índice de confiabilidade de segundo momento de um projeto ou sistema é a distância entre a média das variáveis básicas até o contorno da região de ruína, quando todas as variáveis são medidas em unidades de desvio padrão;

- O índice de confiabilidade é invariante sob qualquer modificação do critério de ruína que obedeça às leis da álgebra e da mecânica.

Segundo Ang \& Cornell (1974) a mínima informação para representar o caráter aleatório das variáveis envolvidas no projeto são o valor médio e uma medida de dispersão (variância ou desvio-padrão).

Aoki \& Falcão (1974) em suas notas de aula já comentavam que o fator de segurança nas obras de engenharia tende modernamente a ser considerado cada vez mais ligado à probabilidade de ruína da obra, considerando a aleatoriedade das variáveis resistência e solicitação.

Hachich, W. (1978) é o primeiro trabalho brasileiro que extende a noção de segurança no projeto estrutural para a geotecnia. Abordam-se os métodos de verificação de segurança e apresenta-se uma revisão crítica sobre a introdução da segurança nas obras geotécnicas até aquele momento. De modo geral, conclui-se que o método dos estados limites é comumente utilizado nas estruturas geotécnicas e que a verificação da segurança no estado limite de serviço é explícita e racional no projeto de fundações.

Grigoriu et al. (1979) afirmam que um dos fatores que limita a aplicação da teoria probabilística em análises de confiabilidade é a arbitrariedade com que as distribuições probabilisticas são escolhidas e que este problema aumenta quando o número de variáveis cresce e a informação sobre as distribuições é limitada.

Whitmann (1984) apresenta, como mostra a Figura 2.1, uma avaliação sobre o risco praticado em algumas atividades. Os resultados da Figura 2.1 fornecem indicações sobre o risco usualmente aceitável e, conseqüentemente, o limite superior do risco admissível em cada caso. 


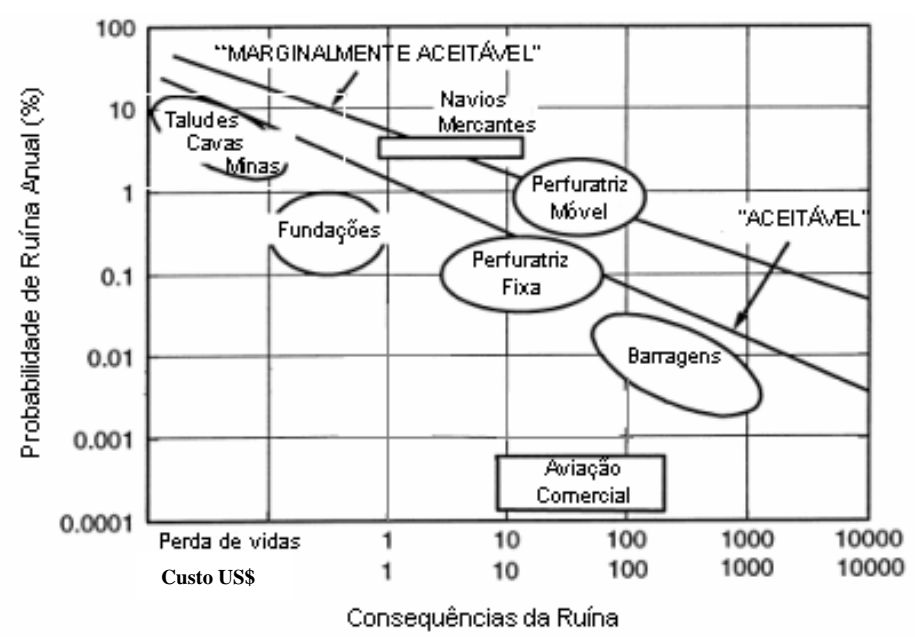

Figura 2.1 - Valores usuais da probabilidade e consequências de ruína. Fonte: Modificado de Whitmann (1984).

Dentre as principais fontes de incerteza na variabilidade dos parâmetros geotécnicos, Whitmann (1984) identifica:

- Erros estatísticos na avaliação do valor médio de uma propriedade, por incertezas decorrentes de uma amostragem reduzida.

- Erros tendenciosos (“measurement bias”), isto é, distúrbio da amostragem ou erros associados com os ensaios in situ, dentre outros.

- Variabilidade espacial das propriedades geotécnicas. Esta é uma variabilidade aleatória, igualmente distinta para identificar tendências que podem ser incorporadas no modelo deterministico.

- Erros aleatórios provenientes de imperfeições de ensaios e de erros humanos, dentre outros fatores ("measurement noise”).

Ang \& Tang (1984) definem a probabilidade de ruína de forma semelhante à de Freudenthal et al. (1966). O livro daqueles autores é considerado uma fonte de consulta bastante didática entre os engenheiros pesquisadores.

Considerando que, para o cálculo mais preciso da probabilidade de ruína, a análise do risco geotécnico de uma obra de engenharia deve levar em conta, além dos parâmetros clássicos, média e variância, uma variável estatística denominada escala de flutuação. Segundo Gimenes (1988) esta variável representa a variabilidade espacial de determinada propriedade. Neste trabalho, apresenta-se uma metodologia baseada em Vanmarcke (1977) para determinação da escala de flutuação. O estudo é aplicado a uma parte do maciço compactado da Usina de Nova Avanhandava nas quais os resultados 
mostram diferenças da ordem de 70\% entre as escalas de flutuação dos parâmetros de compactação e da umidade “in situ”.

Folse (1989) apresenta um método para o cálculo do índice de confiabilidade de estacas submetidas a carregamento lateral, em que a não-linearidade geométrica é utilizada no modelo mecânico da interação estaca-solo. Comenta-se que este procedimento contribui para uma adequada análise probabilística desses elementos.

Moreira (1989) comenta sobre os dois tipos de interpretação da probabilidade de ruína quanto ao comportamento esperado de um empreendimento:

- Probabilidade estatística: representa a probabilidade de ruína propriamente dita. É impessoal e pode ser interpretada quanto à frequência de eventos. Neste caso, um valor $p_{r}=5 \%$ significa que, de cada 100 estruturas construídas sob condições idênticas, cinco são esperadas de entrar em ruína. Em geral, é muito difícil prever a probabilidade de ruína por via analítica e, neste tipo de interpretação, talvez a única forma possível para se inferir sobre probabilidade de ruína seja pela observação de várias repetições do evento estudado, isto é, verificando-se o número de estruturas que entraríam em ruína (amostra de tamanho n), dentre uma quantidade suficientemente grande de estruturas construídas (população de tamanho $N$ ). Assim, de acordo com a interpretação de frequência, ter-se-ía probabilidade de ruína igual a $n / N$.

- Probabilidade de decisão: representa o grau de confiança individual numa análise. Uma interpretação mais objetiva quanto à interpretação da probabilidade de ruína $p_{r}$, neste caso, pode ser feita através da expressão $R=1-p_{r}$, onde $R$ representa a confiabilidade implícita na análise. Assim, um valor estimado como $p_{r}=5 \%$ significa que o analista teria $R=95 \%$ de confiança em seu estudo, levando em conta os elementos e informações disponíveis para a sua análise. Nesta interpretação, $p_{r}$ é estimada pelos métodos probabilísiticos correntes, não se aplicando a interpretação de frequência.

Em Der Kiureghian (1989) define-se dois grupos de incerteza, um relacionado à aleatoriedade das propriedades dos materiais e do carregamento, que não podem ser reduzidas; e o outro composto por incertezas devidas aos erros nos estimadores ou às imperfeições nos modelos, que podem e devem ser reduzidas. Segundo o autor este 
grupo de incertezas pertence a um conjunto denominado de "estado de conhecimento imperfeito”. Observa-se, porém, que a definição conhecimento imperfeito foi primeiramente publicada por Casagrande (1965).

Shigley (1989) comenta sobre a desvantagem do fator de segurança global em adotar somente valores pontuais da resistência e solicitação, sem levar em consideração a dispersão destas variáveis. Este autor propõe uma equação que insere no fator de segurança global a dispersão da resistência e solicitação na tentativa de incorporar numa única expressão a análise de segurança e confiabilidade. Esta equação é:

$$
n=\frac{m_{R}-3 \cdot \sigma_{R}}{m_{S}+3 \cdot \sigma_{S}}
$$

Observa-se que a equação acima tenta fazer o papel dos fatores de segurança parciais, ou seja, diminuir a resistência e aumentar a solicitação levando em consideração o desvio-padrão destas variáveis. Nas versões posteriores de seu livro, este autor retirou esta proposição.

Pacheco (1990) divulga as principais metodologias para os estudos probabilísticos e análise de risco em geotecnia num evento científico brasileiro e mostra três casos práticos: análise probabilística da Barragem de Santa Branca, variabilidade da altura crítica de um corte vertical e variabilidade da capacidade de carga de uma fundação superficial.

Em Lima (1991) desenvolve-se uma metodologia para avaliação probabilística de taludes de terra, através da estimativa da função densidade de probabilidade dos fatores de segurança através do Método de Estimativas Pontuais, desenvolvido por Rosenblueth (1975). Quantifica-se a segurança do talude através de sua probabilidade de ruptura, definida como a probabilidade de ocorrência de fatores de segurança inferiores à unidade. Para tratamento dos dados de ensaios de resistência ao cisalhamento do solo, desenvolve-se uma metodologia objetivando estimar funções densidade de probabilidade das variáveis aleatórias independentes coesão e ângulo de atrito interno. Exemplifica-se a metodologia proposta, através de sua aplicação no talude de jusante da barragem de Santa Branca, e comparam-se os resultados com o Método de Simulação de Monte Carlo.

Segundo Genevois (1991) quando se leva em conta a variabilidade espacial dos parâmetros do solo, obtêm-se dispersões de carga de ruptura de 10 a 100 vezes menores 
que as dispersões obtidas quando se calcula a carga de ruptura pelas equações clássicas da mecânica dos solos e fundações. O trabalho mostra o efeito da variabilidade espacial dos parâmetros do solo na capacidade de carga de uma fundação superficial, utilizando uma malha de elementos finitos com os parâmetros do solo $\left(E_{s}\right.$ e $\left.\phi\right)$ segundo uma lei de distribuição dada. O autor conclui que a dispersão da capacidade de carga é sensível, principalmente, ao número de variáveis aleatórias e às dispersões destas variáveis.

Sandroni e Sayão (1992) apresentam procedimentos simples para a avaliação estatística do fator de segurança de taludes. Um talude de mineração a céu aberto com 200 m de altura e 34 graus de inclinação é utilizado para verificação da metodologia proposta. Dentre os procedimentos utilizados, podem-se citar: fixar os parâmetros geotécnicos médios, buscar a superfície crítica de ruptura, obter o fator de segurança médio, avaliar estatisticamente o fator de segurança através do método do Segundo Momento de Primeira Ordem, estimar o índice de confiabilidade e a correspondente probabilidade de ruptura.

Cherubini et al. (1992) investiga a segurança de uma cortina de estacas prancha ancorada e engastada em solo não coesivo utilizando o método das estimativas pontuais de Rosenblueth (1975). O ângulo de atrito e o peso específico do solo são assumidos como variáveis independentes. De modo geral, os resultados mostram que a probabilidade de falha é consistentemente mais alta quando o ângulo de atrito aumenta.

Risco é uma parte inerente em todos os trabalhos de engenharia. Diferentes tipos de risco existem para diferentes tipos de trabalhos ou projetos: existem diferentes caminhos para avaliar e administrar tais riscos. Entre os engenheiros geotécnicos, os seguintes sentimentos geralmente existem e foram expressos por Steenfelt (1993):

- O melhor caminho para reduzir riscos é dar ao engenheiro projetista liberdade suficiente para desenvolver um bom trabalho.

- Julgamento é indispensável para a prática bem-sucedida da engenharia geotécnica.

Basma (1994) propõe um fator de redução do risco da capacidade de carga última de fundações diretas. Através da expansão da série de Taylor até a primeira ordem, a média e a variância da capacidade de carga última são estimadas, onde a variação da capacidade de carga última é expressa como uma função da variação da coesão e do ângulo de atrito interno. Para desenvolver o fator de redução, várias funções densidade de probabilidade são utilizadas. De modo geral, para as aplicações os resultados indicam 
que o fator redução do risco decresce com o aumento do coeficiente de variação da capacidade de carga última e a diminuição da probabilidade de ruína.

Lima et al. (1994) apresenta procedimentos numéricos implementados para a determinação da confiabilidade estrutural através da determinação direta do ponto de máxima densidade de probabilidade, pelo método dos gradientes conjugados. A superfície de ruína é definida em todo o domínio de integração, a partir dos valores de uma variável aleatória básica de referência que é aproximada por um polinômio de integração. Este programa computacional foi aplicado a estacas de plataformas marítimas onde as variáveis aleatórias básicas são as cargas na cabeça da estaca e os parâmetros do solo nas diversas camadas: coesão não drenada, ângulo de atrito entre o solo e a estaca, resistência de ponta, etc.

Meyerhof (1995) estabelece valores de probabilidade de ruína baseado em observações de campo e estimativas semi-probabilísticas: para fundações offshore e fundações em terra é cerca de $10^{-2}$ e $10^{-4}$, respectivamente.

Li (1995) analisa a confiabilidade de sistemas com deterioração ao longo do tempo. Neste trabalho é proposta uma formulação alternativa quando se considera o carregamento aplicado como variável aleatória. Esta abordagem é aplicável a funções de estado limite globais e a sistemas com diferentes propriedades de materiais.

Em Ellingwood (1996) ressalta-se que a maioria das abordagens probabilísticas se restrigem aos projetos de edifícios novos e que ainda é rara a análise de confiabilidade de construções já existentes. O autor acrescenta que este campo de pesquisa constitui um desafio para os pesquisadores.

Brzakala e Pula (1996) apresenta uma análise de recalques de fundações diretas. Três fontes básicas de aleatoriedade são discutidas: forma aleatória do subsolo, parâmetros aleatórios dos materiais e cargas aleatórias. As análises numéricas são baseadas no método dos elementos finitos acoplado com versões estocásticas da pertubação e o método de expansão de Neumman. No contexto do trabalho, ruína significa exceder a capacidade de carga ou o deslocamento admissível. Exemplos numéricos são apresentados para uma fundação em radier com subsolo elástico. Os resultados comparam a escala de flutuação aleatória das propriedades do solo ou carregamento com a escala de flutuação dos recalques da fundação.

Pacheco e Lima (1996) mostram um critério para estimar a variabilidade dos parâmetros de resistência obtidos a partir de ensaios correntes de laboratório, aplicável aos casos de amostragem reduzida. Segundo os autores, esse critério pode ser aplicado 
como um limite inferior da variabilidade dos parâmetros de resistência do solo, nos casos de superfícies potenciais de deslizamento relativamente longas, onde possa ser desprezada a variabilidade espacial.

Segundo Becker (1996), o modelo geotécnico do terreno, modelo de cálculo, e o efeito do carregamento são considerados nas análises geotécnicas da capacidade de carga e recalque dos materiais da fundação, como mostra a Figura 2.2 Os resultados destas análises, quando apropriadamente ajustados ou modificados pela experiência e julgamento dos engenheiros, são então usados no processo de tomada de decisão para constituir a fundação mais apropriada.

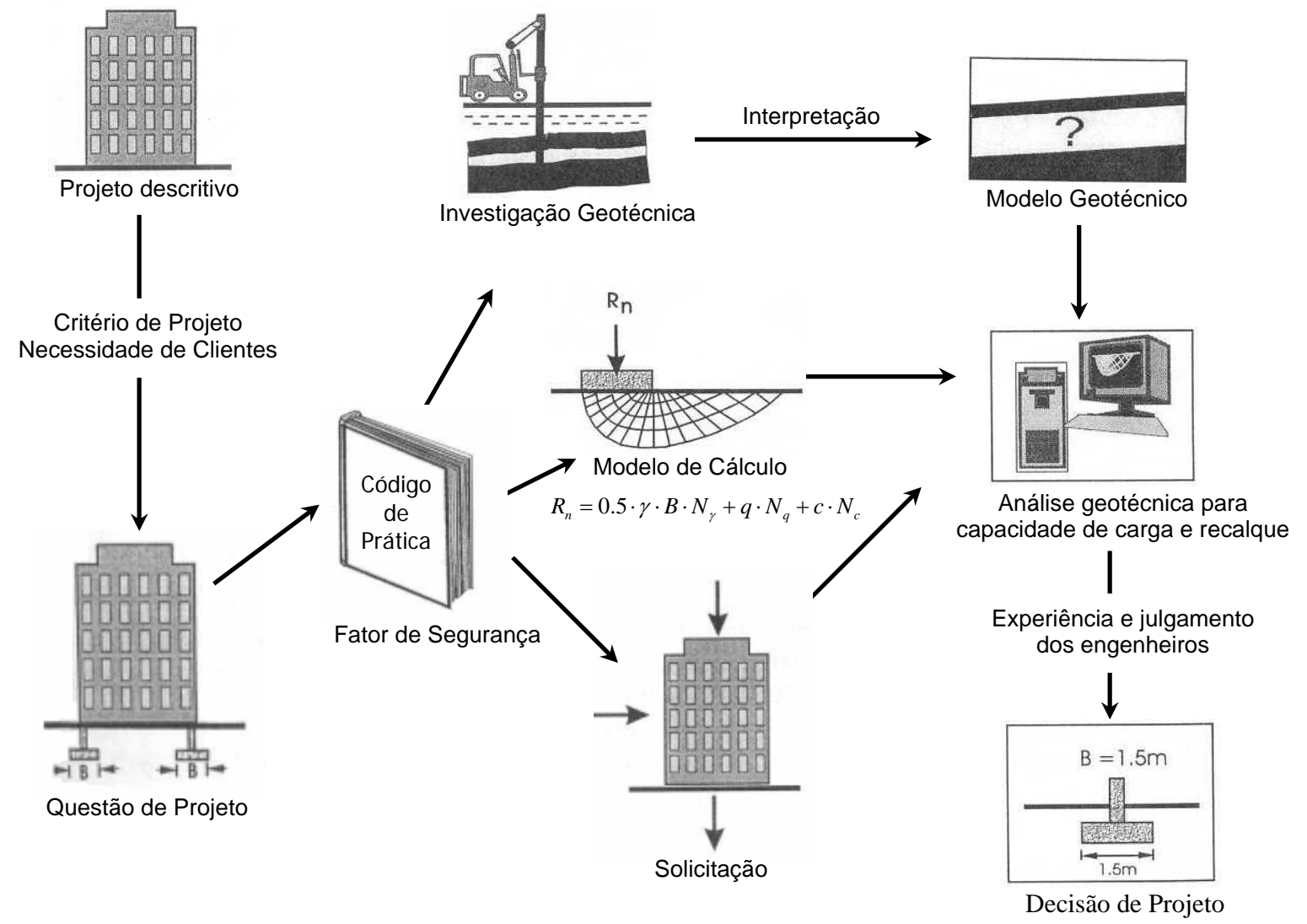

Figura 2.2 - Componentes do projeto da fundação e os códigos de prática. Fonte: Becker (1996).

Ditlevsen (1997) propõe um debate sobre códigos de confiabilidade estrutural de projeto probabilísitico baseado nos conceitos de confiabilidade elementar e análise de decisão. Na opinião deste autor existe uma necessidade urgente para estabelecer normas para projeto baseado na confiabilidade probabilística.

Guedes (1997) descreve um método para a obtenção dos dados necessários à análise probabilística de taludes, incluindo a quantidade e a localização de amostras, o cálculo das médias e variâncias dos parâmetros do solo e a quantificação das incertezas relativas 
a estes valores. Executam-se análises probabilísticas considerando, separadamente, variações da altura e inclinação de taludes de mineração sob condições drenadas. Situações não drenadas também são avaliadas por meio de um quebra-mar sobre argila mole. Neste trabalho apresentam-se os três métodos probabilísticos mais utilizados em geotecnia: Método do Segundo Momento de Primeira Ordem, Método das Estimativas Pontuais e a Simulação Monte Carlo.

Pandey (1998) discute os métodos de integração utilizados para o cálculo da probabilidade de ruína em problemas com número grande de variáveis aleatórias. Propõe-se um método de redução para um espaço unidimensional onde as probabilidades são condicionais e a integral resultante é escrita como um produto de integrais simples. Mesmo necessitando de validação adicional, o autor sugere que o método é simples e preciso.

Marek et al. (1999) discutem a análise da segurança estrutural quanto a transição que passa a verificação da segurança dos fatores parciais para os métodos confiabilísticos e concluem que existe um processo continuo para a concepção de projetos totalmente baseados em modelos probabilísticos. Mostram-se exemplos de análise de confiabilidade com técnicas de simulação e processadores de ultima geração para a época. Conclui-se que a confiabilidade deve ser a ferramenta do futuro para as verificações de segurança.

Phoon e Kulhawy (1999) publicaram dois artigos sobre a variabilidade geotécnica. No primeiro denominado caracterização da variabilidade geotécnica os autores apontam que a variabilidade é um atributo complexo que resulta de muitas fontes de incertezas e caracterizam as três fontes primárias: variabilidade inerente, erro de medição e incertezas de transformação. A variabilidade inerente do solo é modelada como um campo aleatório que pode ser descrito concisamente pelo coeficiente de variação e pela escala de flutuação. O erro de medição é extraído de medições de campo ou de medidas de laboratório e pode ser resumido pelo coeficiente de variação. As incertezas de transformação são avaliadas no segundo artigo Avaliação da variabilidade das propriedades geotécnicas.

Em Camarinopoulos et al. (1999) realiza-se uma análise da sensibilidade e confiabilidade de tubos de aço enterrados destinados à condução de água. As variáveis aleatórias adotadas consideram a resistência dos materiais em função das ações provenientes da degradação ambiental. O propósito do trabalho é utilizar o estudo 
confiabilístico como uma ferramenta de tomada de decisão para substituição de tubos, acarretando maior economia nos reparos.

Sexsmith (1999) relata sobre o desenvolvimento da análise da segurança estrutural baseada na probabilidade nos últimos 50 anos e aponta as vantagens e dificuldades desta abordagem. Com vantagens cita: racionalidade (as incertezas podem e devem ser tratadas com probabilidades); responsabilidade (a teoria adquirida embasa a responsabilidade técnica sobre o projeto); adaptabilidade (aos novos sistemas, materiais e ações sem necessidade de recorrência a testes onerosos) e a transportabilidade (para diferentes modelos mecânicos, tornando simples a implementação, integração e ampliação dos campos de análise). As dificuldades levantadas dizem respeito à obtenção de dados e falta de uniformização das abordagens já existentes inviabilizando o seu uso em normas de projeto atualmente.

Em Ribeiro (2000) desenvolve-se o Método do Segundo Momento de Primeira Ordem para quantificação da confiabilidade inerente ao desempenho de fundações diretas, propõem-se metodologias para racionalizar a adoção de fatores de segurança quanto à ruptura de fundações diretas e quantifica-se o risco associado à probabilidade do recalque estimado ser superior ao recalque admissível. Exemplos são apresentados com base no desempenho de fundações do protótipo submetidas a provas de carga superficiais executadas no campo experimental da PUC-Rio.

No trabalho de Tandjiria et al. (2000) apresenta-se uma comparação de simulações de Monte Carlo com o método da superfície resposta para problemas de fundações em estacas submetidas a carregamento lateral. O modelo probabilístico considera a variabilidade das propriedades mecânicas que traduzem a interação com o solo.

Phoon et al. (2000) comentam que a probabilidade de ruína de projeto que conduz a maior economia pode ser determinada por uma análise de custo-benifício, como mosta a Figura 2.3. As influências do custo inicial, manutenção e expectativa dos custos provenientes das falhas podem ser também relacionadas com a probabilidade de ruína.

Em Wen (2001) estudam-se as incertezas em função do custo total esperado durante a vida útil de uma estrutura. Realiza-se uma análise paramétrica com o objetivo de verificar as influências de cada variável na confiabilidade. Aplica-se a metodologia no projeto de um edifício submetido às ações de vento e sismos. 


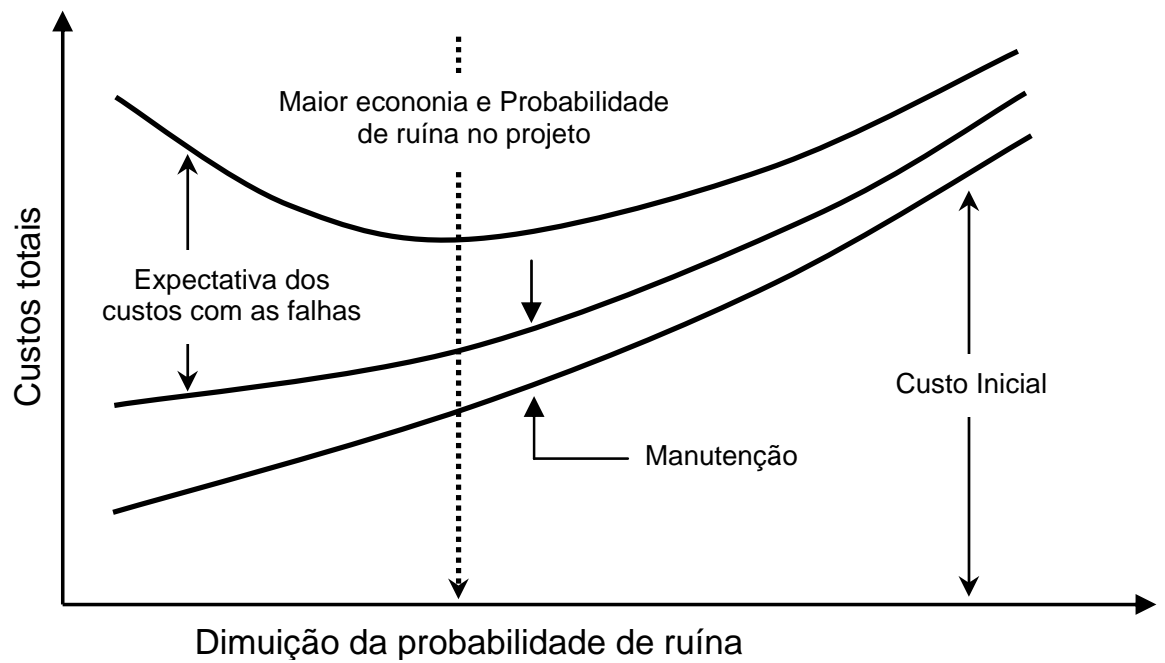

Figura 2.3 - Ilustração da análise de custo-benefício. Fonte: Phoon et al. (2000).

Melchers (2001) sugere que a segurança que se espera de uma estrutura consiste de duas partes independentes, a primeira consistindo da parte técnica e a outra de assuntos não técnicos tais como fatores econômicos e sociais, na qual esta tem influência maior na confiabilidade. Sugere-se que uma otimização baseada em confiabilidade deve respeitar as duas partes individualmente.

Bilfinger (2002) propõe critérios de segurança de fundação em estacas cravadas com consideração de controles executivos. Uma importante conclusão deste trabalho é sugerir uma redução do fator de segurança global estabelecido pela NBR 6122/1996, para obras nas quais as previsões de capacidade de carga sejam complementadas por controle sistemático de cravação das estacas por nega e repique.

Em Soares et al. (2002) apresenta-se um método probabilístico para o cálculo da confiabilidade de pórticos de concreto armado considerando não-linearidades materiais e geométricas. Através do acoplamento do modelo mecânico em elementos finitos com o método da superfície resposta, é feita a análise de confiabilidade realizada com índice de confiabilidade.

Espinosa et al. (2004) apresentam os fundamentos para o estudo da confiabilidade de elementos estruturais de madeira com ênfase as estruturas de pontes de madeira. Aplica-se este estudo a um sistema de ponte de madeira em vigas compostas considerando ações reais, mostrando-se a eficiência e a aplicabilidade do método proposto na deteminação da confiabilidade destas estruturas. 


\subsection{Comentários sobre a Bibliografia Pesquisada}

A diferença na temática dos trabalhos está, principalmente, nas ferramentas utilizadas para a determinação da confiabilidade. Até 1980, os trabalhos publicados eram, em sua grande maioria, teóricos. A partir desta data, as aplicações começaram a crescer e outros problemas foram se incorporando ao processo, como o tempo de processamento.

Desde os trabalhos mais antigos, já se previa que a confiabilidade e segurança de uma estrutura dependia não só de procedimentos técnicos, mas também de fatores vinculados à atividade humana, os chamados erros humanos. Logo qualquer método que pretenda calcular a probabilidade de ruína, está fazendo uma estimativa, pois as incertezas sempre existirão. Apesar da probabilidade de ruína ser finita, as incertezas podem ser consideradas infinitas, ou melhor, não totalmente conhecidas.

Percebe-se que, na última década, houve uma aceitação da confiabilidade como a próxima alternativa para avaliar a segurança e a confiabilidade de sistemas estruturais e geotécnicos (edifícios, pontes, barragens, fundações, etc), como pode se notar nas diversas aplicações em todo mundo e na utilização deste estudo em normas, por exemplo, no Eurocode 0 (2001).

Em muitos trabalhos, a definição de segurança e confiabilidade ainda é expressa como se não houvesse diferença entre elas, pois é comum a utilização de índice de confiabilidade e índice de segurança indiscriminadamente. $\mathrm{O}$ autor entende que segurança está relacionada à utilização dos fatores de segurança global e parciais e que confiabilidade está associada à probabilidade de ruína de uma estrutura qualquer, na qual devem existir duas variáveis principais: resistência e solicitação. Partindo deste entendimento, uma estrutura pode ser caracterizada como:

- Segura e confiável

- Segura e não confiável

- Insegura e confiável

- Insegura e não confiável

Muitos autores relatam que calculam a probabilidade de ruína sem considerar a variável solicitação. Na verdade, o que estes pesquisadores fazem é o cálculo da probabilidade de ocorrência da estrutura apresentar uma determinada resistência. Neste caso, a definição de probabilidade de ocorrência de uma resistência inferior ao valor correspondente de probabilidade parece ser mais propicia. 
As expressões probabilidade de ruína e probabilidade de falha também são usadas sem um devido esclarecimento em que situações se adequa melhor cada termo. Na engenharia estrutural é comum utilizar o termo probabilidade de falha e na engenharia geotécnica frequentemente se utiliza probabilidade de ruína. Entende-se que a escolha do termo mais adequado deveria levar em consideração o objeto de estudo, pois falha dá idéia de eventos que não necessariamente levam a ruína de uma estrutura. Logo, no caso de fundações por estacas, onde o objeto de estudo é a superfície resistente, é mais conveniente utilizar a expressão probabilidade de ruína.

No campo da confiabilidade, a engenharia geotécnica foi, talvez, a que menos se desenvolveu em relação às outras engenharias (mecânica, estrutural, aeronáutica, etc). Esta evolução está vinculada à variabilidade dos sistemas e aos materiais estudados na geotecnia. Entretanto, é nesta área que se utiliza uma variável importante na avaliação dos ensaios in situ: a escala de flutuação, variável espacial de determinada propriedade.

Ainda é pouca a bibliografia sobre confiabilidade em fundação por estacas e o que mais se encontra são estudos sobre confiabilidade em fundação direta. Este fato também é um motivador para a elaboração desta dissertação. 


\section{Métodos de Verificação de Segurança}

Segurança é um conceito qualitativo ou quantitativo?

Os métodos de segurança adotados pelas normas medem a segurança de forma quantitativa, através do fator de segurança definido pela ABCP (1967) como fator pelo qual, ou se multiplicam as solicitações a fim de efetuar-se o cálculo da estrutura em regime de ruína, ou se dividem as tensões de ruptura ou de escoamento do material a fim de fazer-se o cálculo da estrutura em regime elástico.

O conceito qualitativo é uma questão ainda subjetiva que deve ser analisada por projetistas, executores e clientes para cada tipo de obra.

Ao longo da história da construção civil os métodos de cálculo de engenharia vêm se aperfeiçoando e levando em conta estudos estatísticos na consideração das solicitações (efeito das ações) e das resistências dos materiais. Observa-se que tanto as solicitações quanto as resistências podem ser dependentes de outras tantas variáveis pouco ou muito influentes.

Os métodos de introdução de segurança podem ser classificados seguindo diversos critérios e formas de apresentação. A forma que o autor escolheu para apresentar nesta dissertação tem como base os trabalhos de: Fusco (1976), Zagottis (1974), Hachich (1978), Oliveira (1998) e Silva, F. (2003). Optou-se pela simplicidade e generalização dos critérios, considerando os seguintes parâmetros:

- população finita imposta pela definição de superfície resistente (Aoki, 2002);

- formulações determinísticas: fator de segurança global (Método das Tensões Admissíveis - MTA);

- formulações semi-probabilísticas: fatores de segurança parciais (Método dos Estados Limites - MEL); 
- formulações probabilísticas: cálculo da probabilidade de ruína (Freudenthal et al., 1966), considerando os dois eventos de mesma natureza que caracterizam a ruína de uma estrutura: solicitação e resistência.

A Figura 3.1 mostra os métodos de cálculo utilizados nos projetos de engenharia, em função das variáveis solicitação e resistência.

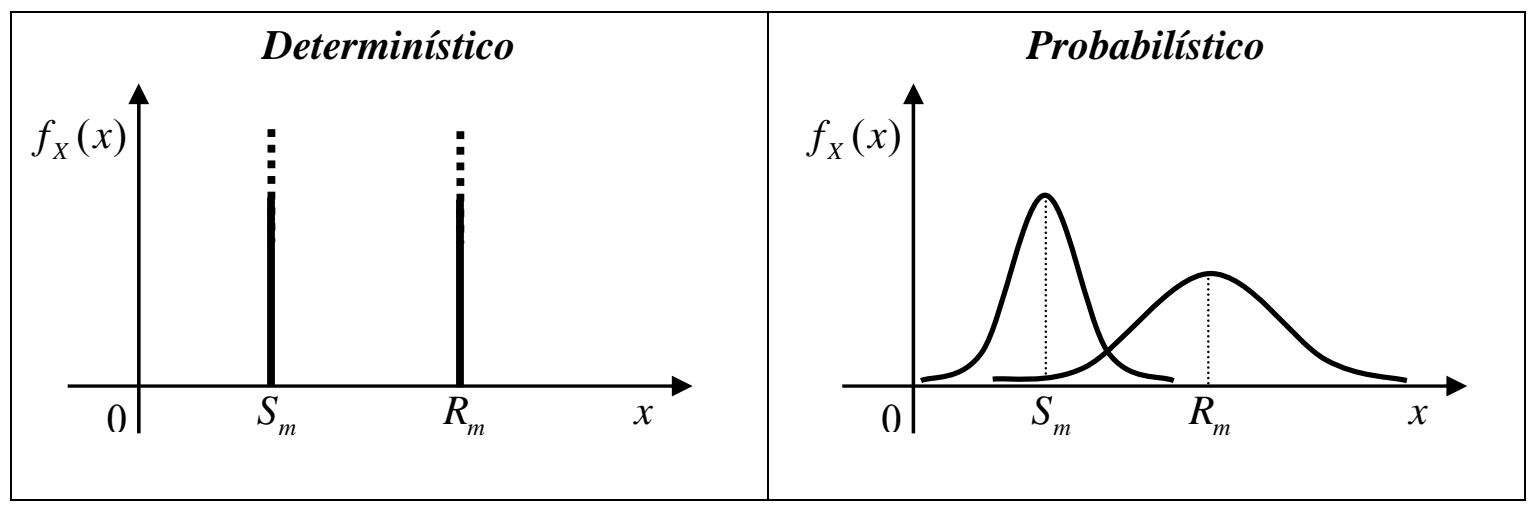

Semi-Probabilístico

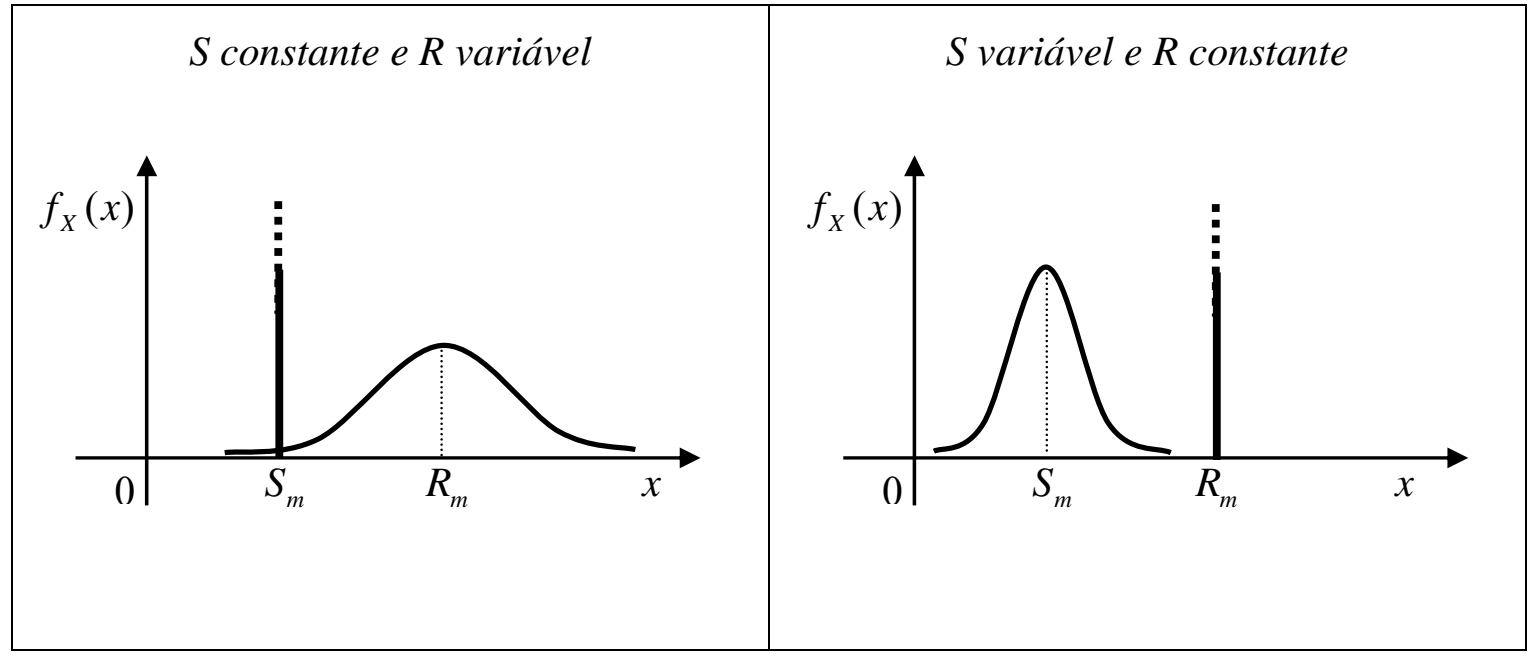

Figura 3.1 - Métodos de verificação da segurança.

Fixadas as curvas de S e R, observa-se que, independente do método de verificação de segurança, o fator de segurança global deverá ter o mesmo valor, já que tal fator é o quociente entre os valores mais prováveis (esperança) da resistência e solicitação. Na abordagem do fator de segurança, não se considera a forma das curvas de solicitação e resistência, ou seja, a dispersão é desprezada. 


\subsection{Formulações Determínisticas ( $F_{S}$ e MTA)}

O MTA consiste basicamente na verificação do estado limite de serviço, onde no ponto mais solicitado da estrutura não seja ultrapassada a tensão admissível do material, afastada da tensão de ruptura por um fator de segurança interno $\gamma_{i}$.

Segundo Zagottis (1974), a principal crítica quanto ao MTA está na distância que ele introduz entre a ruína e a situação de serviço da estrutura. Este mesmo autor considera que seria mais interessante pesquisar quais carregamentos correspondem a tais situações.

Os fatores de segurança globais utilizados no MTA são classificados como externos (vinculados ao carregamento imposto) e interno (vinculado a resistência).

- F F $_{\mathrm{S}}$ externo: Obtido pelo quociente do carregamento de ruína pelo de serviço. Estes fatores são utilizados geralmente nas engenharias de estruturas e de geotecnia, nesta especificamente, na engenharia de fundações, onde conforme Hachich (1978) permite a verificação de segurança no estado de serviço com maior clareza e racionalidade.

- F F $_{S}$ interno: Hachich (1978) sugere que no caso de estruturas onde a ação do peso próprio é principal, caso se opte por uma análise global, é legítima a escolha do fator de segurança interno. Esta condição parece ser exclusiva das estruturas geoténcias, como taludes, obras enterradas e de contenção, etc.

\subsection{Formulações Semi-Probabilísticas ( $F_{S}$ Parciais e MEL)}

A essência da formulação semi-probabilística é transformar valores característicos (ou médios) das grandezas em valores de cálculo pela aplicação de todos os fatores de ponderação. A condição de verificação de segurança é: $S_{d} \leq R_{d}$.

O método dos estados limites (MEL) supre a principal deficiência apresentada pelo MTA. No MEL, o carregamento é o parâmetro adotado para verificar a condição de serviço e ruína da estrutura.

A idéia inicial dos fatores parciais de segurança é proposta por Hansen (1956), este considera que o fator de segurança global seja distribuído por fatores intervenientes no projeto de uma estrutura, tais como: cargas ambientais e funcionais, materiais estruturais, etc. 
De acordo com Zagottis (1981) e a NBR 6118/2003, dentre os fenômenos geradores do estados limites, estão:

口 Estado limite último:

- perda de equilíbrio da estrutura, admitida como corpo rígido;

- falha por deformação plástica excessiva;

- solicitações dinâmicas;

- colapso da estrutura;

- deterioração por efeito de fadiga;

- casos especiais que eventualmente podem ocorrer.

- Estado limite de serviço:

- deformações excessivas;

- vibração excessiva;

- dano estrutural local limitado (exemplo: fissuração).

Segundo Hachich (1978) o MSP é um melhoramento do método probabilista condicionado - MPC nível I (apresentado adiante), pois leva em consideração, de forma racional, todos os fatores que influenciam a segurança de uma estrutura. O mesmo pesquisador classifica tais fatores em incertezas e erros e apresenta-os em conexão com as grandezas que eles influenciam:

a. Incertezas a respeito das:

i. Ações

ia. Intensidade

ib. Probabilidade de ação simultânea

ii. Solicitações

iia. Características mecânicas de deformabilidade dos materiais, em laboratório

iib. Características mecânicas de deformabilidade dos materiais, do laboratório para a obra

iic. Imprecisões geométricas construtivas

iii. Solicitações-Limites ou resistência

iiia. Características mecânicas de resistência dos materiais, em laboratório

iib. Características mecânicas de resistência dos materiais, do laboratório para a obra

iic. Imprecisões geométricas construtivas 
b. Erros nas:

i. Solicitações

ia. Devidos ao modelo e ao método de análise (erros teóricos)

ib. Devidos ao processo de cálculo (erros numéricos)

ii. Solicitações-Limites ou resistência

iia. Devidos ao modelo e ao método de análise (erros teóricos)

iib. Devidos ao processo de cálculo (erros numéricos)

c. Responsabilidade da estrutura:

i. Comportamento da estrutura na iminência de atingir um estado limite último: capacidade de redistribuição de esforços e de dar aviso de ruína

ii. Gravidade da ruína: prejuízos materiais e pessoais.

O MEL permite adotar formulações determinísticas e probabilíticas, nas quais somente as últimas fornecem uma estimativa da probabilidade de ruína da estrutura.

\subsection{Formulações Probabilísticas (Probabilidade de Ruína)}

A formulação probabilística se divide em método probabilísitico condicionado (MPC) e puro (MPP). Segundo Hachich (1978), no MPC as probabilidades envolvidas correspondem à configuração de ruína da análise determinística do comportamento da estrutura enquanto que no MPP não existe uma única configuração de ruína associada a ruína, logo conclui-se que o MPP é mais geral.

\section{- Método probabilista condicionado (MPC)}

No MPC as probabilidades envolvidas são aquelas associadas a uma determinada configuração de ruína. Neste método existem três níveis de processos que aqui serão apresentados em grau crescente de generalidade.

\section{- Nível I - processo dos valores extremos}

A condição de verificação de segurança é dada por:

$$
S\left(X_{1, e x t r}, X_{2, e x t r}, \ldots, X_{m, e x t r}, C_{X}\right) \leq R\left(Y_{1, e x t r}, Y_{2, e x t r}, \ldots, Y_{m, e x t r}, C_{Y}\right)
$$

Aos valores de $\mathrm{X}_{\mathrm{i}, \text { extr }}$ e $\mathrm{Y}_{\mathrm{i} \text {,extr }}$ correspondem probabilidades aceitas a priori de que $\mathrm{X}_{\mathrm{i}}$ e $Y_{i}$ assumam valores mais desfavoráveis. 
Segundo Hachich (1978) e Bilfinger (2002) o MPC nível I não considera erros devidos a modelo, método de análise, processos de cálculo e aspectos econômicos.

Por razões de similaridade existem autores que não diferencia o MPC nível I do MSP, como Maranha das Neves (1994).

\section{- Nível II - processo dos extremos funcionais}

Chamado de processo dos extremos funcionais, a condição de verificação de segurança é: $S_{\text {extr }} \leq R_{\text {extr }}$, onde tais valores extremos de $\mathrm{S}$ e $\mathrm{R}$ correspondem a probabilidades aceitas a priori de que $\mathrm{S}$ e $\mathrm{R}$ assumam, independentemente, valores mais desfavoráveis, como mostra a Figura 3.2.
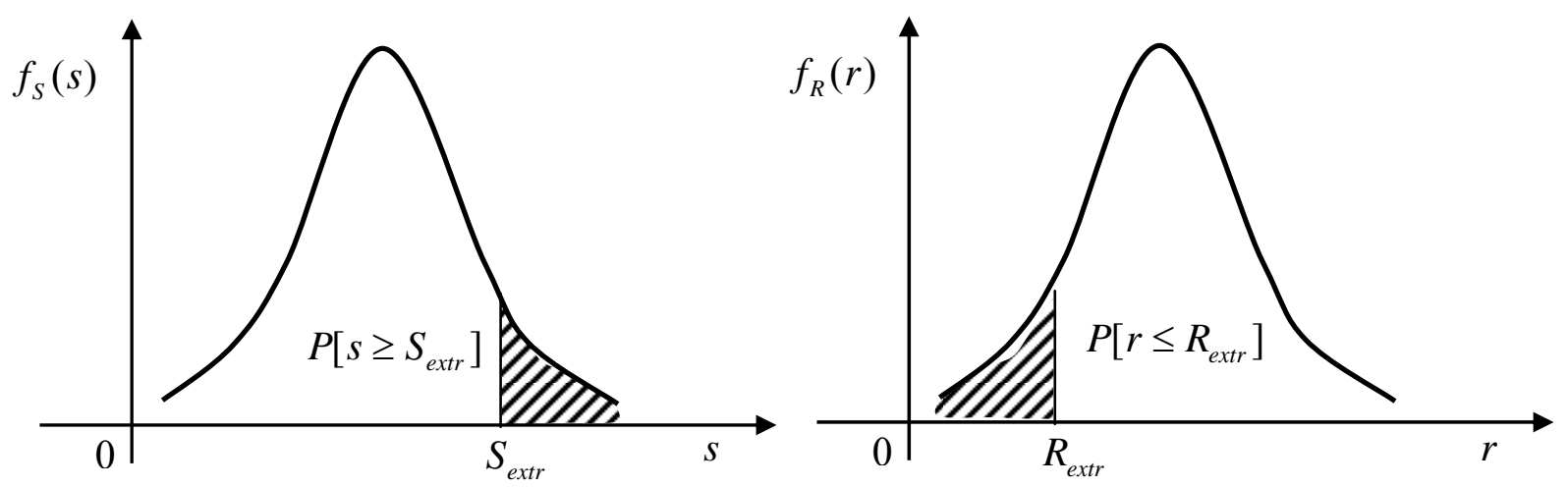

Figura 3.2 - Processo dos extremos funcionais. Fonte: Hachich (1978).

A diferença desta condição para o nível III, a seguir, reside no fato da probabilidade de ruína não estar explicitada, pois as probabilidades efetuadas até aqui dizem respeito a condições limites de $\mathrm{R}$ ou $\mathrm{S}$. Os valores de $\mathrm{S}_{\text {extr }}$ e $\mathrm{R}_{\text {extr }}$ ocorrem na forma de valores médios $\left(S_{m}\right.$ e $\left.R_{m}\right)$ ou característicos $\left(S_{k}\right.$ e $\left.R_{k}\right)$ multiplicados e divididos por fatores de ponderação, respectivamente. Observa-se que este método é adequado para quantificar os fatores parciais de segurança e segundo Maranha das Neves (1994), o nível II pode ser chamado de método do índice de confiabilidade.

\section{- Nível III - processo exato (ou avançado)}

Conceitualmente este processo é o mais rigoroso e é aquele que realmente estima a probabilidade de ruína. A condição de verificação de segurança é estabelecida quando 
$F S_{\text {extr }} \geq 1$, onde $F S_{\text {extr }}$ é o valor da $F S$ corespondente a uma probabilidade de ruína aceitável.

A probabilidade de ruína $\left(\mathrm{p}_{\mathrm{r}}\right)$ pode ser obtida prescidindo da distribuição de $\mathrm{R}$ e $\mathrm{S}$ separadamente, sendo a $p_{r}$ dada pela integral de todas as situações possíveis em que $R \leq S$. Esta $p_{\mathrm{r}}$ é chamada de integral de convolução e será explicada no Capítulo 4.

\section{- Método probabilista puro (MPP)}

Neste método, a ruína não está associada a uma única configuração de ruína, ou seja, pode acontecer em locais (seção, superfície) menos prováveis, bastando para isso que ocorra $R / S \leq 1$.

Segundo Zagottis (1974), quando o MPC é prepoderante, os erros cometidos na utilização do MPC são toleráveis. Porém, como comenta Hachich (1978) infelizmente existem estruturas que se enquadram no MPP, especialmente na engenharia geotécnica.

$\mathrm{Na}$ visão do autor, o MPP apesar filosoficamente compreensível está distante da realidade prática da engenharia, pois entende-se que a consideração de "todas" as variáveis envolvidadas no processo de ruína, além de ser uma tarefa matematicamente complicada, pode proporcionar maior insegurança no processo de tomada de decisão.

\subsection{Verificação de Segurança em Fundações}

Nos projetos de fundações por estacas, a verificação ao estado limite último deve atender simultâneamente à norma de estruturas de concreto NBR 6118 e a norma de fundações NBR 6122, além da norma de ações e segurança nas estruturas NBR 8681. Pela NBR 6122, existem atualmente duas maneiras de se introduzir segurança: pelo método das cargas admissíveis (fator de segurança global) e pelo método dos estados limites (fatores parciais de segurança). Com base nestas normas e nos trabalhos de Oliveira (1998), Cintra \& Aoki (1999), Aoki (2003) e Silva, F. (2003) serão discutidos alguns procedimentos quanto ao projeto de fundações. 


\section{- Projeto de fundações a partir da carga admissível}

Pela NBR 6122/1996 a carga admissível é definida como sendo a força aplicada sobre a estaca ou o tubulão isolado, provocando apenas recalques que a construção pode suportar sem inconvenientes e oferecendo, simultaneamente, segurança satisfatória contra a ruptura ou o escoamento do solo ou do elemento estrutural de fundação. A carga admissível depende da sensibilidade da construção projetada aos recalques, especialmente aos recalques diferenciais específicos, os quais, de ordinário, são os que podem prejudicar sua estabilidade ou funcionalidade.

A carga admissível é limitada pela capacidade do elemento estrutural de receber e transmitir a carga para o solo e pela capacidade do solo suportar as cargas transmitidas pelo elemento estrutural de fundação. Geralmente, a carga admissível é comandada pelo solo que apresenta valor de capacidade de carga menor que a resistência do elemento estrutural de fundações.

Observa-se pela definição da carga admissível que, a norma brasileira recomenda o uso deste conceito a cada elemento isolado de fundação e não ao conjunto de EIF que compõem a fundação. Este procedimento gera a não consideração da dispersão existente desta propriedade, ou seja, o fator de segurança é específico de cada EEF.

No método da carga admissível $\mathrm{P}_{\mathrm{adm}}$, o fator de segurança global $\mathrm{F}_{\mathrm{S}}$ é definido pela expressão 3.2 .

$$
P_{a d m} \leq R_{m} / F_{S}
$$

No Brasil, é costume proceder a verificação da resistência geotécnica a partir de métodos semiempíricos baseados no índice de resistência à penetração $N_{S P T}$ do amostrador da sondagem de simples reconhecimento.

Portanto, a metodologia para se determinar a profundidade de assentamento em cada local de sondagem exige a fixação da resistência média esperada da expressão

$$
R_{m, e} \geq R_{m, g}=P_{a d m} \cdot F_{S}
$$

sendo:

$R_{m, e}:$ carga admissível estrutural

$R_{m, g}$ : carga admissível geotécnica do sistema estaca-solo 
A Tabela 3.1 apresenta os valores do fator de segurança global preconizado pela norma brasileira NBR 6122/1996:

Tabela 3.1 - Fatores de segurança globais mínimos para estacas e tubulões. Fonte: NBR 6122/1996.

\begin{tabular}{cc}
\hline Condição & $\mathrm{F}_{\mathrm{S}}$ \\
\hline Capacidade de carga de fundações superficiais & 3,0 \\
Capacidade de carga de estacas e tubulões sem prova de carga & 2,0 \\
Capacidade de carga de estacas e tubulões com prova de carga & 1,6
\end{tabular}

A Figura 3.3 resume a metolodogia atual de dimensionamento a partir da carga admissível.

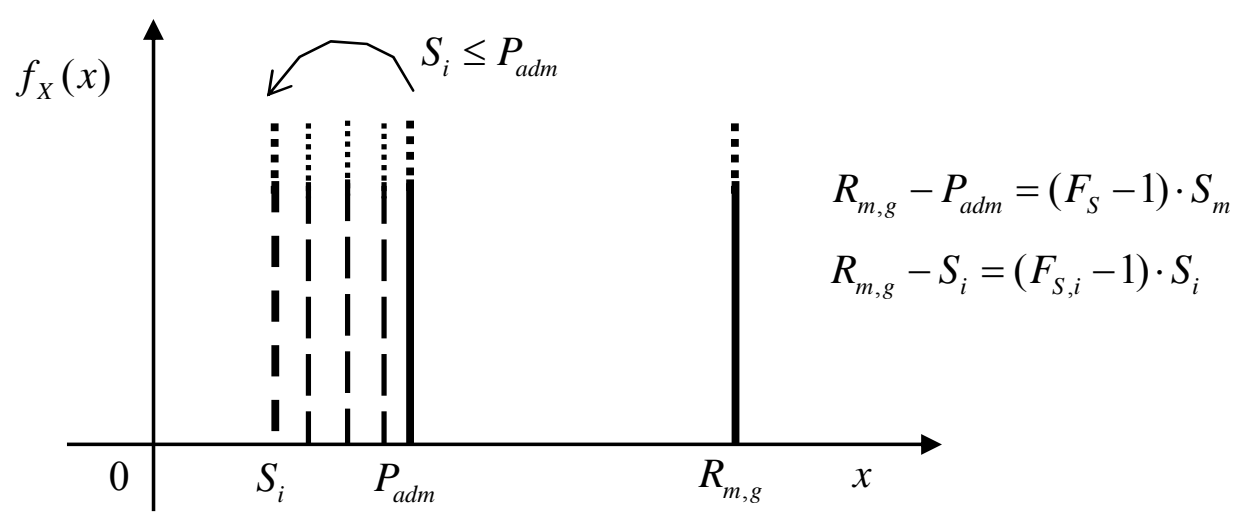

Figura 3.3 - Determinação da carga admissível. Fonte: Aoki (2003).

Como a metodologia da carga admíssivel é aplicada a cada EIF quando $\mathrm{F}_{\mathrm{S}, \mathrm{i}}>\mathrm{F}_{\mathrm{S}}$, surgem dúvidas sobre o mínimo valor aceitável para o $\mathrm{F}_{\mathrm{S}, \mathrm{i}}$, principalmente quando este for obtido por prova de carga.

Considerando a análise sistemática das sondagens, Aoki (2003) resume os principais pontos relativos ao método da carga admissível, na prática brasileira:

- O conceito de carga admissível é aplicado a cada elemento isolado;

- A abordagem é determinista seja no caso da solicitação seja no caso da resistência;

- Não se analisa a variabilidade destas variáveis;

- Não se sabe o valor mínimo do fator de segurança aceitável no caso da prova de carga não fornecer os valores recomendados pela NBR 6122. 


\section{- Projeto de fundações a partir do método dos estados limites}

O método dos estados limite pertence à formulação semi-probabilística, onde as incertezas associadas às variáveis resistência e solicitação são consideradas através da aplicação de fatores de segurança parciais.

Conforme Bilfinger (2002), o método semi-probabílistico consiste na utilização de modelos de cálculo deterministas, mas reconhecendo explicitamente as variabilidades das grandezas envolvidas. Valores de cálculo são os dados de entrada para os cálculos e são obtidos a partir da aplicação de um fator de ponderação a valores característicos ou médios. As solicitações de cálculo não podem exceder as resistências de cálculo.

Segundo Becker (1996) e Oliveira (1998), a filosofia de projetos baseada nos estados limites envolve os procedimentos abaixo:

- Identificação de todas as potenciais formas de ruína ou estados limites que a estrutura pode sofrer. $\mathrm{O}$ termo ruína representa condições na qual a estrutura deixa de atender aos requisitos para os quais foi projetada, não significa necessariamente esgotamento da capacidade de carga;

๑ Verificação de cada estado limite;

- Demonstração de que a ocorrência de estados limite é improvável ou aceitável.

A Figura 3.4 mostra as curvas de solicitações e resistências e os fatores de segurança global $\mathrm{F}_{\mathrm{S}}$ e parciais $\gamma_{S}, \gamma_{R}, \gamma_{f}$ e $\gamma_{m}$ associados a estas variáveis.

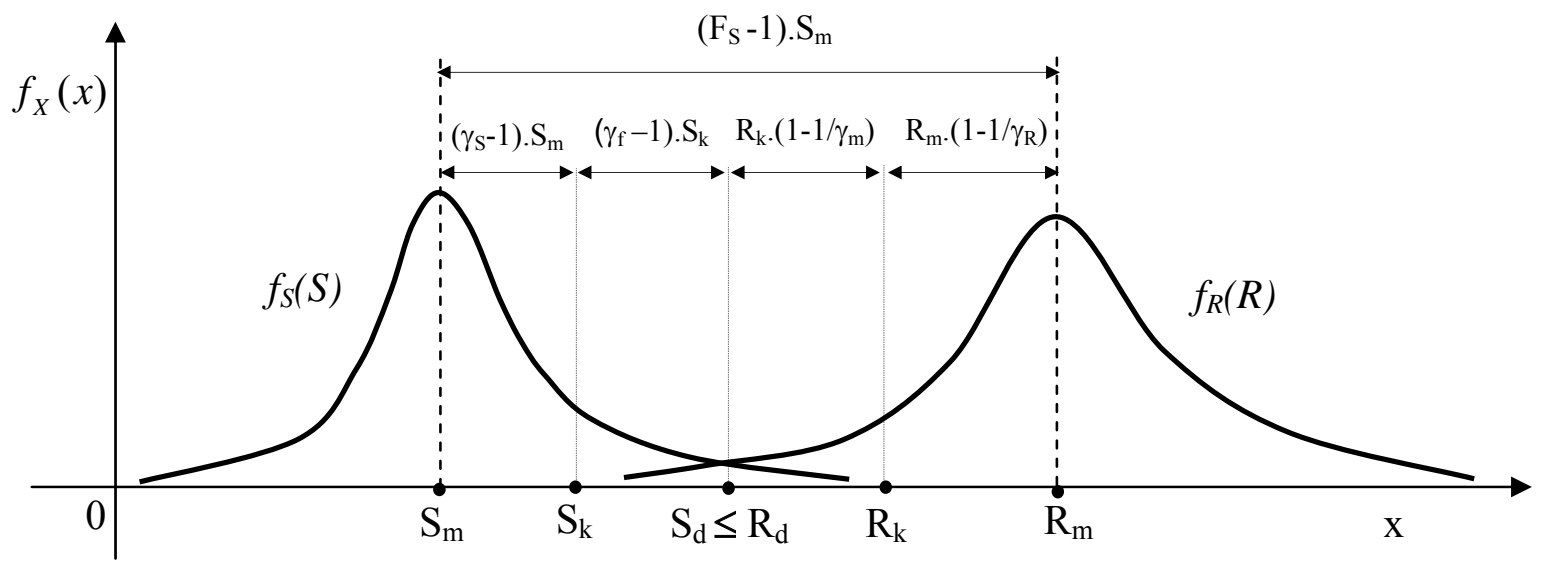

Figura 3.4 - Curvas de solicitações e resistências e fatores de segurança global e parciais. Fonte: Aoki (2002). 
Utilizando a distribuição normal nas funções de densidade de probabilidade para as variáveis aleatórias, os fatores de segurança parciais são definidos abaixo, onde os valores característicos das solicitações e resistências referem-se à probabilidade de $5 \%$ de ocorrência.

- Fator parcial de segurança função da variabilidade da solicitação:

$$
\gamma_{S}=\frac{S_{k}}{S_{m}}=\left(1+1,645 \cdot v_{S}\right)
$$

sendo: $v_{S}=$ coeficiente de variação da solicitação

- Fator parcial de segurança função da variabilidade da resistência:

$$
\gamma_{R}=\frac{R_{m}}{R_{k}}=\frac{1}{\left(1-1,645 \cdot v_{R}\right)}
$$

sendo: $v_{R}=$ coeficiente de variação da resistência

- Fator parcial de majoração das solicitações (mínimo fixado em norma): $\gamma_{f}$

- Fator parcial de minoração das resistências (mínimo fixado em norma): $\gamma_{m}$

No caso particular de fundações, a NBR6122/1996 fixa os seguintes valores mínimos dos fatores parciais de segurança:

- $\gamma_{\mathrm{m}}=1,2$ (para obra com prova de carga);

- $\gamma_{\mathrm{m}}=1,5$ (para obra sem prova de carga);

A NBR 8186 (item 5.1.4.1) apresenta diversos valores para o fator de majoração de carga considerando tipos de carga. Um exemplo típico é adotar $\gamma_{\mathrm{f}}=1,4$, que corresponde a ações permanentes diretas agrupadas para edificação onde as cargas acidentais superam $5 \mathrm{kN} / \mathrm{m}^{2}$.

A partir dos fatores de segurança parciais, pode-se determinar o fator de segurança global pela multiplicação dos fatores característicos e os fatores vinculados à variabilidade da solicitação e resistência.

$$
F_{S}=\left(\gamma_{S} \cdot \gamma_{R}\right) \cdot\left(\gamma_{f} \cdot \gamma_{m}\right)=\left(\gamma_{v}\right) \cdot\left(\gamma_{k}\right)
$$

Observa-se que o fator de segurança global é definido por uma parcela constante proveniente das normas $\left(\gamma_{\mathrm{k}}\right)$ e outra variável $\left(\gamma_{\mathrm{v}}\right)$ que depende das curvas de solicitação e resistência. 
Comparando os métodos da carga admissível e dos estados limites aplicados a fundações, Aoki (2003) comenta:

Como os valores $S_{k}$ e $R_{k}$ dependem da forma das curvas de solicitação $f_{S}(S)$ e resistência $f_{R}(R)$ deve-se discutir as variabilidades destas funções antes de proceder à fixação pura e simples dos valores característicos. $\mathrm{Na}$ prática verifica-se que a forma das curvas não importa no cálculo com fatores de segurança parciais. Esta pode ser uma desvantagem do método dos estados limites. 


\section{Probabilidade de Ruína}

A probabilidade de ruína é obtida a partir da relação existente entre a solicitação $S$ e a resistência $R$. O evento ruína ocorre quando $R-S<0$ ou $R / S<1$. Freudenthal et al. (1966) e Ang \& Tang (1984) definem a probabilidade de ruína como sendo a integral de zero a infinito do produto das funções $F_{R}(x)$ e $f_{S}(x)$, como mostra a Equação 4.1 e a Figura 4.1. A probabilidade de ruína definida pela Equação 4.1, considera que não existe condicionamento: as variáveis $\mathrm{S}$ e $\mathrm{R}$ são independentes.

$$
p_{r}=\int_{0}^{\infty} F_{R}(x) \cdot f_{S}(x) \cdot d x
$$

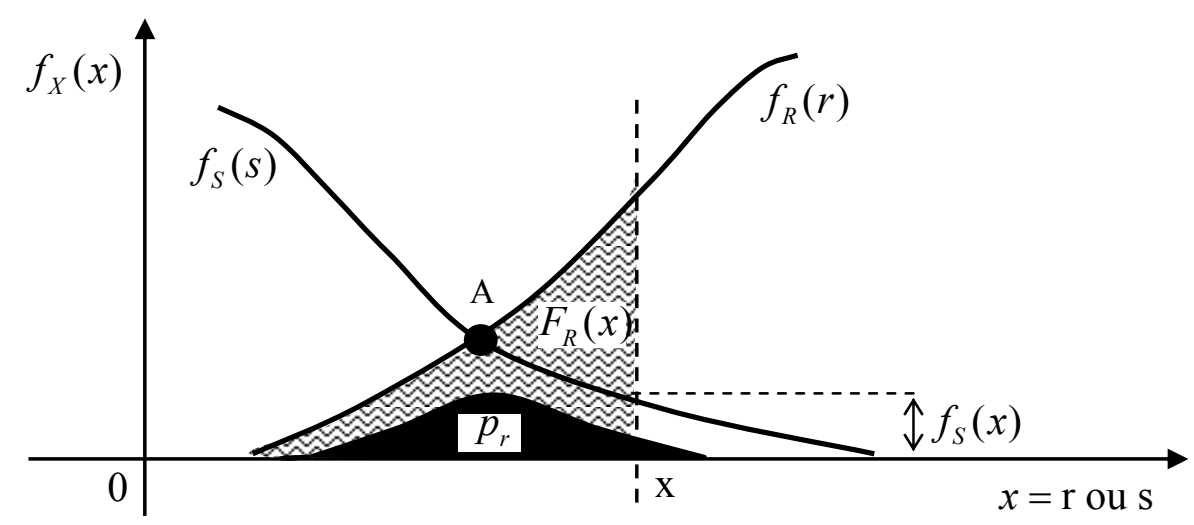

Figura 4.1 - Funções densidades $f_{R}(r)$ e $f_{S}(s)$. Fonte: Modificado de Ang \& Tang (1984).

Para se chegar a Equação 4.1, chamada de integral de convolução, a ruína é causada pela ocorrência simultânea de ambas as condições abaixo:

1. $P(r \leq x)=\int_{-\infty}^{x} f_{R}(x) \cdot d x$

2. $P(x \leq s \leq x+d x)=f_{S}(x) \cdot d x$ 
Logo, considerando que a resistência e solicitação como eventos independentes, tem-se:

3. $P(r \leq x \leq s \leq x+d x)=f_{S}(x) \cdot d x \cdot \int_{-\infty}^{x} f_{R}(x) \cdot d x$

Como a ruína pode ocorrer para qualquer valor de x, com $R>0$ e $S>0$, faz-se:

4. $p_{r}=\int_{-\infty}^{+\infty} f_{S}(x) \cdot d x \cdot \int_{-\infty}^{x} f_{R}(x) \cdot d x=\int_{0}^{\infty} f_{S}(x) \cdot d x \cdot F_{R}(x)$

No ponto A da Figura 4.1 $f_{R}(r)$ e $f_{S}(s)$ são iguais. A área em preto na Figura 4.1 representa a probabilidade de ruína $\mathrm{p}_{\mathrm{r}}$, região sob as curvas de resistência à esquerda do ponto A e solicitação à direita do mesmo ponto. Quanto maior a área sob esta curva, maior a probabilidade de ruína, ou seja, menor a confiabilidade da fundação.

Quando há condicionamento entre solicitação e resistência a probabilidade de ruína é dita condicionada e o condicionamento pode ser obtido, por exemplo, ordenando-se todos os valores de resistência em ordem crescente e comparando-se, termo a termo, com todos os valores de solicitação ordenados em ordem decrescente e vice-versa. A Figura 4.2, mostra a probabilidade de ruína condicionada com resistência crescente $\mathrm{p}_{\mathrm{r}, \mathrm{r}} \mathrm{e}$ com solicitação crescente $\mathrm{p}_{\mathrm{r}, \mathrm{s}}$.

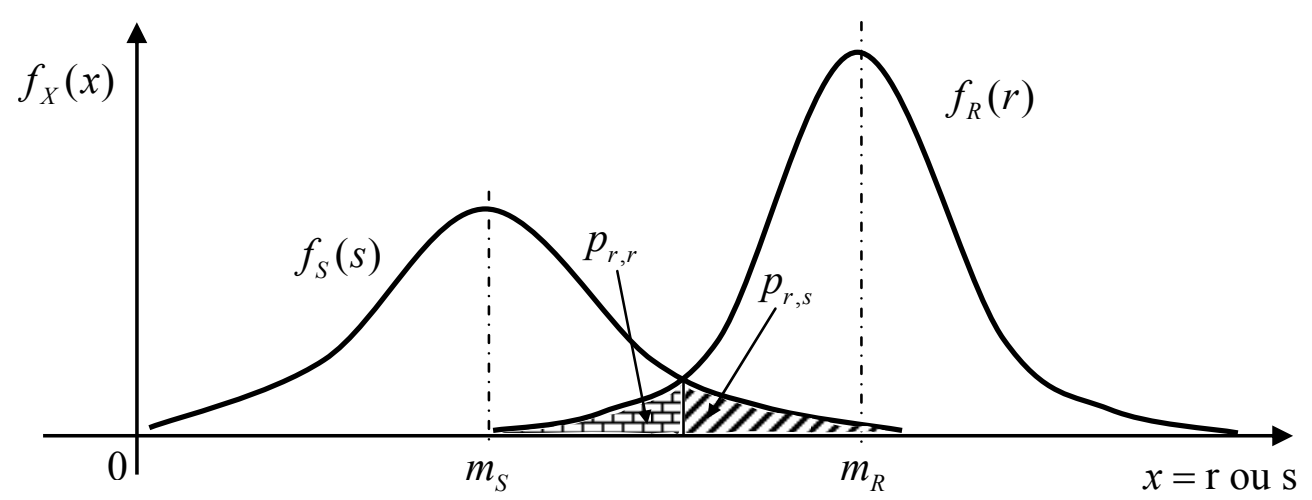

Figura 4.2 - Probabilidade de ruína condicionada: $p_{r, r}$ e $p_{r, s}$ Fonte: Aoki \& Cintra (2003).

A probabilidade de ruína pode ser determinada a partir da função linear margem de segurança $(M S=R-S)$ e da função não-linear fator de segurança $(F S=R / S)$, que dependem das funções densidade de probabilidade $f_{S}(s)$ e $f_{R}(r)$. O grau de dispersão ou coeficiente de variação, $v=\sigma / m$ representa a forma destas curvas e influencia a magnitude da probabilidade de ruína (Ang \& Tang (1984)).

O problema de resistência e solicitação pode ser formulado analiticamente em termos das funções margem de segurança $M S$ e fator de segurança $F S$, através de seus 
respectivos índices de confiabilidade $\left(\beta_{M S}\right.$ e $\left.\beta_{F S}\right)$ que medem o afastamento da condição de ruína em termos de desvios padrões.

\subsection{Função Margem de Segurança}

Como $R$ e $S$ são variáveis aleatórias e $M S$ é uma função linear de $R$ e $S$, então $M S$ é uma variável aleatória. Quando $M S$ for menor ou igual a zero ocorre a ruína como mostra a Figura 4.3. Logo, a probabilidade de ruína é $p_{r}=P[M S \leq 0]$, áreas hachuradas na Figura 4.3.

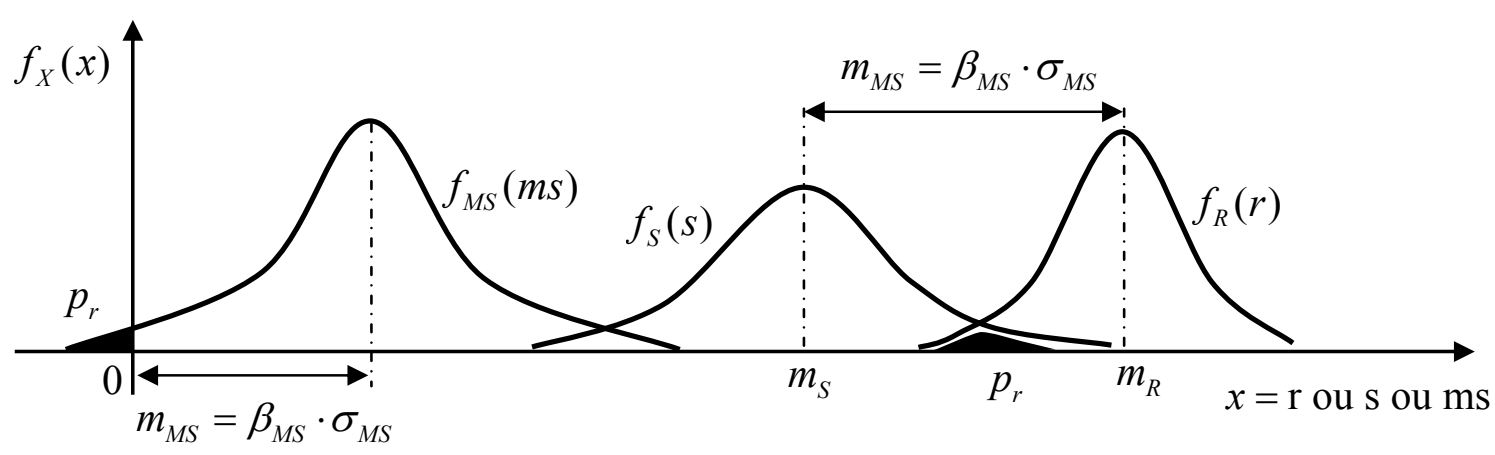

Figura 4.3 - Margem de segurança e respectivo índice de confiabilidade.

Geralmente, não há informações suficientes sobre as extremidades da distribuição de $M S$ e o critério $p_{r}=P[M S \leq 0]$ é substituído por outro que envolve a média e o desvio padrão de $M S$.

Conhecendo-se a média e o desvio padrão das variáveis aleatórias contínuas $R$ e $S$, obtém-se a média e o desvio padrão de $M S$, sabendo que a espectância é um operador linear e que a variância obedece a expressão abaixo (Benjamin \& Cornell (1970)), onde $X$ é uma variável aleatória qualquer.

$$
\operatorname{Var}[X]=E\left[X^{2}\right]-E^{2}[X]
$$

Considerando $\rho_{R S}$, o coeficiente de correlação entre $R$ e $S$, a média e o desvio padrão de $M S$ são:

$$
\begin{gathered}
m_{M S}=m_{R}-m_{S} \\
\sigma_{M S}=\sqrt{\sigma_{R}{ }^{2}+\sigma_{S}{ }^{2}-2 \cdot \rho_{R S} \cdot \sigma_{R} \cdot \sigma_{S}}
\end{gathered}
$$


Na Figura 4.3, o parâmetro $\beta_{M S}$, denominado índice de confiabilidade, pode ser obtido a partir de diferentes distribuições de $R$ e $S$.

$$
\beta_{M S}=\frac{m_{M S}}{\sigma_{M S}}=\frac{m_{R}-m_{S}}{\sqrt{\sigma_{R}^{2}+\sigma_{S}^{2}-2 \cdot \rho_{R S} \cdot \sigma_{R} \cdot \sigma_{S}}}
$$

Estabelecida a forma das curvas densidade de probabilidade de solicitação e resistência, sintetizada pelos seus respectivos coeficientes de variação, existe uma relação entre o fator de segurança global $\left(F S=m_{F S}=m_{R} / m_{S}\right)$ e o índice de confiabilidade. A dedução desta relação, conforme Aoki (2002), é mostrada a seguir.

Da definição de $\beta_{M S}$, Figura 4.3, tem-se:

$$
m_{R}-m_{S}=\beta_{M S} \cdot \sigma_{M S}
$$

Dividindo-se a Equação 4.6, por $m_{R}$ resulta:

$$
F S=m_{R} /\left(m_{R}-\beta_{M S} \cdot \sigma_{M S}\right)
$$

Explicitando $\sigma_{M S}$ na equação anterior, as relações entre $F_{S}$ e $\beta_{M S}$ escrevem-se:

$$
\begin{gathered}
F S=\frac{m_{R}}{m_{R}-\beta_{M S} \cdot \sqrt{{\sigma_{R}}^{2}+\sigma_{S}^{2}-2 \cdot \rho_{R S} \cdot \sigma_{R} \cdot \sigma_{S}}} \\
\beta_{M S}=\frac{1-1 / F S}{\sqrt{v_{R}{ }^{2}+(1 / F S)^{2} \cdot v_{S}{ }^{2}-\frac{2 \cdot \rho_{R S} \cdot \sigma_{R} \cdot \sigma_{S}}{m_{R}{ }^{2}}}}
\end{gathered}
$$

O índice de confiabilidade também encontra-se em Ditlevsen (1997) e Cardoso \& Fernandes (2001) como mostram as equações 4.10 e 4.11, respectivamente, porém nestes trabalhos as variáveis são mutuamente independentes $\left(\rho_{R S}=0\right)$ e não é explicitada a relação direta entre fator de segurança global $F_{S}$ e índice de confiabilidade $\beta_{M S}$.

$$
\begin{gathered}
\frac{E[R]}{E[S]}=\frac{1+\beta_{M S} \cdot \sqrt{v_{S}{ }^{2}+v_{R}{ }^{2}-\beta_{M S}{ }^{2} \cdot v_{S}{ }^{2} \cdot v_{R}{ }^{2}}}{1-\beta_{M S}{ }^{2} \cdot v_{R}{ }^{2}} \\
\beta_{M S}=\frac{1-m_{S} / m_{R}}{\sqrt{v_{R}^{2}+\left(m_{S} / m_{R}\right)^{2} \cdot v_{S}^{2}}}
\end{gathered}
$$




\subsection{Função Fator de Segurança}

Como $R$ e $S$ são variáveis aleatórias e $F S$ é uma função não-linear de $R$ e $S$ então $F S$ é uma variável aleatória. Quando $F S$ for menor ou igual a 1 ocorre a ruína como ilustra a Figura 4.4. Logo, a probabilidade de ruína é $p_{r}=P[F S \leq 1]$, área hachurada na Figura 4.4 .

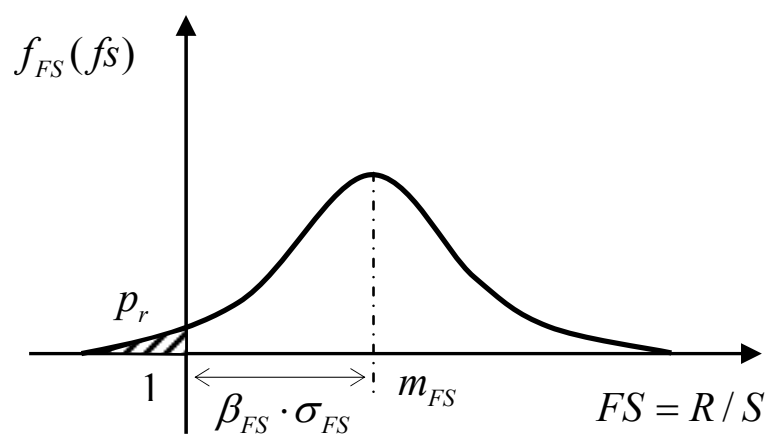

Figura 4.4-Fator de Segurança e respectivo índice de confiabilidade.

Como indica a Figura 4.5 pode-se observar que não existe matematicamente uma proporcionalidade entre o fator de segurança global $\left(m_{F S}\right)$ e a probabilidadade de ruína $\left(p_{r}\right)$. Isto ocorre, pois as variáveis $m_{F S}, p_{r}$ e $\sigma_{F S}$ são independentes.

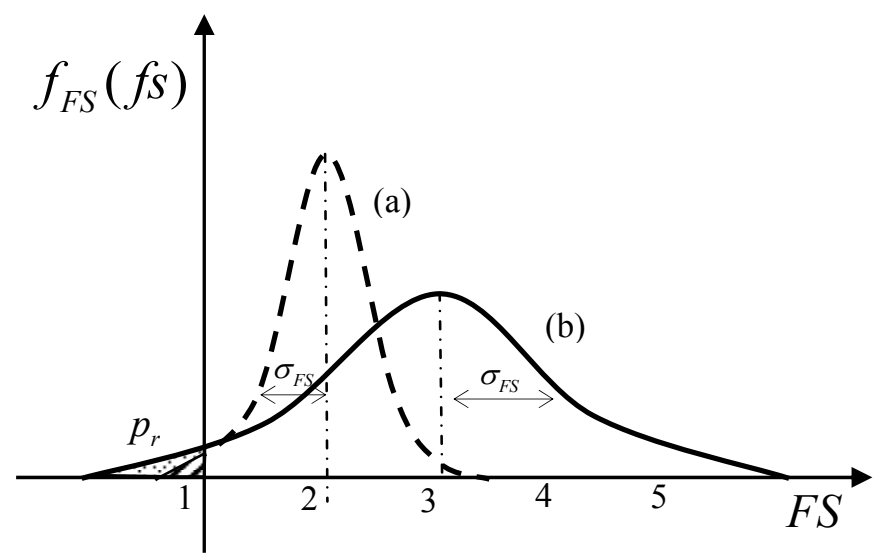

Figura 4.5 -Distribuição probabilística do FS considerando duas condições (a) e (b). Fonte: Lacasse \& Goulois (1989)

A média da função fator de segurança, denominada fator de segurança global $(F s)$, e o desvio padrão de $F S$, considerando um procedimento semelhante ao realizado com a função margem de segurança e desenvolvendo a função desempenho $F S$ em Série de Taylor até a primeira ordem (linearização), são: 


$$
\begin{gathered}
m_{F S}=\frac{m_{R}}{m_{S}}=F_{S} \\
\sigma_{F S}=\sqrt{\frac{\sigma_{R}^{2}}{m_{S}{ }^{2}}+\frac{\sigma_{S}{ }^{2} \cdot m_{R}{ }^{2}}{m_{S}{ }^{4}}-2 \cdot \rho_{R S} \cdot \sigma_{R} \cdot \sigma_{S} \cdot \frac{m_{R}}{m_{S}{ }^{3}}}
\end{gathered}
$$

O índice de confiabilidade $\beta_{F S}$ passa a ser:

$$
\beta_{F S}=\frac{m_{F S}-1}{\sigma_{F S}}=\frac{F S-1}{\sqrt{F S^{2} \cdot\left(v_{R}{ }^{2}+v_{S}{ }^{2}\right)-\frac{2 \cdot \rho_{R S} \cdot \sigma_{R} \cdot \sigma_{S} \cdot F S}{m_{S}{ }^{2}}}}
$$

Quando $v_{S}=0$, o índice de confiabilidade obtido a partir de $F S$ e $M S$ tornam-se equivalentes:

$$
\beta_{M S}=\beta_{F S}=\frac{F S-1}{F S \cdot v_{R}}
$$

Observa-se que os valores de $\beta_{M S}$ e $\beta_{F S}$ não são absolutos, pois somente quantificam as incertezas identificadas na obtenção das variáveis R e S. As diversas outras incertezas não contempladas na análise de confiabilidade são oriundas das simplificações na determinação de R e S e por simples desconhecimento.

Os valores admissíveis para o índice $\beta$ devem ser adotados a partir de uma avaliação dos parâmetros: tipo de superestrutura, EEF, formação geológica, etc, e devem ser julgados, mesmo que subjetivamente, por um engenheiro geotécnico.

\subsection{Distribuições de R e S}

O conhecimento dos dois primeiros momentos probabilísticos das funções margem de segurança e fator de segurança não são suficientes para a definição da função densidade de probabilidade. É também necessário o conhecimento da forma da distribuição da função de desempenho. Na prática, é usual fazer a hipótese de distribuição normal ou lognormal. 
Caso as variáveis aleatórias $R$ e $S$ apresentem distribuição normal, os índices de confiabilidade $\beta_{M S}$ e $\beta_{F S}$ estão relacionados com a probabilidade de ruína através da expressão seguinte, onde $\Phi$ é a função de distribuição acumulada normal padrão.

$$
\beta=-\Phi^{-1}\left(p_{r}\right) \text { ou } P_{r}=\Phi(-\beta)=1-\Phi(\beta)
$$

Quando R e S são assumidos com distribuição lognormal, a Equação 4.5 passa a ser, admitindo $\left(\rho_{R S}=0\right)$.

$$
\beta_{M S, L N}=\frac{E[\log R]-E[\log S]}{\sqrt{\operatorname{Var}(\log R)+\operatorname{Var}(\log S)}}
$$

Utilizando as regras da função logarítmica e os parâmetros correspondentes da distribuição lognormal, a partir de $m_{R}, m_{S}, \sigma_{R}, \sigma_{S}$, tem-se:

$$
\begin{gathered}
\beta_{M S, L N}=\frac{\log E[R]-\frac{1}{2} \log \left(1+v_{R}^{2}\right)-\log E[S]+\frac{1}{2} \log \left(1+v_{S}^{2}\right)}{\sqrt{\log \left(1+v_{R}^{2}\right)+\log \left(1+v_{S}^{2}\right)}} \\
\beta_{M S, L N}=\frac{\log \left[F_{S} \cdot \sqrt{\frac{1+v_{S}^{2}}{1+v_{R}^{2}}}\right]}{\sqrt{\log \left[\left(1+v_{R}^{2}\right) \cdot\left(1+v_{S}^{2}\right)\right]}}
\end{gathered}
$$

Conforme Ang \& Cornell (1974), caso $v_{R}$ e $v_{S}$ não assumam valores maiores que 0,30, o índice de confiabilidade pode ser escrito por:

$$
\beta_{M S, L N} \approx \frac{\log \left(F_{S}\right)}{\sqrt{v_{R}^{2}+v_{S}^{2}}}
$$

Quando a solicitação ou a resistência é considerada determinística $\left(v_{R}=0 \mathrm{ou}\right.$ $\left.v_{S}=0\right)$ e $\left(\rho_{R S}=0\right)$, resulta:

$$
\begin{aligned}
& \beta_{M S, N}\left(v_{R}=0\right)=\frac{F S-1}{v_{S}} \\
& \beta_{M S, N}\left(v_{S}=0\right)=\frac{F S-1}{F_{S} \cdot v_{R}}
\end{aligned}
$$




$$
\begin{gathered}
\beta_{M S, L N}\left(v_{R}=0\right)=\frac{\log \left[\left(1+\beta_{M S, N} \cdot v_{S}\right) \cdot \sqrt{1+v_{S}^{2}}\right]}{\sqrt{\log \left(1+v_{S}^{2}\right)}} \\
\beta_{M S, L N}\left(v_{S}=0\right)=\frac{\log \left[1 /\left(\left(1-\beta_{M S, N} \cdot v_{R}\right) \cdot \sqrt{1+v_{R}^{2}}\right)\right]}{\sqrt{\log \left(1+v_{R}^{2}\right)}}
\end{gathered}
$$

\subsection{O Método de Monte-Carlo}

A estimativa da probabilidade de ruína pode ser obtida também quando se utiliza um método de simulação. O método de Monte Carlo é um dos mais utilizados e consiste na repetição de soluções determinísticas, que resulta num conjunto de valores gerados de acordo com suas respectivas distribuições de probabilidades que se supõem conhecidas. Este conjunto de valores é semelhante a um conjunto de informações oriundas de observações experimentais. Os valores determinísticos criados podem ser tratados estatisticamente, sendo aplicáveis todos os métodos de inferência estatística.

Em essência, o Método de Monte Carlo consiste numa técnica de amostragem, e seus resultados, como em qualquer outro processo de amostragem, estão sujeitos a erros. Segundo Lima (1991), para se obter soluções "exatas" o número de simulações deve se aproximar do infinito, o que é uma desvantagem do método.

\subsection{População Finita e Infinita}

Considerar uma população finita ou infinita para a estimativa da probabilidade de ruína de uma estrutura de engenharia civil é um fator relevante? No caso do tamanho das amostras já se sabe que são finitas e, em geral, pequenas.

Em síntese, este final de capítulo discute esta pergunta, e ainda alguns tópicos relacionados à estimativa da probabilidade de ruína de fundações, tais como:

- Evento, amostra e população;

- Proposição de Aoki (2002) para população finita e as estatísticas de ordem;

- A depedência entre resistência e solicitação na probabilidade de ruína; 
- O Método de Monte-Carlo e a formulação simplificada no capítulo 4.

Ainda neste capítulo, são utilizados dois exemplos para a análise dos tópicos supracitados, o primeiro referente a um edifício de concreto armado e o segundo a alguns casos de fundações extraídos do banco de dados publicados por Silva, F. (2003).

Parte destes exemplos também encontram-se publicados em dois eventos nacionais pelo autor e orientador desta dissertação: Silva, J. \& Aoki (2005) e Silva, J. \& Aoki (2006).

\subsubsection{Evento x Amostra x População}

Como comenta Silva, N. (2004), a análise probabilística pode ser entendida como o estudo sobre a previsão comportamental de uma determinada experiência, definida por um processo aleatório que é controlado total ou parcialmente por um mecanismo de casualidade, sorte ou azar (chance). A variável objeto da experiência é chamada de aleatória pois assume valores diferentes e não previsíveis.

Quando se trabalha na engenharia civil com estatística, geralmente leva-se em consideração um espaço amostral de uma população que quase sempre é definida como infinita. Portanto, os valores estatísticos obtidos deste espaço amostral podem, no máximo, aproximar-se das características da população dita infinita.

Qualquer subconjunto de um espaço amostral é definido como evento, enquanto que o conjunto de todas as observações realizadas é denominado de população. Silva, J. e Aoki (2005) exemplificam populações infinitas e finitas. No primeiro caso, citam a aleatoriedade da solicitação e da resistência dos materiais que compõem um elemento estrutural (viga, pilar, laje, etc). No outro caso, considera-se a aleatoriadade da solicitação e resistência que se referem à seção mais desfavorável de qualquer elemento estrutural que compõem o grupo de elementos analisados (conjunto de pilares, vigas, lajes, etc).

Matematicamente, população é definida por um conjunto de elementos que possuem pelo menos uma característica em comum. Nesta dissertação, os elementos analisados são os elementos isolados de fundação que são localizados no espaço e no tempo, nos quais a característica comum avaliada é a capacidade de carga referente à superfície 
resistente. Logo, uma obra de fundação tem população finita definida pela superfície resistente.

Quando a população é finita, existem duas formas de abordar os parâmetros populacionados (média e coeficiente de variação) necessários para o cálculo da probabilidade de ruína. Estas formas serão expostas a seguir:

\subsubsection{População Finita - Proposição de Aoki (2002)}

Em fundações, onde a população é finita, o que se têm verificado na prática é que a estatística da amostra, obtida a partir de sondagens de simples reconhecimento e/ou de provas de carga estática e/ou dinâmica, representa satisfatoriamente os parâmetros da população finita (Aoki (2002)), como ilustra a Figura 4.6. Logo, a média e o desvio padrão da amostra podem ser tomados como média e desvio padrão da população finita.

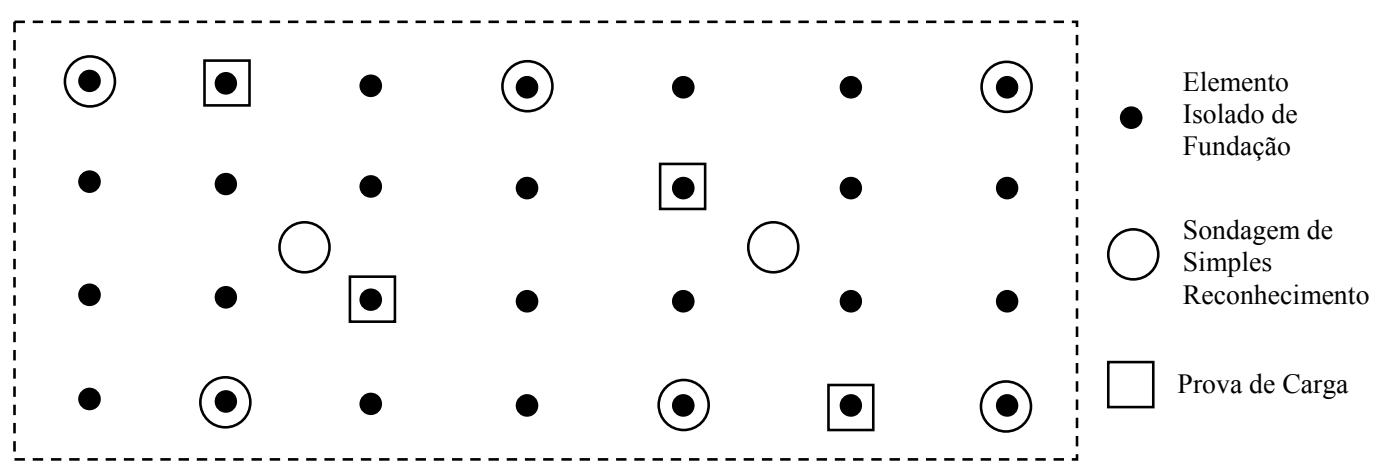

Figura 4.6 - Amostra e população de uma fundação.

O levantamento por amostragem permite a obtenção de informações a respeito de valores populacionais desconhecidos, por meio da observação de apenas uma parte (amostra) do universo de estudo (população) (Figura 4.6). As amostras são estimativas que passam a ser a informação disponível para os valores populacionais desconhecidos. Em fundações, a sondagem de simples reconhecimento é geralmente realizada antes do ínicio da obra para a elaboração do projeto e a prova de carga é frequentemente realizada na execução da obra. Em ambos os ensaios obtêm-se características como a capacidade de carga e o recalque da fundação, sendo que a sondagem estima e a prova de carga comprova tais características.

O plano de amostragem na engenharia de fundações compreende basicamente o tamanho $n$ da amostra, principal responsável pela precisão dos resultados entre amostra e população (Figura 4.6), visto que o desenho da amostragem em planta não obedece a 
critérios definidos devido à desconhecida variabilidade do solo. Pensar que o tamanho da amostra pode reduzir a variabilidade do maciço de solo é um erro, pois esta é uma característica instrínseca do meio geológico-geotécnico.

$\mathrm{Na}$ prática, trabalha-se com uma única amostra e consequentemente dispõe-se apenas de estimativas únicas calculadas nessa amostra. A partir da amostragem podemse fazer inferências sobre os valores populacionais através da distribuição amostral, associada aos critérios de ausência de vício (quando o estimador possui esperança igual ao valor populacional) e de normalidade assintótica (quando para determinados tamanhos de amostras, a distribuição amostral da média estiver próxima da distribuição normal, ou seja, é válido o teorema central do limite).

A simplificação proposta por Aoki (2002) carece de uma avaliação do erro envolvido quando se supõe que o desvio padrão da amostra de tamanho $n$ é representativo do desvio padrão da população de tamanho $N$. Neste sentido uma pergunta é crucial para o sucesso das estimativas através da amostragem: qual o tamanho da amostra $n$ ? Observa-se que a resposta depende de uma série de outras questões como: variabilidade do maciço de solo, formação geológica, tipo de elemento estrutural de fundação, tamanho $N$ da população, etc. Estas questões inviabilizam determinar o número adequado para o tamanho $n$ da amostra. Sabe-se, porém que estatisticamente o menor número é 2 e que por razões de confiabilidade o menor número mais adequado é 3 .

$\mathrm{Na}$ verdade, considerar o tamanho da amostra pequeno ou grande dependerá também do tamanho da população. Quando esta é infinita sempre o tamanho da amostra será pequeno.

\subsubsection{Estatísticas de Ordem}

Com base no trabalho de Holeyman (2001), o orientador deste mestrado sugeriu verificar a possibilidade de utilizar as estatísticas de ordem quando o tamanho da amostra $n$ for pequeno, caso comum na engenharia de fundações.

As estatísticas de ordem se baseiam em ordenar os elementos de um conjunto e utilizar os valores extremos: $X_{\max }$ e $X_{\min }$. A principal justificativa da utilização desta ferramenta se baseia no fato do número de testes ( prova de carga ou ensaios in situ) ser geralmente pequeno.

As estimativas do valor médio e do desvio padrão são dados, respectivamente, por: 


$$
\begin{aligned}
& E[\mu]=\frac{\left(X_{\text {max }}+X_{\min }\right)}{2} \\
& E[\sigma]=\frac{\left(X_{\text {max }}-X_{\min }\right)}{d n}
\end{aligned}
$$

Onde $d n$ é escolhido de acordo com a tabela 4.1 abaixo como função do número de amostras $n$ :

Tabela 4.1 - Ajuste do valor de $E[\sigma]$ em função do tamanho da amostra $n$. Fonte: David (1980).

\begin{tabular}{c|c|c|c}
\hline$n$ & $d n$ & $n$ & $d n$ \\
\hline & & 11 & 3.175 \\
2 & 1.129 & 12 & 3.257 \\
3 & 1.692 & 13 & 3.333 \\
4 & 2.058 & 14 & 3.401 \\
5 & 2.326 & 15 & 3.472 \\
6 & 2.532 & 16 & 3.534 \\
7 & 2.703 & 17 & 3.584 \\
8 & 2.849 & 18 & 3.636 \\
9 & 2.967 & 19 & 3.690 \\
10 & 3.077 & 20 & 3.731 \\
\hline
\end{tabular}

As relações supracitadas são utilizadas para expressar a estimativa do coeficiente de variação $E[V]$ (estimativa do desvio padrão dividido pela estimativa do valor médio) como função de $\mathrm{X}_{\min } / \mathrm{X}_{\max }$ e $\mathrm{X}_{\min } / \mathrm{X}_{\operatorname{med}}$. Estas relações são:

$$
\begin{aligned}
& \frac{X_{\min }}{X_{\text {med }}}=1-\eta \cdot \frac{E[V]}{2} \\
& \frac{X_{\min }}{X_{\max }}=\frac{2-\eta \cdot E[V]}{2+\eta \cdot E[V]}
\end{aligned}
$$

A utilização dos valores extremos amostrais para a estimativa dos parâmetros populacionais pode ser tornar uma vantagem ou desvantagem no cálculo da probabilidade de ruína, em função da dispersão dos valores amostrais. Observa-se que quando o tamanho da amostra é pequeno parece ser coerente a adotação da estatística dos conjuntos ordenados .

As aplicações mostradas a seguir tratam-se de estruturas onde o objeto de estudo são populações finitas. A primeira aplicação trata-se de analisar no conjunto de pilares de 
um edifício a seção mais desfavorável e a outra aplicação refere-se a análise de fundações, na qual o tamanho da amostra é menor que o número de elementos da população definida pela superfície resistente.

\subsubsection{Aplicação 1 - Edifício de Concreto Armado}

O principal aspecto da utilização deste exemplo é mostrar que, dependendo do objeto de estudo, existem casos na engenharia onde o tamanho da população é igual ao tamanho da amostra, logo a proposição de Aoki (2002) deve ser utilizada, sem nenhuma preocupação quanto ao erro advindo da amostragem para a estimativa dos parâmetros populacionais.

Nesta primeira aplicação, analisa-se a segurança e a probabilidade de ruína do sistema estrutural composto por 26 pilares do andar térreo de um edifício, distribuídos numa área de aproximadamente $400 \mathrm{~m}^{2}$. A Figura 4.7 mostra as dimensões e a solicitação de serviço de cada pilar.

Os pilares são constituídos de concreto, $\operatorname{com} f_{c k}$ de $25 \mathrm{MPa}$, e aço, $\operatorname{com} f_{y k}$ igual a $500 \mathrm{MPa}$. Considera-se que as peças de concreto são super armadas e que a ruptura se dará por esmagamento do concreto. As duas variáveis consideradas são a tensão de compressão em serviço e a resistência do material à compressão simples.

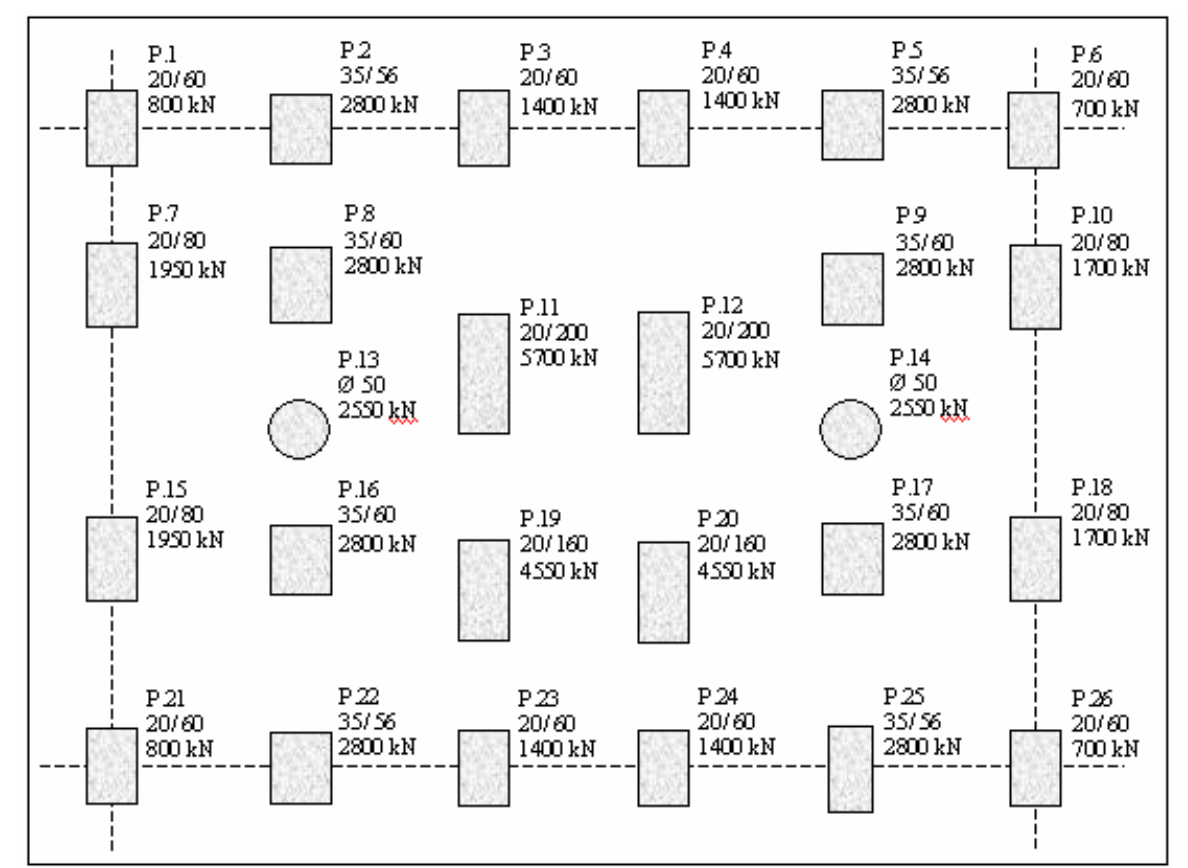

Figura 4.7 - Esquema de locação e solicitações nos pilares do andar térreo. 


\section{- Determinação das Solicitações}

Santos (1983) estima o esforço solicitante de uma viga de concreto como sendo o quociente entre o momento máximo na viga e o módulo de resistência no estádio I. De modo semelhante a solicitação nos pilares em termos de tensão, pode ser obtida dividindo-se a carga de serviço pela seção transversal de cada pilar.

Como os pilares são de concreto armado, utiliza-se a seção homogeneizada equivalente com módulo de elasticidade igual ao do concreto, como mostra a Figura 4.8.
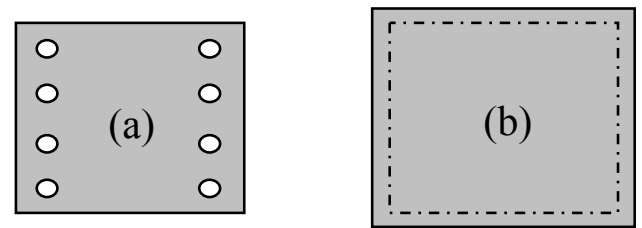

Figura 4.8 - Seção transversal do pilar: (a) Real e (b) Homogeneizada.

A Equação 4.29 define a área da seção homogeneizada, com módulo de elasticidade do concreto e do aço iguais a $23800 \mathrm{MPa}$ e $210000 \mathrm{MPa}$, respectivamente. A área da seção homogeneizada tem módulo de elasticidade secante do concreto igual a 23800 MPa, obtido segundo a NBR 6118/2003. A utilização da seção homogeneizada é uma simplificação satisfatória no cálculo da probabilidade de ruína, pois se admite que a ruptura se dará por esmagamento do concreto.

$$
A_{\mathrm{hom}}=A_{c}+\frac{E_{s} \cdot A_{s}}{E_{c}}
$$

Conforme a NBR 6118/2003 foram calculados os valores limites das armaduras longitudinais dos pilares e o valor médio. A partir da seção homogeneizada e da carga média nos pilares, que neste caso é igual a carga característica, calcula-se a tensão máxima, mínima e média nos pilares. A Tabela 4.2 mostra os valores estatísticos das solicitações nos pilares.

Tabela 4.2 - Análise estatística das solicitações nos pilares.

\begin{tabular}{c|ccll}
\hline Tensão $(\mathrm{MPa})$ & Mínima & Máxima & Média \\
\hline$m_{S}$ & 7 & 11,3 & 9,2 \\
$\sigma_{S}$ & 1,6 & 2,5 & 2,1 \\
$v_{S}$ & 0,229 & 0,223 & 0,225 \\
mínimo & 3,4 & 5.6 & 4.5 \\
máximo & 8,4 & 13.5 & 10.9 \\
\hline
\end{tabular}




\section{ם Determinação das Resistências}

A resistência à compressão do grupo de pilares foi determinada a partir da qualidade de execução do concreto prevista em norma. A antiga norma NB-1/1978 permite obter a resistência média através da Equação 3.5 e do desvio padrão estimado em função da qualidade de execução do concreto. A Tabela 4.3 mostra o tipo de execução e o valor do desvio padrão adotado neste trabalho, com base na norma NB-1/1978.

Tabela $4.3-\sigma_{R}$ em função da qualidade de execução do concreto.

\begin{tabular}{c|c}
\hline Execução & $\sigma_{R}(\mathrm{MPa})$ \\
\hline Ótima & 2,5 \\
Boa & 4,0 \\
Regular & 5,5 \\
Sofrível & 7,0 \\
\hline
\end{tabular}

A Tabela 4.4 mostra a análise estatística das resistências para o conjunto de pilares analisado, em função da qualidade do concreto.

Tabela 4.4 - Análise estatística das resistências nos pilares.

\begin{tabular}{c|ccccc}
\hline $\mathrm{R}$ & \multicolumn{4}{|c}{ Qualidade de execução do concreto } \\
\cline { 2 - 5 }$(\mathrm{MPa})$ & Otima & Boa & Regular & Sofrível \\
\hline$f_{c k}$ & 25 & 25 & 25 & 25 \\
$f_{c m}$ & 29,11 & 31,58 & 34,05 & 36,52 \\
$\sigma_{R}$ & 2,5 & 4 & 5,5 & 7 \\
$v_{R}$ & 0,086 & 0,127 & 0,162 & 0,192 \\
\hline
\end{tabular}

\section{- Segurança e Confiabilidade}

Através da formulação mostrada no ínicio deste capítulo, obteve-se os valores de $F_{S}$, $\beta_{M S, N}$ e $p_{r}$ para 12 casos de estudo correspondentes a diferentes combinações de resistências e solicitações. As resistências dependem de quatro tipos de controle de qualidade de execução do concreto. As solicitações dependem de três critérios da NBR 6118/2003 para cálculo das armaduras longitudinais dos pilares (mínima, máxima e valor intermediário).

As tabelas 4.5, 4.6 e 4.7 mostram o fator de segurança global, índice de confiabilidade e probabilidade de ruína para os doze casos analisados, respectivamente. 
Tabela $4.5-F_{S}$ para 12 casos de resistência e solicitação.

\begin{tabular}{c|c|c|c|c}
\hline$F_{S}$ & \multicolumn{4}{|c}{ Resistência } \\
\hline Solicitação (MPa) & Ótima & Boa & Regular & Sofrível \\
\hline Mínima & 4,16 & 4,51 & 4,86 & 5,21 \\
Máxima & 2,57 & 2,79 & 3 & 3,22 \\
Média & 3,17 & 3,44 & 3,71 & 3,98 \\
\hline
\end{tabular}

Tabela 4.6 - $\beta_{M S, N}$ para 12 casos de resistência e solicitação.

\begin{tabular}{c|cccc}
\hline$\beta_{M S, N}$ & \multicolumn{4}{|c}{ Resistência } \\
\hline Solicitação (MPa) & Ótima & Boa & Regular & Sofrível \\
\hline Mínima & 7,44 & 5,70 & 4,72 & 4,11 \\
Máxima & 5 & 4,28 & 3,75 & 3,38 \\
Média & 6,15 & 4,98 & 4,23 & 3,75 \\
\hline
\end{tabular}

Tabela $4.7-p_{r}$ para 12 casos de resistência e solicitação.

\begin{tabular}{c|c|c|c|c}
\hline$p_{r}$ & \multicolumn{4}{|c}{ Resistência } \\
\hline Solicitação (MPa) & Ótima & Boa & Regular & Sofrível \\
\hline Mínima & $4,95 \mathrm{E}-14$ & $5,92 \mathrm{E}-09$ & $1,18 \mathrm{E}-06$ & $1,99 \mathrm{E}-05$ \\
Máxima & $2,90 \mathrm{E}-07$ & $9,46 \mathrm{E}-06$ & $8,79 \mathrm{E}-05$ & $3,59 \mathrm{E}-04$ \\
Média & $3,94 \mathrm{E}-10$ & $3,23 \mathrm{E}-07$ & $1,15 \mathrm{E}-05$ & $8,97 \mathrm{E}-05$ \\
\hline
\end{tabular}

Analisando-se parametricamente, os resultados mostram, de forma geral que:

- Tabela 4.5:

$\checkmark$ Para uma dada solicitação quanto melhor o controle de qualidade do concreto menor poderia ser o fator de segurança;

$\checkmark$ Quanto maior a solicitação, que nos casos analisados implica em uma menor área de armadura longitudinal, menor o fator de segurança;

- Tabela 4.6 e 4.7:

$\checkmark$ Quanto melhor o controle de qualidade do concreto maior o índice de confiabilidade e quanto maior a solicitação, menor o índice de confiabilidade.

$\checkmark$ A probabilidade de ruína do sistema estrutural analisado aumenta quanto maior for a solicitação e quanto pior for o controle da qualidade de execução do concreto.

Contudo, o resultado mais importante deste trabalho é concluir que o mesmo valor de $f_{c k}$ de projeto pode conduzir a diferentes probabilidades de ruína, uma vez que esta depende fundamentalmente do controle de qualidade do concreto na obra. Logo, obras com mesmo $f_{c k}$ e iguais fatores de segurança podem apresentar diferentes probabilidades de ruína. Logo, propõe-se que as obras deveriam fixar $f_{c m}$ e $\sigma_{R}$ (qualidade do concreto), o que implicaria $F_{S}$ e $p_{r}$ constantes. 
Como comentado anteriormente, observa-se que no caso analisado, não há necessidade de utilizar a estatística dos conjuntos ordenados, pois o tamanho da população analisada é igual ao tamanho da amostragem.

\subsubsection{Aplicação 2 - Casos de Fundações}

Em fundações, é bastante incomum acontecer este fato: tamanho da amostra igual ao tamanho da população. Se acontecer é por um motivo particular, como pesquisas em universidades. Sendo assim, os casos de fundações tratados aqui terão como objetivo utilizar tanto a proposição de Aoki (2002) como as estatísticas de orderm.

Analisam-se os resultados de 13 fundações localizadas em diversos estados brasileiros, publicados por Silva, F. (2003). A característica semelhante destas fundações é que o elemento estrutural de fundação utilizado é o mesmo: Estacas moldadas in situ do tipo hélice contínua. Logo, a variabilidade da resistência da fundação é predominante oriunda da formação geológica-geoténica onde cada obra foi executada.

As variáveis solicitação e resistência referentes às superfícies resistentes destas fundações estão indicadas na Tabela 4.8. Salienta-se que a resistência é determinada a partir de provas de carga estática à compressão e que o número $n$ corresponde a quantidade de provas de carga para cada fundação analisada. Ainda nesta tabela encontra-se o fator de segurança global $F_{S}$, onde se observa que somente o resultado do caso 4 não satisfaz a recomendação do item 5.5.1 da NBR 6122/1996: $F_{S} \geq 2$ e $F_{S} \geq 1.6$ para obras com provas de carga.

Tabela 4.8 - Resistência e Solicitação das 13 fundações utilizadas. Fonte: Silva, F. (2003).

\begin{tabular}{|c|c|c|c|c|c|c|c|c|c|c|}
\hline \multirow{2}{*}{ CASO } & \multicolumn{2}{|c|}{ Localização } & \multirow[b]{2}{*}{$n$} & \multirow{2}{*}{$F_{S}$} & \multicolumn{3}{|c|}{ Resistência } & \multicolumn{3}{|c|}{ Solicitação } \\
\hline & $\mathbf{U F}$ & Cidade & & & $m_{R}$ & $\sigma_{R}$ & $v_{R}$ & $m_{S}$ & $\sigma_{S}$ & $v_{S}$ \\
\hline 1 & RJ & Jacarepaguá & 6 & 2.9 & 11526,2 & 1517,7 & 0,132 & 3965,6 & 119,4 & 0,03 \\
\hline 2 & $\mathrm{MG}$ & B. Horizonte & 3 & 2.4 & 9472,7 & 1626 & 0,172 & 3919,9 & 51 & 0,013 \\
\hline 3 & $\mathrm{SP}$ & Guarulhos & 6 & 3.3 & 13552,3 & 2368,4 & 0,175 & 4074,4 & 0 & 0 \\
\hline 4 & MG & B. Horizonte & 3 & 1.5 & 6300,1 & 1318,9 & 0,209 & 4157,5 & 0 & 0 \\
\hline 5 & ES & Aracruz & 5 & 2.6 & 10427,7 & 2408,9 & 0,231 & 3963 & 69,1 & 0,017 \\
\hline 6 & SP & Imirim & 5 & 2.5 & 10116 & 2619,9 & 0,259 & 4027,6 & 0 & 0 \\
\hline 7 & $\mathrm{BA}$ & Camaçari & 7 & 3.5 & 14118,5 & 3769,1 & 0,267 & 4047,1 & 46,6 & 0,012 \\
\hline 8 & $\mathrm{SC}$ & S. Fco. Sul & 4 & 2.9 & 11567 & 3096,6 & 0,268 & 4050,5 & 47,7 & 0,012 \\
\hline 9 & SP & Jacareí & 6 & 3.6 & 14426,4 & 4328,3 & 0,3 & 4040,5 & 74 & 0,018 \\
\hline 10 & RS & P. Alegre & 4 & 3.8 & 14922,1 & 4634,8 & 0,311 & 3912,6 & 44,2 & 0,011 \\
\hline 11 & $\mathrm{RS}$ & P. Alegre & 3 & 2.9 & 11677,9 & 4114,8 & 0,352 & 4042,5 & 55,1 & 0,014 \\
\hline 12 & PR & S. J. Pinhais & 5 & 3.3 & 13287,1 & 6028,8 & 0,454 & 3998 & 42,7 & 0,011 \\
\hline 13 & MG & Contagem & 6 & 3.0 & 14709,6 & 7133,1 & 0,485 & 4951,5 & 0 & 0 \\
\hline
\end{tabular}


A seguir, serão efetuadas análises sobre alguns tópicos relativos a estimativa da probabilidade de ruína das fundações citadas na Tabela 4.8.

\section{- O Método de Monte-Carlo e a Proposição de Aoki (2002)}

A Tabela 4.9 mostra o índice de confiabilidade $\beta_{M S, N}$ calculado considerando a simplificação de Aoki (2002), para $\left(\rho_{R S}=0\right)$. Os resultados obtidos com esta proposição são compatíveis com os valores encontrados na literatura: $p_{r}$ entre $10^{-2}$ e $10^{-4}$. A Tabela 4.9 também mostra $\beta_{M S, N}$ para 20000 simulações Monte Carlo. Observa-se a precisão entre os resultados obtidos com a simplificação de Aoki (2002) e a Simulação MonteCarlo.

Tabela 4.9 - Obtenção de $\boldsymbol{\beta}_{M S, N}$ a partir da Simulação Monte - Carlo e Aoki (2002).

\begin{tabular}{c|cc|cc}
\hline \multirow{2}{*}{ CASO } & \multicolumn{2}{|c|}{ Aoki (2002) } & \multicolumn{2}{c}{ Monte - Carlo } \\
\cline { 2 - 5 } & $\boldsymbol{\beta}_{\mathbf{M S}, \mathbf{N}}$ & $\mathbf{p}_{\mathbf{r}}$ & $\boldsymbol{\beta}_{\mathbf{M S}, \mathbf{N}}$ & $\mathbf{p}_{\mathbf{r}}$ \\
\hline $\mathbf{1}$ & 4.97 & $3.42 \mathrm{E}-07$ & 4.98 & $3.18 \mathrm{E}-07$ \\
$\mathbf{2}$ & 3.41 & $3.21 \mathrm{E}-04$ & 3.42 & $3.13 \mathrm{E}-04$ \\
$\mathbf{3}$ & 4.00 & $3.14 \mathrm{E}-05$ & 3.97 & $3.60 \mathrm{E}-05$ \\
$\mathbf{4}$ & 1.62 & $5.21 \mathrm{E}-02$ & 1.61 & $5.37 \mathrm{E}-02$ \\
$\mathbf{5}$ & 2.68 & $3.65 \mathrm{E}-03$ & 2.67 & $3.79 \mathrm{E}-03$ \\
$\mathbf{6}$ & 2.32 & $1.01 \mathrm{E}-02$ & 2.34 & $9.64 \mathrm{E}-03$ \\
$\mathbf{7}$ & 2.67 & $3.77 \mathrm{E}-03$ & 2.67 & $3.79 \mathrm{E}-03$ \\
$\mathbf{8}$ & 2.43 & $7.61 \mathrm{E}-03$ & 2.41 & $7.98 \mathrm{E}-03$ \\
$\mathbf{9}$ & 2.40 & $8.22 \mathrm{E}-03$ & 2.40 & $8.20 \mathrm{E}-03$ \\
$\mathbf{1 0}$ & 2.38 & $8.77 \mathrm{E}-03$ & 2.38 & $8.66 \mathrm{E}-03$ \\
$\mathbf{1 1}$ & 1.86 & $3.18 \mathrm{E}-02$ & 1.86 & $3.14 \mathrm{E}-02$ \\
$\mathbf{1 2}$ & 1.54 & $6.17 \mathrm{E}-02$ & 1.53 & $6.30 \mathrm{E}-02$ \\
$\mathbf{1 3}$ & 1.37 & $8.57 \mathrm{E}-02$ & 1.36 & $8.69 \mathrm{E}-02$ \\
\hline
\end{tabular}

\section{口 Índice de Confiabilidade $\left(\beta_{M S, N}\right.$ e $\left.\beta_{F S, N}\right)$ e Dependência $\left(\rho_{R S}\right)$}

Sobre o índice de confiabilidade obtido através das funções margem de segurança e fator de segurança, a Figura 4.9 mostra a variação de $\beta_{M S, N}$ e $\beta_{F S, N}$ com o coeficiente de correlação $\rho_{R S}$. Para os casos 3, 4, 6 e 13, os índices de confiabilidade valem 4, 1.62, 2.32 e 1.37, respectivamente, onde $v_{S}=0$ e a Equação 4.15 é utilizada.

Através da Figura 4.9 deduz-se que o índice de confiabilidade deduzido a partir das funções margem de segurança e fator de segurança apresenta comportamentos diferentes, principalmente, quanto maior for a dependência entre resistência e 
solicitação. Quando as variáveis R e S são mutuamente independentes $\left(\rho_{R S}=0\right): \beta_{M S, N}$ é praticamente igual a $\beta_{F S, N}$, e isso implica sugerir que em análises preliminares convém considerar estas variáveis como mutuamente independentes.
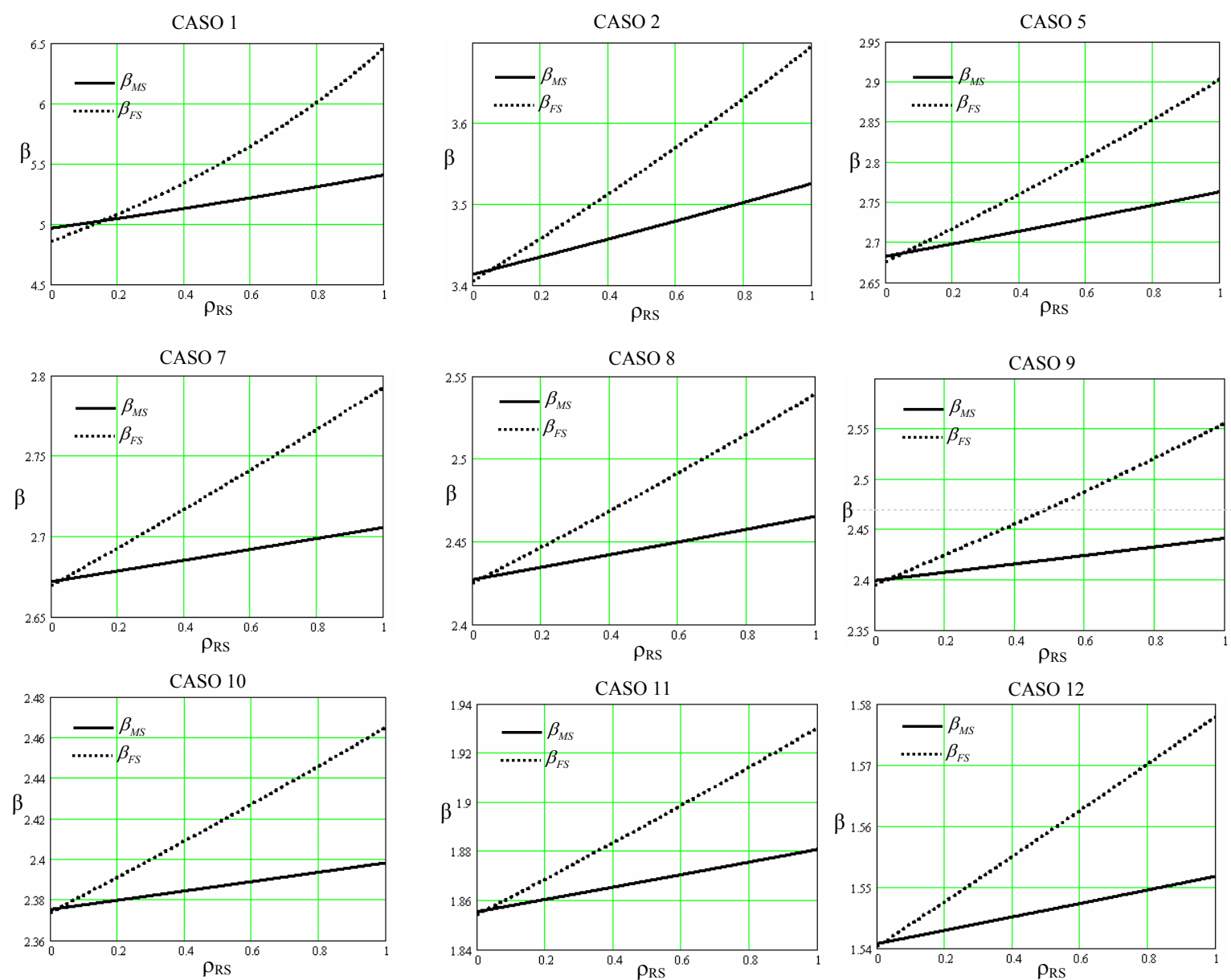

Figura 4.9 - Resultados da variação de $\beta_{M S, N}$ e $\beta_{F S, N} \operatorname{com} \rho_{R S}$.

\section{- Tamanho $\mathbf{N}$ da População}

Ao tratar da quantificação da confiabilidade expressa em termos da probabilidade de ruína é necessário levar em conta o tamanho $N$ da população analisada. Em príncipio, a probabilidade de ruína passaria a ser motivo de preocupação quando seu valor fosse maior que $1 / N$. No caso dos dados contantes da Tabela 4.8 não se sabe o tamanho da população de cada fundação.

A Tabela 4.10 apresenta o valor de $N$ a partir do qual a questão da confiabilidade passaria a ser um fator preocupante para os dados da Tabela 4.8 e para valores fixos de $F_{S}=1.6$ e $F_{S}=2.0$ (mínimos valores recomendados pela NBR 6122/96). O valor de $N$ 
para $F_{S}$ constante é obtido calculando a nova solicitação média e admitindo-se que o coeficiente de variação da solicitação seja o mesmo fornecido pela Tabela 4.8.

Tabela 4.10 - Análise paramétrica de $N$ para condições de $\beta_{M S, N}$ e $F_{S}$.

\begin{tabular}{c|c|c|c|c|c|c}
\hline \multirow{2}{*}{ CASO } & \multicolumn{2}{|c|}{ Tabela 5.8} & \multicolumn{2}{c|}{$\boldsymbol{F}_{\boldsymbol{S}}=\mathbf{1 . 6}$} & \multicolumn{2}{c}{$\boldsymbol{F}_{\boldsymbol{S}}=\mathbf{2 . 0}$} \\
\cline { 2 - 7 } & $\boldsymbol{\beta}_{\boldsymbol{M S}, \boldsymbol{N}}$ & $\boldsymbol{N}$ & $\boldsymbol{\beta}_{\boldsymbol{M S}, \boldsymbol{N}}$ & $\boldsymbol{N}$ & $\boldsymbol{\beta}_{\boldsymbol{M S}, \boldsymbol{N}}$ & $\boldsymbol{N}$ \\
\hline $\mathbf{1}$ & 4.97 & 2925829 & 2.82 & 416 & 3.77 & 12380 \\
$\mathbf{2}$ & 3.41 & 3116 & 2.18 & 69 & 2.91 & 555 \\
$\mathbf{3}$ & 4.00 & 31803 & 2.15 & 63 & 2.86 & 474 \\
$\mathbf{4}$ & 1.62 & 19 & 1.79 & 27 & 2.39 & 118 \\
$\mathbf{5}$ & 2.68 & 274 & 1.62 & 19 & 2.16 & 65 \\
$\mathbf{6}$ & 2.32 & 99 & 1.45 & 14 & 1.93 & 37 \\
$\mathbf{7}$ & 2.67 & 265 & 1.40 & 12 & 1.87 & 33 \\
$\mathbf{8}$ & 2.43 & 131 & 1.40 & 12 & 1.87 & 32 \\
$\mathbf{9}$ & 2.40 & 122 & 1.25 & 9 & 1.67 & 21 \\
$\mathbf{1 0}$ & 2.38 & 114 & 1.21 & 9 & 1.61 & 19 \\
$\mathbf{1 1}$ & 1.86 & 31 & 1.06 & 7 & 1.42 & 13 \\
$\mathbf{1 2}$ & 1.54 & 16 & 0.83 & 5 & 1.10 & 7 \\
$\mathbf{1 3}$ & 1.37 & 12 & 0.77 & 5 & 1.03 & 7 \\
\hline
\end{tabular}

Vale salientar que o valor $N$ obtido na Tabela 4.10 é específico para não condicionamento e independência entre as variáveis resistência e solicitação, ou seja, fatores como o efeito de grupo não é levado em consideração. Finalmente, os valores da Tabela 4.10 indicam que o tamanho $N$ da população deve ser considerado na interpretação da confiabilidade de uma fundação.

\section{- Estatísticas de Ordem}

Utilizando as estatísticas de ordem e os parâmetros da Tabela 4.8, a análise de confiabilidade das fundações está indicada na Tabela 4.11.

Tabela 4.11 - Utilização das estatísticas da ordem.

\begin{tabular}{|c|c|c|c|c|c|c|c|c|c|c|c|c|c|}
\hline \multirow[b]{2}{*}{ CASO } & \multicolumn{5}{|c|}{ Resistência } & \multicolumn{5}{|c|}{ Solicitação } & \multirow[b]{2}{*}{$F_{S}$} & \multirow[b]{2}{*}{$\boldsymbol{\beta}_{M S, N}$} & \multirow[b]{2}{*}{$\boldsymbol{N}_{\text {ORDEM }}$} \\
\hline & $\max$ & $\min$ & $m_{R}$ & $\sigma_{R}$ & $v_{R}$ & $\max$ & $\min$ & $m_{S}$ & $\sigma_{S}$ & $v_{S}$ & & & \\
\hline 1 & 14046.7 & 10024.8 & 12035.8 & 1588.4 & 0.13 & 4157.5 & 3890.5 & 4024.0 & 105.5 & 0.026 & 2.99 & 5.03 & 4129708 \\
\hline 2 & 10943.9 & 7726.8 & 9335.4 & 1901.4 & 0.20 & 3978.9 & 3890.5 & 3934.7 & 52.2 & 0.013 & 2.37 & 2.84 & 442 \\
\hline 3 & 17511.3 & 11093.6 & 14302.5 & 2534.6 & 0.18 & 4074.4 & 4074.4 & 4074.4 & 0 & 0 & 3.51 & 4.04 & 36659 \\
\hline 4 & 7276.4 & 4799.7 & 6038.1 & 1463.8 & 0.24 & 4157.5 & 4157.5 & 4157.5 & 0 & 0 & 1.45 & 1.28 & 10 \\
\hline 5 & 14298.8 & 8343.8 & 11321.3 & 2560.2 & 0.23 & 4027.6 & 3890.5 & 3959.1 & 58.9 & 0.015 & 2.86 & 2.87 & 495 \\
\hline 6 & 12714.5 & 7371 & 10042.8 & 2297.3 & 0.23 & 4027.6 & 4027.6 & 4027.6 & 0 & 0 & 2.49 & 2.62 & 226 \\
\hline 7 & 19981 & 8153 & 14067.0 & 4375.9 & 0.31 & 4074.4 & 3978.9 & 4026.7 & 35.3 & 0.009 & 3.49 & 2.29 & 92 \\
\hline 8 & 15277.7 & 8404.2 & 11841.0 & 3339.9 & 0.28 & 4074.4 & 3978.9 & 4026.7 & 46.4 & 0.012 & 2.94 & 2.34 & 104 \\
\hline 9 & 20093 & 8064.4 & 14078.7 & 4750.6 & 0.34 & 4157.5 & 3978.9 & 4068.2 & 70.5 & 0.017 & 3.46 & 2.11 & 57 \\
\hline 10 & 21194.8 & 10399.3 & 15797.1 & 5245.6 & 0.33 & 3978.9 & 3890.5 & 3934.7 & 43.0 & 0.011 & 4.01 & 2.26 & 84 \\
\hline 11 & 16383.2 & 8753.3 & 12568.3 & 4509.4 & 0.36 & 4074.4 & 3978.9 & 4026.7 & 56.4 & 0.014 & 3.12 & 1.89 & 34 \\
\hline 12 & 21194.8 & 5177.8 & 13186.3 & 6886.1 & 0.52 & 4074.4 & 3978.9 & 4026.7 & 41.1 & 0.010 & 3.27 & 1.33 & 11 \\
\hline 13 & 21194.8 & 7207.3 & 14201.1 & 5524.3 & 0.39 & 4951.5 & 4951.5 & 4951.5 & 0 & 0 & 2.87 & 1.67 & 21 \\
\hline
\end{tabular}


Observando a Tabela 4.11 e a Tabela 4.8, quanto aos fatores de segurança globais não houve mudança, ou seja, os valores médios da resistência e solicitação inferidos pelas estatísticas de ordem se aproximaram da proposição de Aoki (2002). Porém, analisando a Tabela 4.11 e a Tabela 4.10 (terceira coluna), quanto à confiabilidade expressa pelo inverso da probabilidade de ruína $(\mathrm{N})$ tem-se que não há uma concordância entre as estatísticas de ordem e a proposição de Aoki (2002), pois há casos onde as estatísticas de ordem resultou numa maior confiabilidade $\left(\mathrm{N}_{\text {ORDEM }}>\mathrm{N}_{\mathrm{AOKI}}\right)$ e há casos onde ocorreu o inverso $\left(\mathrm{N}_{\mathrm{ORDEM}}>\mathrm{N}_{\mathrm{AOKI}}\right)$. O tamanho da amostra não influiu na discordância entre $\mathrm{N}_{\mathrm{ORDEM}} \mathrm{e} \mathrm{N}_{\mathrm{AOKI}}$.

Logo, de modo geral, conclui-se que as estatísticas de ordem é uma ferramenta promissora para a estimativa dos parâmetros populacionais finitos.

\section{- Considerações Finais}

Considerações importantes podem ser extraídas das análises efetuadas nesta aplicação, tais como:

- O método de Simulação de Monte Carlo é um bom estimador da probabilidade de ruína;

- Os índices de confiabilidade deduzidos a partir das funções margem de segurança e fator de segurança são diferentes quando existe dependência entre resistência e solicitação;

- Quanto maior for a dependência entre resistência e solicitação, maior o valor do índice de confiabilidade, logo sugere-se que em análises preliminares convém considerar estas variáveis como mutuamente independentes;

- O tamanho da população, definido pelo conjunto de elementos estruturais da fundação deve ser considerado na análise de confiabilidade;

- Frente à proposição de Aoki (2002), as estatísticas de ordem parece ser uma ferramenta promissora para a estimativa dos parâmetros populacionais das fundações. 


\section{Proposta para o Projeto de Fundações}

$\mathrm{Na}$ fase de projeto, a prática brasileira de análise do conjunto de valores de capacidade de carga pode ser classificada nas três metodologias expostas por Cintra \& Aoki (1999) e descritas abaixo:

1a Metodologia: fixa-se a carga admissivel (igual à carga nominal, por exemplo) e, com os dados das sondagens, calculam-se os comprimentos das estacas de modo que, para cada furo de sondagem se tenha a capacidade de carga dada por:

$$
R=F_{S} \cdot P_{a d m}
$$

$2^{a}$ Metodologia: fixa-se uma profundidade de assentamento para todos os elementos estruturais de fundação (o que é típico em projetos de fundações por tubulões e também pode ocorrer para estacas moldadas in situ, em geral, por limitação da profundidade máxima executável pelo equipamento disponível) e, com os dados de cada furo de sondagem, calculam-se os diferentes valores de capacidade de carga $(R)$ e, em seguida, o valor médio da capacidade de carga $\left(R_{\text {med }}\right)$. Finalmente, a carga admissivel é dada por:

$$
P_{a d m}=\frac{m_{R}}{F_{S}}
$$

$3^{a}$ Metodologia: adota-se um critério prévio para limite de profundidade de execução do elemento estrutural de fundação (por exemplo, o índice de resistência à penetração do SPT adequado para a ponta da estaca ou base 
do tubulão) e, para cada furo de sondagem, calculam-se a profundidade e a capacidade de carga (Li e R) resultantes para essa condição. Nesse caso, a carga admissível também é dada pela Equação 5.2

Como comenta Cintra \& Aoki (1999), é importante lembrar que:

- Independentemente da metodologia, a carga admissível é sempre um conceito que se aplica ao conjunto dos EIF de uma determinada obra.

\ Negas iguais não necessariamente implicam mesma capacidade de carga.

- Ao se realizar uma prova de carga estática após o estaqueamento concluído de uma obra, e se encontrar um fator de segurança inferior ao adotado no projeto. Em conseqüência, deve-se reforçar o estaqueamento? Não necessariamente, pois o fator de segurança se aplica ao valor médio da capacidade de carga $\left(m_{R}\right)$ e não a cada um dos valores (R). Quem concluir pelo reforço, nesse caso, ou acredita que não haja dispersão nos valores de capacidade de carga, ou supõe equivocadamente que, como o valor médio é estatisticamente o mais provável, a capacidade de carga obtida no ensaio de uma estaca escolhida aleatoriamente coincide com a capacidade de carga média de todo o estaqueamento.

No método da carga admissível a dispersão é ignorada pois só é levado em consideração o valor médio da capacidade de carga. Cintra \& Aoki (1999) concluem que em duas obras com iguais valores médios de capacidade de carga, a carga admissível de projeto será a mesma, indiferentemente da existência ou não de controle durante a execução, o que é uma grave deficiência do método de carga admissível.

Observa-se que as três metodologias são interdependentes, ou seja, a utilização de todas estas em conjunto resultará no projeto mais adequado do ponto de vista da melhor superfície resistente para a fundação. 


\subsection{Metodologia Proposta}

O objetivo da metodologia é incluir na verificação de segurança dos projetos de fundações por estacas a análise da confiabilidade, obtida pelo cálculo da probabilidade de ruína.

A metodologia propõe a determinação do índice de confiabilidade e da probabilidade de ruína para a superfície resistente inferida a partir da metodologia proposta por Cintra \& Aoki (1999). Para garantir que a fundação analisada seja segura e confiável dois critérios deverão ser obedecidos nesta metodologia de projeto:

1. Fator de Segurança: A fundação, caracterizada pela superfície resistente projetada, deve obedecer aos fatores de segurança mínimos regulamentados pelas normas vigentes.

2. Probabilidade de Ruína: O valor da probabilidade de ruína a ser considerado adequado para a fundação analisada deverá ser motivo de avaliação dos engenheiros projetistas, executores e, também, do proprietário da obra.

Nas análises da confiabilidade da fundação, o não condicionamento das variáveis aleatórias resistência e solicitação é sugerido, especialmente, em análises preliminares quando não se conhece a dependência entre resistência e solicitação.

Observa-se que a metodologia de Cintra e Aoki (1999) pode ser reavaliada, considerando a probabilidade de ruína como fator alvo:

$1^{a}$ Metodologia: fixa-se a carga admissivel (igual à carga nominal, por exemplo) e, com os dados das sondagens, calculam-se os comprimentos das estacas de modo que, para cada furo de sondagem se tenha a capacidade de carga dada por:

$$
R=F_{S} \cdot P_{a d m}
$$

Observa-se que, no caso de solicitação constante, a utilização desta primeira metodologia pode ser desprezada na metodologia proposta, pois 
não se considera a dispersão da resistência, o que acarreta numa probabilidade de ruína teórica igual a zero.

$2^{a}$ Metodologia: fixa-se uma profundidade de assentamento para todos os elementos estruturais de fundação (o que é típico em projetos de fundações por tubulões e também pode ocorrer para estacas moldadas in situ, em geral, por limitação da profundidade máxima executável pelo equipamento disponível) e, com os dados de cada furo de sondagem, calculam-se os diferentes valores de capacidade de carga $(R)$ e, em seguida, o valor médio da capacidade de carga $\left(m_{R}\right)$ e o valor do desviopadrão $\left(\sigma_{R}\right)$. Finalmente, para o caso de solicitação constante, a carga admissivel e o índice de confiabilidade são dados por:

$$
\begin{gathered}
P_{a d m}=\frac{m_{R}}{F_{S}} \\
\beta=\frac{m_{R}-P_{a d m}}{\sigma_{R}}
\end{gathered}
$$

$3^{a}$ Metodologia: adota-se um critério prévio para limite de profundidade de execução do elemento estrutural de fundação (por exemplo, o indice de resistência à penetração do SPT adequado para a ponta da estaca ou base do tubulão) e, para cada furo de sondagem, calculam-se a profundidade e a capacidade de carga (Li e R) resultantes para essa condição. Nesse caso, a carga admissivel e o indice de confiabilidade também são dados pelas Equações 5.4 e 5.5 .

Observação importante: Quando se tem disponível a variabilidade da solicitação nas estacas, provenientes do cálculo estrutural da superestrutura, deve-se utilizar a seguinte equação 5.6 para o índice de confiabilidade. A probabilidade de ruína é dada pela equação 4.16.

$$
\beta=\frac{m_{R}-m_{S}}{\sqrt{{\sigma_{R}}^{2}+\sigma_{S}^{2}}}
$$


Segundo Silva, F. (2003), a probabilidade de ruína de uma estaca de um grupo de estacas isoladas é diferente da probabilidade de ruína de uma estaca de um grupo de estacas sob blocos com um número variado de estacas, obedecidas as distâncias mínimas entre estacas. A resistência de uma estaca isolada é menor que a resistência de uma estaca de um grupo de estacas capeadas por um bloco. Sendo assim, a metodologia proposta com base na probabilidade de ruína de um elemento isolado de fundação é a favor da confiabilidade da fundação.

A seguir são abordadas as premissas da metodologia proposta, quanto à forma como serão determinadas as curvas de distribuição de freqüências, das solicitações e das resistências, considerando as variabilidades que influenciam estas variáveis e as simplificações adotadas no seu cálculo.

Observa-se que, para garantir que a probabilidade de ruína de projeto seja mantida após a execução da fundação, controles executivos de campo devem ser adotados no projeto. Estes controles serão discutidos quando se abordar a determinação da variável resistência.

\subsection{Determinação da Solicitação}

Segundo o Eurocode 0 (2001), a solicitação pode ser definida pelo efeito das ações (ou efeito da ação) em membros estruturais, por exemplo: esforços internos, tensão, deformação; ou na estrutura como um todo: flexão, rotação, etc. No caso de fundações, além do elemento estrutural, existe o meio contínuo representado pelo maciço de solo onde, em cada ponto do maciço, surge uma solicitação representada por um estado de tensões definido pelo tensor de tensões. As ações aleatórias ambientais e funcionais que geram a variável solicitação na fundação podem ser classificadas de acordo com a origem (acidentais, sísmicas, geotécnicas, etc.), a forma de atuação (dinâmica, estática, constante, variável, uniforme, periódica, etc.) e, são variáveis ao longo da vida útil da estrutura.

Em cada elemento isolado de fundação as solicitações calculadas são variáveis. Esta variabilidade é função da variação das cargas, da complexidade do modelo matemático de interação solo-estrutura, da superfície resistente e da variabilidade das propriedades dos materiais que formam a superestrutura e a fundação. 
De forma simplificada a solicitação pode ser determinada através dos seguintes procedimentos:

a) Consideração da solicitação de cada EIF, que compõe a fundação da obra, com valor determinado máximo no projeto;

b) Esta solicitação máxima deve ser calculada, considerando um modelo estrutural pertinente, sujeito às várias combinações de cargas e parâmetros previstos pelas normas;

c) Determinação dos parâmetros probabilísticos (média e desvio padrão), que caracterizam a curva de densidade de probabilidade de ocorrência das solicitações, através da análise estatística dos valores individuais de cada EIF do conjunto.

d) Ressalta-se que caso haja um estudo da interação solo-estrutura, este deverá ser adicionado às informações sobre a variável solicitação para um tratamento mais realístico do comportamento da fundação.

A medição da solicitação real ainda é um assunto não muito investigado na engenharia. Esta afirmação é baseada nos poucos trabalhos encontrados na literatura, principalmente em observações em escala natural (Neto, 2005). Geralmente, estima-se a solicitação a partir das cargas ambientais e funcionais mais importantes para o tipo de obra analisado.

\subsection{Determinação da Resistência}

Em termos da capacidade de carga, a análise de fundações por estacas pode ser dividida em dois tipos fundamentais:

- Fase de projeto: baseadas em dados indiretos, como ensaios de laboratório e ensaios de campo (SPT, CPT, DMT, etc);

- Fase de execução: análise do EIF, desde a sua nega, até a realização de provas de carga estáticas, repique e provas de carga dinâmicas.

\subsubsection{Fase de Projeto}

Geralmente, o elo mais fraco do sistema estaca-solo é o solo. A verificação da resistência estrutural é normatizada pela NBR 6118/2003 e a resistência geotécnica pela 
norma NBR 6122/1996. Em obras correntes de fundação, as análises correspondentes aos estados-limite últimos e aos estados-limite de utilização se reduzem à verificação do estado-limite último.

As resistências dos elementos isolados de fundação da obra dependem da mesma superfície resistente, do tipo de elemento estrutural de fundação (estaca, tubulão), da seção transversal e, da variabilidade das propriedades dos materiais que formam os elementos estruturais e o maciço de solo.

De acordo com o item 7.2 da NBR 6122/96, de modo geral, a capacidade de carga de um elemento isolado de fundação pode ser avaliada de três maneiras: Métodos estáticos semi-empíricos, empíricos ou teóricos; provas de carga estáticas e métodos dinâmicos.

$\mathrm{Na}$ fase de projeto, a capacidade de carga de cada elemento isolado de fundação pode ser estimada através de métodos teóricos, empíricos e semi-empíricos baseados no tipo de EEF e nos dados geotécnicos, que na prática brasileira se resumem, na maioria dos casos, às informações de sondagens à percussão.

\section{\ Métodos Estáticos Semi-Empíricos}

Os métodos semi-empíricos utilizam correlações com ensaios in situ. Como comenta Schnaid (2000), no Brasil assim como em praticamente todo o mundo os métodos rotineiros de projetos de fundações diretas e profundas usam sistematicamente os resultados da sondagem de simples reconhecimento (SPT).

Para exemplificação de métodos semi-empíricos, a seguir, são resumidos dois métodos que prevêem a capacidade de carga do EIF: Aoki \& Velloso (1975) e Décourt \& Quaresma (1978).

\section{a) Aoki \& Velloso (1975)}

O método de Aoki \& Velloso (1975) foi originalmente criado através de correlações entre resultados de penetração estática (cone) e dinâmica (SPT). A equação geral que avalia a capacidade de carga última, ou de ruptura, do elemento isolado de fundação é: 


$$
R=a_{p} \cdot \frac{K \cdot N_{p}}{F_{1}}+P \cdot \sum \frac{\alpha \cdot K \cdot N_{m}}{F_{2}} \cdot \Delta L
$$

sendo:

$a_{p}:$ área da ponta do EEF

P: perímetro do EEF

$\Delta L$ : espessura de cada camada de solo $N_{p}: N_{S P T}$ próximo à ponta do $\mathrm{EEF}$
$N_{m}: N_{S P T}$ médio para cada $\Delta L$

$\mathrm{K}$ e $\alpha$ : coeficientes dependentes do tipo de solo

$\mathrm{F}_{1}$ e $\mathrm{F}_{2}$ : coeficientes de correção das resistências de ponta e lateral

b) Décourt \& Quaresma (1978)

Baseado em resultado de ensaios SPT, o método de Décourt \& Quaresma (1978), modificado por Décourt (1996), tem como equação geral:

$$
R=\alpha \cdot K \cdot N_{p} \cdot a_{p} \cdot+P \cdot \beta \cdot \sum 10 \cdot\left(\frac{N_{m}}{3}+1\right) \cdot \Delta L
$$

sendo:

$a_{p}:$ área da ponta do EEF

$\mathrm{P}$ : perímetro do EEF

$\Delta L$ : espessura de cada camada de solo

$N_{m}: N_{S P T}$ médio para cada $\Delta L$

$\mathrm{K}$ : coeficiente que relaciona a resistência de ponta com o valor $\mathrm{N}_{\mathrm{p}}$ em função do tipo de solo

$N_{p}: N_{S P T}$ médio entre os valores de $N_{S P T}$ anterior

$\alpha$ e $\beta$ : coeficientes em função do tipo de EEF e e o posterior à ponta do EEF do tipo de solo

Vale salientar que todas as vezes que for comentado nesta dissertação sobre o método de Décourt \& Quaresma (1978) na verdade está se falando do método de Décourt \& Quaresma modificado por Décourt (1996).

Observando-se as equações propostas por Aoki \& Velloso (1975) e Décourt \& Quaresma (1978) para a estimativa da capacidade de carga do EIF, conclui-se que a tendência é que haja menor dispersão nos resultados fornecidos pelo método Décourt \& Quaresma (1978) devido à homogeneização nos valores da resistência de ponta $N_{p}$ que este método propõe. Este procedimento contribui para que haja uma melhor avaliação da resistência de ponta, principalmente, quando não houver penetração adequada da 
ponta do EEF na camada resistente, conduzindo assim a valores mais realísticos da resistência de ponta.

\subsubsection{Fase de Execução - Controles Executivos de Campo}

\section{- Provas de Carga Estáticas}

A resistência, ou seja, a capacidade de carga também pode ser avaliada por provas de carga estática segundo a NBR 12131 e o disposto no item 7.2.2 da NBR 6122/96.

Conforme a NBR 6122/96 (item 7.8.3.6.2, Nota b), em EEF comprimidos as provas de carga estáticas devem ser executadas em número de $1 \%$ do conjunto de estacas de mesmas características na obra, respeitando-se o mínimo de uma prova de carga. No caso de estacas escavadas, em obras com mais de 100 estacas para carga de trabalho acima de 3000 kN, a NBR 6122/96 (item 7.9.7.2.4) recomenda a execução de pelo menos uma prova de carga, de preferência em uma estaca instrumentada.

A capacidade de carga deve ser considerada quando ocorrer a ruptura nítida (NBR 6122/96), porém por motivos de carregamento inferiores à carga de ruptura do EIF a curva carga-recalque pode não caracterizar uma ruptura nítida e nestes casos deve-se utilizar critérios que definam uma ruptura. A seguir serão resumidos três critérios de ruptura convencional (função de um valor de recalque máximo finito) e um critério de ruptura física (função de um recalque infinito), respectivamente:

a) Terzaghi: considera como capacidade de carga a carga que corresponde a um recalque igual a $10 \%$ do diâmetro do EEF.

b) NBR 6122/96: a capacidade de carga refere-se ao recalque expresso pela fórmula:

$$
\rho=\frac{D}{30}+\frac{R \cdot L}{A \cdot E}
$$

sendo:

\begin{tabular}{|ll|}
$\rho:$ recalque de ruptura convencional & A: área da seção transversal do EEF \\
$R:$ capacidade de carga convencial & E: módulo de elasticidade do material do EEF \\
L: comprimento do EEF & D: diâmetro do EEF \\
\hline
\end{tabular}


c) Método de Davisson: A fórmula geral deste método é semelhante a proposta pela NBR 6122/96 com os mesmos parâmetros.

$$
\rho=\frac{D}{120}+3,8 m m+\frac{R \cdot L}{A \cdot E}
$$

d) Van der Veen (1953): Basicamente é uma extrapolação da curva carga-recalque pela função exponencial abaixo.

$$
P=R \cdot\left(1-e^{-a \cdot \rho}\right)
$$

sendo:

$\begin{array}{ll}\rho: \text { recalque } & \mathrm{R}: \text { carga de ruptura } \\ \mathrm{P}: \text { carga } & \text { a: coeficiente que define a forma da curva }\end{array}$

Aoki (1976) propõe que seja adicionado o parâmetro b no método de Van der Veen (1953), este parâmetro representa o intercepto, no eixo dos recalques, da reta obtida na escala semilogarítmica, como mostra a Equação 5.12.

$$
P=R \cdot\left(1-e^{-a \cdot \rho+b}\right)
$$

Segundo Décourt (1994) não existe no Brasil consenso sobre um método em relação a outro, embora exista uma tendência de aplicação maior do método de Van der Veen (1953).

\section{Métodos Dinâmicos}

A verificação da capacidade de carga é determinada através de ensaios de carregamento dinâmico que é executado segundo a NBR 13208 e o disposto no item 7.2.3 da NBR 6122/96. Estes ensaios são adequados a EEF comprimidos (estacas cravadas), porém existem experiências do ensaio com estacas escavadas e tubulões como comenta Moraes (2005).

Segundo a NBR 6122/96 (item 7.8.3.6.2): os ensaios de carregamento dinâmico devem ser executados em número de 3\% do conjunto de EEF de mesmas características na obra, respeitando-se o mínimo de três estacas instrumentadas. Os resultados dos métodos simplificados que forem utilizados para interpretação dos dados de 
instrumentação de cada conjunto de EEF de mesmas características devem ser aferidos por métodos numéricos baseados na equação da onda em pelo menos uma recravação de estaca ou aferidos por uma prova de carga estática. Os processos de cálculo mais conhecidos são os métodos CASE, IPT-CASE/PC, CAPWAP e CAPWAPC.

Quanto à forma de aplicação da carga, as provas de carga dinâmica se dividem em PCD com energia constante e PCD com energia crescente. Observa-se, na metodologia proposta, que a variável resistência refere-se à resistência última e não à resistência mobilizada.

A partir da comprovação de que existe uma boa correlação entre a resistência na ruptura determinada através de provas de carga estática e dinâmica, diversos trabalhos têm sido publicados analisando as provas de carga dinâmicas para estimar a capacidade de carga em diferentes tipos de estacas e formações geológicas-geotécnicas. Dentre estes, podem-se citar: Aoki (1997), Balech (2000), Ávila (2001), Bilfinger (2002), entre outros.

Aoki (1997) apresenta método baseado no princípio de provas de carga dinâmicas sucessivas executadas com energia crescente. Neste método, a abordagem dada à capacidade de carga está associada à energia complementar, mostrando que a capacidade de carga última do EIF é alcançada quando a energia complementar de golpes sucessivos se mantém constante.

\section{- Nega e Repique}

Nega e repique são os controles de campo mais utilizados na engenharia de fundações. Este fato é comum, pois em nas obras dificilmente se instrumentam todas as estacas.

A ABEF (1999) estipula nega e repique como sendo os parâmetros de controle que deverão ser obtidos para todas as estacas, recomendando que sejam obtidos os boletins de cravação de no mínimo $10 \%$ das estacas.

A forma mais comum de se registrar a nega e o repique durante a cravação de uma estaca, é colar uma folha de papel à estaca e pressionar um lápis ou caneta contra este papel, apoiando-o em um ateparo fixo, como indica a Figura 5.1. 


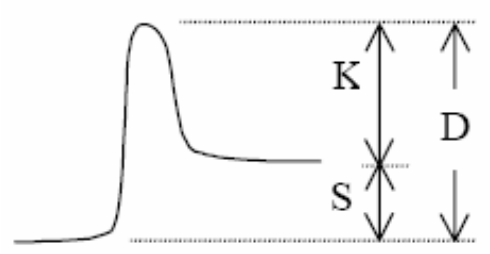

Figura 5.1 - Deslocamento D do topo da estaca (nega S e repique K).

Através do uso de fórmulas dinâmicas a nega pode sugerir a capacidade de carga de um elemento isolado de fundação. Diversos autores comentam sobre a inadequação deste procedimento, tais como Cintra \& Aoki (1999) e Bifinger (2002). Aoki (1991) afirma que negas iguais não necessariamente implicam mesma capacidade de carga.

Bilfinger (2002) comenta que dentre as fórmulas dinâmicas mais utilizadas estão às fórmulas dos dinamarqueses, Janbu e Hiley.

O repique é um critério de controle mais recente que a nega, deformação plástica permanente do solo, e correponde à deformação elástica que a estaca sofre durante um golpe. Assim como para a nega, existem diversas fórmulas dinâmicas utilizando-se como parâmetro o repique.

O autor entende que todos os parâmetros utilizados para avaliar o comportamento da fundação, quando bem interpretados, podem sugerir mudanças necessárias no momento adequado, ou seja, na execução. Aoki e Cintra (1996) sugerem a associação de medidas de repique e provas de carga dinâmicas e explicam que esta pode ajudar na otimização da superfície resistente, que eles definem como sendo a superfície que cada um dos elementos estruturais de fundação deve alcançar em profundidade para atender o valor da carga admissivel de projeto, considerando sua interação com o maciço de solos.

\subsection{Limitações da Metodologia Proposta}

A diferença da metodologia proposta em relação ao atual método de projeto de fundação da NBR 6122/96 é que, além de considerar a segurança através dos fatores de segurança global e/ou parciais, adiciona a confiabilidade através do conhecimento das curvas de distribuição de freqüências das solicitações e resistências da superfície resistente da fundação. Entretanto, esta metodologia possui limitações decorrentes de simplificações e desconsideração de alguns efeitos, tais como:

- O efeito de grupo das estacas; 
- A redistribuição de esforços que existe nas estruturas hiperestáticas, e pode também existir nas estruturas isostáticas como mostra Neto (2005);

- A necessidade de uma adequada caracterização da resistência, que compreende a investigação geotécnica e os métodos semi-empíricos, estáticos e/ou dinâmicos;

- A degradação da superestrutura e da fundação ao longo do tempo. A probabilidade de ruína aceitável das estruturas cresce com o estado de deterioração das estruturas ao longo do tempo. O Eurocode 0 (2001) recomenda que se deve considerar uma redução do valor do índice de confiabilidade quando se atinge um período referente a 50 anos;

- Os riscos não calculáveis, tais como desastres naturais, humanos e mistos;

A probabilidade de ruína cresce com o estado de deterioração das estruturas ao longo tempo. A durabilidade é um item essencial comumente implícito nos projetos de engenharia. Este item é totalmente influenciado pela qualidade das obras. Wolle e Hachich (1998) discutem os requisitos da qualidade das fundações, nos mais diferentes aspectos: projeto, execução e fundação acabada. O autor deste trabalho entende que a qualidade das fundações influencia diretamente no sucesso de uma obra, porém sua medição é dificilmente quantificada. Não é objetivo desta dissertação discutir a qualidade das fundações. Supõe-se que todos os serviços relacionados à fundação foram executados com profissionalismo e responsabilidade. A probabilidade de ruína calculada leva em consideração somente os aspectos técnicos de projeto: resistência e solicitação.

Apesar das simplificações e limitações da metodologia proposta baseada na estimativa da probabilidade de ruína, entende-se que esta é uma alternativa para se prever o comportamento de uma fundação ainda na fase de projeto.

Engana-se quem pensa que, somente, a realização de provas de carga após a conclusão do estaqueamento, qualquer que seja o número delas, aumente a segurança e confiabilidade da fundação, pois as provas de carga apenas constatam ou verificam os valores da resistência in situ. A segurança e confiabilidade só podem ser impostas se: a) durante a execução, for possível quantificar a resistência a cada profundidade e, sempre que necessário, aumentar a profundidade de apoio do elemento estrutural de fundação; b) após a execução da fundação outras medidas possam ser adotadas: reforço, alteração da superestrutura para redução da solicitação, etc. 


\section{Estudo de Caso}

A aplicação da metodologia proposta baseia-se em dados reais da fundação do Píer 3 (transição e berços 301 e 302) do Porto de Vila do Conde situado no Estado do Pará. As informações desta fundação referem-se, basicamente, a sondagens de simples reconhecimento $\left(\mathrm{N}_{\mathrm{SPT}}\right)$ e provas de carga dinâmica de energia crescente.

\subsection{Sobre o Porto de Vila do Conde}

Segundo informações do site: www.cdp.com.br/porto_vila_conde.aspx (acessado no dia 06/09/2005), o Porto de Vila do Conde foi inaugurado em 24 de outubro de 1985 e está localizado no município de Barcarena, no local denominado Ponta Grossa, às margens do rio Pará, na latitude $1^{\circ} 32^{\prime} 42^{\prime \prime}$ sul e longitude $48^{\circ} 45^{\prime} 00^{\prime \prime}$ oeste; hora local GMT $-3 h$.

As instalações de acostagem do Porto de Vila do Conde estão construídas obedecendo ao formato de um "T" maiúsculo, em que, no travessão, estão localizados os Berços de atracação alinhados com a direção da correnteza do Rio Pará, dispensando a utilização de rebocadores nas manobras de atracação ou desatracação dos navios que utilizam o Porto. A ligação a terra é feita através de uma Ponte de Acesso, com 378m de comprimento. A Figura 6.1 mostra uma visão panorâmica do Porto e identifica os três píeres e os terminais.

As cargas predominantes no Porto de Vila do Conde são: alumina, lingotes de alumínio, bauxita, coque, óleo combustível, madeira e piche. 


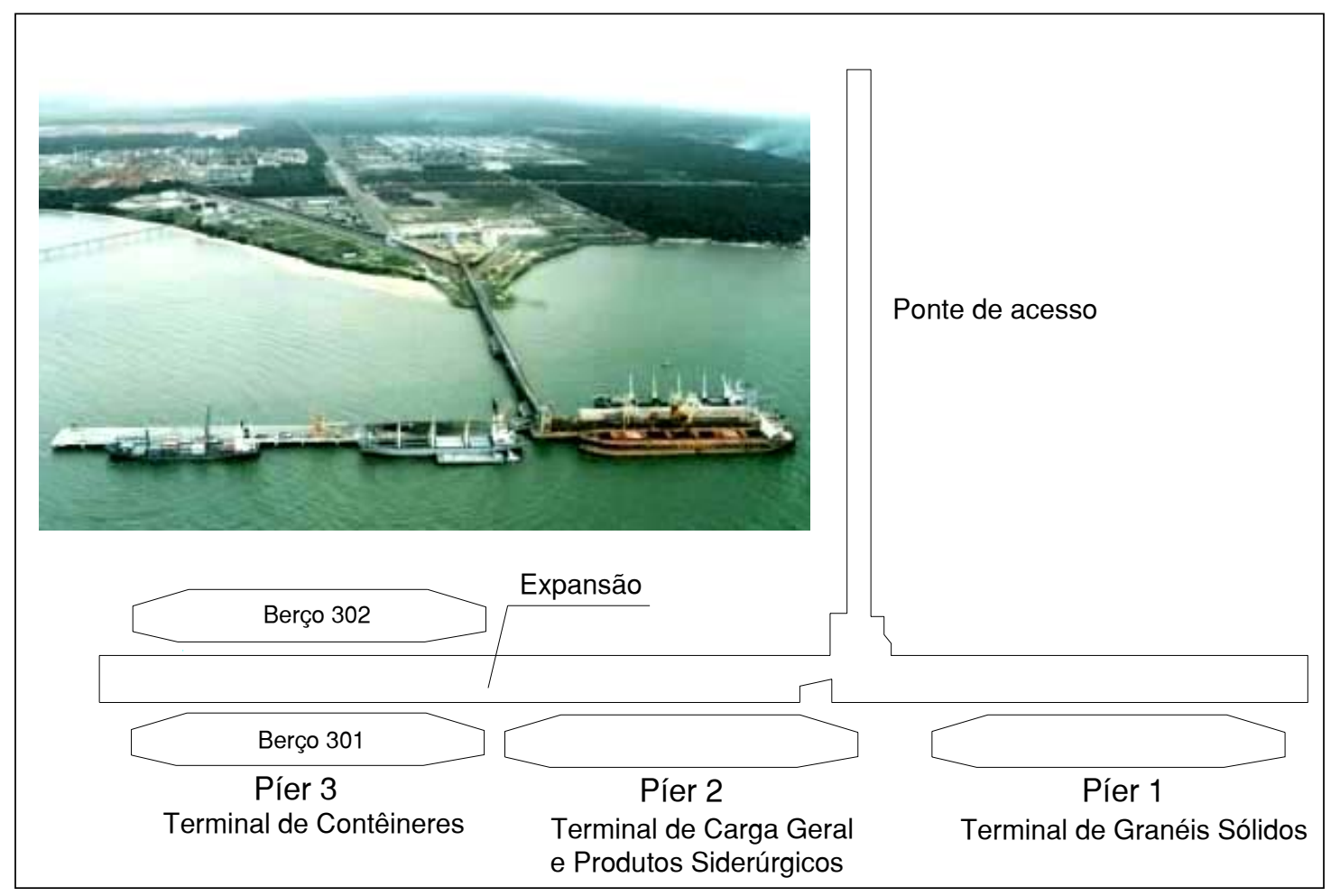

Figura 6.1 - Vista panorâmica e esquema simplificado do Porto de Vila do Conde. Fonte: www.cdp.com.br/porto_vila_conde.aspx

As condições meteorológicas e hidrográficas na região onde se situa o Porto de Vila do Conde estão descritas na Tabela 6.1.

Tabela 6.1 - Condições meteorológicas e hidrográficas do Porto de Vila do Conde. Fonte: www.cdp.com.br/porto_vila_conde.aspx

\begin{tabular}{l|c}
\hline nível médio & $2,36 \mathrm{~m}$ \\
\hline nível médio das preamares de sizígia & $3,04 \mathrm{~m}$ \\
\hline nível médio das baixa-mares de sizígia & $0,30 \mathrm{~m}$ \\
\hline nível médio das preamares de quadratura & $2,48 \mathrm{~m}$ \\
\hline nível médio das baixa-mares de quadratura & $0,78 \mathrm{~m}$ \\
\hline nível médio de redução & $0,69 \mathrm{~m}$ \\
\hline altura máxima das ondas & $0,85 \mathrm{~m}$ \\
\hline período & $3,6 \mathrm{~s}$ \\
\hline
\end{tabular}

\subsection{Características Geológicas-Geotécnicas}

Segundo Ferreira (2004), o estado do Pará apresenta um clima equatorial quente e úmido. O Porto de Vila do Conde situa-se no município de Barcarena com unidade básica de compartimentação geológica-geotécnica denominada de Formação Barreiras, 
com espessura de pacote sedimentar entre 80 a $135 \mathrm{~m}$ e profundidade do topo de 0 a 70 m. Esta formação pode ser classificada em períodos (quaternário e terciário) e épocas (holoceno, pleistoceno e mioceno) diferentes. Os horizontes constituintes desta formação, conforme Costa (2001) são:

- Horizonte Ferruginoso: mineralogicamente constituído por quartzo, caulinita, hematita e goethita, em diferentes proporções a depender da fácies avaliada.

- Fácies Concrecionário: possui matriz areno-argilosa a areno-siltosa, envolvendo concreções lateríticas irregulares distribuídas aleatoriamente; coloração amarelada ou avermelhada, a espessura varia de alguns centímetros até $5 \mathrm{~m}$.

- Fácies Areno Argilosa: constituída por areias argilosas maciças de coloração avermelhadas. Ocorrem ao mesmo nível topográfico da fácies Concrecionário, resultando de uma variação lateral desta fácies.

- Fácies Arenito Ferruginoso: ocorre, em geral, logo abaixo da fácies Concrecionário, fazendo contato inferior com o Horizonte Argiloso. É formada por matriz arenoargilosa a areno-siltosa envolvendo blocos de arenito ferruginoso de dimensões centimétricas a métricas, de cor preta, constituídos de grãos de tamanho em geral areia podendo chegar até pedregulhos de quartzo cimentados por hematita. Tem ocorrência irregular e restrita, sua espessura pode chegar a 2,5m. São conhecidas na RMB (região metropolitana de Belém) como pedra preta ou grés do Pará.

- Fácies Arenoso Ferruginizado: constituída por seqüências essencialmente arenosas (mais de $80 \%$ de areia) ferruginizadas, de coloração amarelada e avermelhada. Ocorre também na base da fácies Concrecionária, em alguns locais ocorrem em contato direto com o Horizonte de Solo separados por linha de seixos.

- Horizonte Argiloso: ocorre logo abaixo do Horizonte Ferruginoso; é formado por uma espessa camada de argila que pode chegar até a $8 \mathrm{~m}$ de espessura, ocorrendo em três fácies.

- Fácies Argila Mosqueada: forma seqüências essencialmente argilosas (caulinita) tendo algum quartzo formando lentes centimétricas de areia, além de hematita e goethita as quais são responsáveis pela formação de manchas irregulares com tons variados de vermelho e amarelo. No contato com a fácies arenito Ferruginoso 
apresenta-se endurecido pela presença de hematita.

- Fácies Argilitos: Laminado, formada por argilas (caulinita) finamente laminadas de coloração branca com manchas avermelhas. É formada mineralogicamente por caulinita e pouco quartzo, tendo goethita e hematita como acessórios os quais forma manchas insipientes. Ocorre também logo abaixo do Horizonte Ferruginoso.

- Fácies Argilito Maciço: são formadas por argilas brancas (caulinita), compostas por caulinita e algum quartzo. Ocorrem logo abaixo da fácies Argila Mosqueada e apresenta espessura superior a $1 \mathrm{~m}$.

- Intercalações sedimentos siliciclásticos representados por argilitos, arenitos, comumente ferruginizados, com estratificações.

\subsection{Sondagens de Simples Reconhecimento}

De forma esquemática, a Figura 6.2 apresenta a localização das sondagens analisadas.

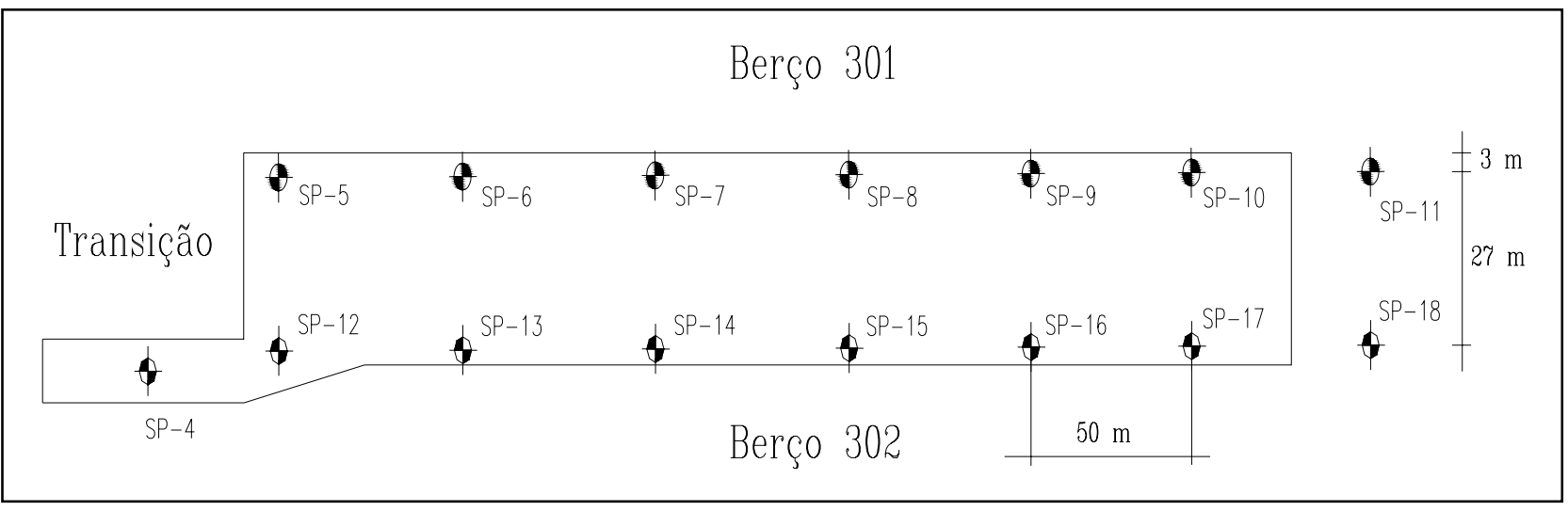

Figura 6.2 - Localização das sondagens no Píer 3.

Após 15 sondagens na região do píer 3 do porto, pode-se dizer que o subsolo apresenta camadas de depósitos fluviais e sedimentos aluvionares inconsolidados argiloarenosos e areno-argilosos. Estes sedimentos são provenientes de rochas silicosas detríticas, provavelmente da era Cenozóica, com coloração variada, com predominância do cinza e do vermelho, em diversos tons.

Os perfis geotécnicos típicos considerando as seções tranversais de SP-05 a SP-11 e SP-12 a SP-18, encontram-se no anexo A. Neste anexo também encontra-se a sondagem 4. De modo geral, tais perfis mostram que existe uma variabilidade geotécnica 
considerável e que as camadas de solos apresentam formas indefinidas, talvez se aproximando do formato nuvear.

\subsection{Solicitações Atuantes}

As solicitações atuantes nas estacas do trecho de transição e do berço 300 foram determinadas pela Planave S.A. Estudos e Projetos de Engenharia, para os casos de peso próprio, guindastes e demais cargas atuantes. No anexo B apresentam-se as solicitações em cada estaca.

$\mathrm{Na}$ Tabela 6.2 apresenta-se o resumo da análise estatística do conjunto de solicitações máximas para a ação do peso próprio, peso próprio mais cargas de operação e peso próprio mais as cargas correspondentes à situação de tormenta, no caso de máxima carga de compressão resultante, em cada estaca individualmente.

Tabela 6.2 - Análise estatística das solicitações máximas (kN): berço 300 + transição

\begin{tabular}{ccccc}
\hline Valores & Peso próprio & Peso Próprio + Operação & Peso Próprio + Tormenta \\
\hline $\mathrm{m}_{\mathrm{S}}$ & 756 & 2239 & 2295 \\
$\sigma_{\mathrm{S}}$ & 66 & 203 & 247 \\
$\mathrm{v}_{\mathrm{S}}$ & 0,09 & 0,09 & 0,11 \\
$\min$ & 479 & 1082 & 1066 \\
$\max$ & 1117 & 2761 & 3053 \\
\hline
\end{tabular}

\subsection{Resistências dos Elementos Isolados de Fundação}

\subsubsection{Elemento Estrutural de Fundação}

O estaqueamento do Píer 3 é composto por aproximadamente 450 elementos isolados de fundação. O elemento estrutural de fundação é classificado quanto ao material construtivo como estaca mista fabricada no canteiro da obra. A parte superior da estaca consiste de um elemento em concreto pré-moldado com fck igual a $18 \mathrm{MPa}$, com armadura protendida e armadura frouxa, com diâmetro externo e espessura de parede iguais a $80 \mathrm{~cm}$ e $13 \mathrm{~cm}$, respectivamente. 
As estacas possuem uma ponteira metálica que consiste de um tubo de aço com diâmetro externo de $80 \mathrm{~cm}$ e espessura de parede de $16 \mathrm{~mm}$. A extremidade inferior da ponteira é aberta.

Todas as estacas ensaiadas possuem um tampão de concreto na região da transição do concreto com a ponteira metálica, sendo que o mesmo tem espessura de 1 metro no interior da estaca de concreto e de $0,50 \mathrm{~m}$ no interior da ponteira metálica.

Os detalhes das estacas estão desenhados na Figura 6.3.

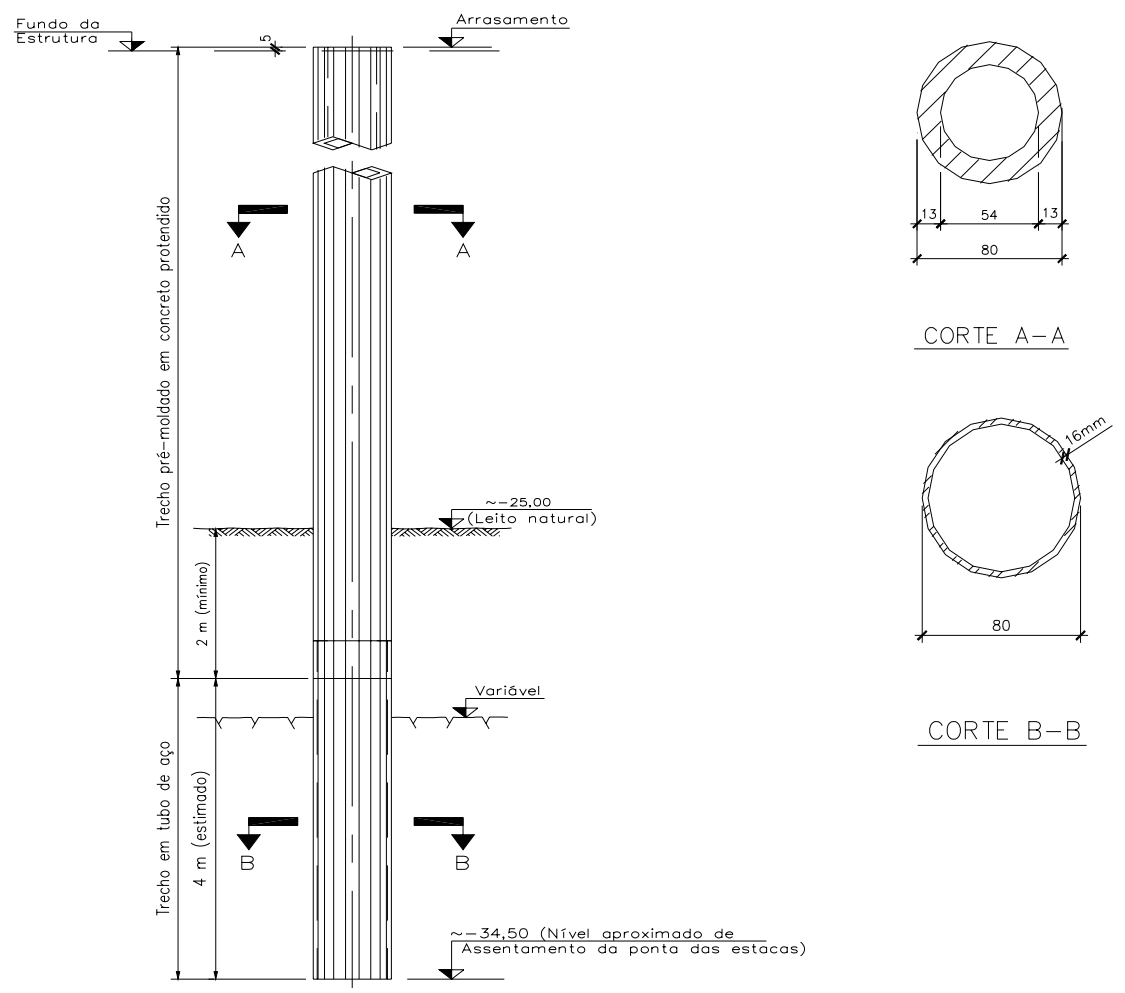

Figura 6.3 - Detalhe típico das estacas.

\subsubsection{Previsão por Métodos Semi-Empíricos}

As previsões das resistências na ruptura dos EIF pelos métodos de Aoki e Velloso (1975) e Décourt \& Quaresma (1978) foram realizadas para cada sondagem. Os cálculos da capacidade de carga do sistema estaca-solo correspondem ao caso de estaca pré-moldada de concreto de diâmetro $80 \mathrm{~cm}$ com a ponta fechada, assim como a carga admissível estrutural que vale $8000 \mathrm{kN}$ (para um fck do concreto igual a $18 \mathrm{MPa}$ ).

A Tabela 6.3 apresenta os resultados de resistência do sistema estaca-solo em duas profundidades consecutivas consideradas adequadas e correspondentes ao valor médio 
de ruptura em torno de $5000 \mathrm{kN}$. Para análise estatística da cota de assentamento, comprimento e resistência, foram consideradas todas as profundidades apresentadas na Tabela 6.3.

Tabela 6.3 - Resistência estaca pré-moldada de diâmetro $80 \mathrm{~cm}$ com a ponta fechada.

\begin{tabular}{|c|c|c|c|c|c|c|c|c|c|c|}
\hline \multirow{2}{*}{ Sond. } & \multirow{2}{*}{$\begin{array}{c}\text { Prof. } \\
\text { (m) }\end{array}$} & \multirow{2}{*}{$\begin{array}{c}\text { Cota } \\
\text { (m) }\end{array}$} & \multirow{2}{*}{$\begin{array}{c}\text { Comp. } \\
\text { (m) }\end{array}$} & \multicolumn{3}{|c|}{$\mathrm{AV}(\mathrm{kN})$} & \multicolumn{3}{|c|}{ DO (kN) } & \multirow{2}{*}{$\begin{array}{l}\text { Média } \\
\mathrm{R}(\mathrm{kN})\end{array}$} \\
\hline & & & & PL & $\mathbf{P P}$ & PR & PL & PP & PR & \\
\hline \multirow[t]{2}{*}{ SP-04 } & 14 & $-38,72$ & 44,22 & 2510 & 3890 & 6400 & 1918 & 2111 & 4029 & 5215 \\
\hline & 15 & $-39,72$ & 45,22 & 2780 & 3130 & 5910 & 2069 & 2031 & 4100 & 5005 \\
\hline \multirow{2}{*}{ SP-05 } & 4 & $-29,82$ & 35,32 & 310 & 4600 & 4910 & 494 & 3954 & 4448 & 4679 \\
\hline & 5 & $-30,82$ & 36,32 & 540 & 5620 & 6160 & 645 & 4356 & 5001 & 5581 \\
\hline \multirow[t]{2}{*}{ SP-06 } & 5 & $-30,72$ & 36,22 & 800 & 4720 & 5520 & 603 & 3380 & 3983 & 4752 \\
\hline & 6 & $-31,72$ & 37,22 & 1180 & 7950 & 9130 & 754 & 3862 & 4616 & 6873 \\
\hline \multirow[t]{2}{*}{ SP-07 } & 6 & $-30,97$ & 36,47 & 780 & 6960 & 7740 & 762 & 3054 & 3816 & 5778 \\
\hline & 7 & $-31,97$ & 37,47 & 1150 & 5500 & 6650 & 913 & 3275 & 4188 & 5419 \\
\hline \multirow[t]{2}{*}{ SP-08 } & 6 & $-30,72$ & 36,22 & 788 & 5378 & 6166 & 653 & 3874 & 4527 & 5347 \\
\hline & 7 & $-31,72$ & 37,22 & 1221 & 5170 & 6391 & 804 & 4293 & 5097 & 5744 \\
\hline \multirow[t]{2}{*}{ SP-09 } & 5 & $-28,91$ & 34,41 & 1311 & 3619 & 4930 & 670 & 6622 & 7292 & 111 \\
\hline & 6 & $-29,91$ & 35,41 & 1551 & 4403 & 5954 & 821 & 2851 & 3672 & 813 \\
\hline \multirow[t]{2}{*}{ SP-10 } & 3 & $-28,83$ & 34,33 & 1075 & 4524 & 5599 & 452 & 3639 & 4091 & 4845 \\
\hline & 4 & $-29,83$ & 35,33 & 1410 & 6635 & 8045 & 603 & 3975 & 4578 & 312 \\
\hline \multirow[t]{2}{*}{ SP-11 } & 6 & $-31,12$ & 36,62 & 1674 & 4584 & 6258 & 905 & 3631 & 4536 & 397 \\
\hline & 7 & $-32,12$ & 37,62 & 2083 & 5170 & 7253 & 1056 & 4717 & 5773 & 6513 \\
\hline \multirow[t]{2}{*}{ SP-12 } & 6 & $-30,72$ & 36,22 & 1050 & 4620 & 5670 & 855 & 3042 & 3897 & 784 \\
\hline & 7 & $-31,72$ & 37 & 1340 & 5310 & 6650 & 1005 & 2903 & 3908 & 5279 \\
\hline \multirow[t]{2}{*}{ SP-13 } & 12 & $-35,02$ & 40,52 & 2690 & 3720 & 6410 & 1659 & 2449 & 4108 & 5259 \\
\hline & 13 & $-36,02$ & 41,52 & 2960 & 5210 & 8170 & 1810 & 2891 & 4701 & 6436 \\
\hline \multirow[t]{2}{*}{ SP-14 } & 6 & $-29,82$ & 35,32 & 956 & 6434 & 7390 & 712 & 3297 & 4009 & 5700 \\
\hline & 7 & $-30,82$ & 36,32 & 1330 & 6032 & 7362 & 863 & 3780 & 4643 & 6003 \\
\hline \multirow[t]{2}{*}{ SP-15 } & 7 & $-30,99$ & 36,49 & 1514 & 3791 & 5305 & 855 & 3909 & 4764 & 5035 \\
\hline & 8 & $-31,99$ & 37,49 & 2050 & 5871 & 7921 & 1005 & 3446 & 4451 & 6186 \\
\hline \multirow[t]{2}{*}{ SP-16 } & 6 & $-30,12$ & 35,62 & 888 & 4323 & 5211 & 754 & 3378 & 4132 & 4672 \\
\hline & 7 & $-31,12$ & 36,62 & 1268 & 8344 & 9612 & 905 & 3619 & 4524 & 7068 \\
\hline \multirow[t]{2}{*}{ SP-17 } & 4 & -27 & 33,12 & 721 & 4711 & 5432 & 578 & 3987 & 4565 & 4999 \\
\hline & 5 & $-28,62$ & 34,12 & 1472 & 5302 & 6774 & 729 & 5163 & 5892 & 6333 \\
\hline \multirow[t]{2}{*}{ SP-18 } & 4 & $-23,77$ & 29,27 & 431 & 3902 & 4333 & 603 & 2694 & 3297 & 3815 \\
\hline & 5 & $-24,77$ & 30,27 & 925 & 20681 & 21606 & 754 & 12667 & 13421 & 8000 \\
\hline \multicolumn{2}{|c|}{$\mathbf{m}_{\mathbf{R}}$} & -31.02 & 36.52 & 1359 & 5670 & 7029 & 907 & 3895 & 4802 & 5598 \\
\hline \multicolumn{2}{|c|}{$\sigma_{R}$} & 3.25 & 3.25 & 688 & 3087 & 3021 & 412 & 1889 & 1798 & 870 \\
\hline \multicolumn{2}{|c|}{$v_{R}$} & -0.10 & 0.09 & 0.51 & 0.54 & 0.43 & 0.45 & 0.48 & 0.37 & 0.16 \\
\hline & & -39.72 & 29.27 & 310 & 3130 & 4333 & 452 & 2031 & 3297 & 3815 \\
\hline & & -23.77 & 45.22 & 2960 & 20681 & 21606 & 2069 & 12667 & 13421 & 8000 \\
\hline
\end{tabular}

A última coluna da Tabela 6.3 mostra o valor médio da capacidade de carga calculada pelos métodos de Aoki-Velloso (1975) e Décourt-Quaresma (1978) para cada profundidade. Estes valores foram utilizados na estimativa da probabilidade de ruína, pois este foi o critério adotado para representar a condição de ruptura do EIF no projeto. 
Vale ressaltar que como na cota $-24,77 \mathrm{~m}$ da sondagem SP-18, a resistência obtida pela associação dos métodos de Aoki-Velloso (1975) e Décourt-Quaresma (1978) apresenta um valor maior que a resistência estrutural, considerou-se o menor valor, ou seja, $8000 \mathrm{kN}$.

A superfície resistente prevista encontra-se no Anexo C.

\subsubsection{PCD de Energia Crescente}

Foram realizados 6 ensaios de carregamento dinâmico de energia crescente nas estacas E-36, E-64, E-307, E-344, E-364, E-397 no trecho do Píer 3 pela PDI Engenharia. As características das estacas ensaiadas são mostradas na Tabela 6.4.

Tabela 6.4 - Características das estacas ensaiadas.

\begin{tabular}{cccc}
\hline $\begin{array}{c}\text { Estaca } \\
\mathrm{N}^{\mathbf{0}}\end{array}$ & $\begin{array}{c}\text { Comprimento } \\
\text { total }(\mathrm{m})\end{array}$ & $\begin{array}{c}\text { Comprimento } \\
\text { da ponteira }(\mathrm{m})\end{array}$ & $\begin{array}{c}\text { Módulo de } \\
\text { Elasticidade }(\mathrm{MPa})\end{array}$ \\
\hline E-344 & 39 & 4 & 35100 \\
E-397 & 39 & 4 & 36100 \\
E-36 & 39 & 4 & 35100 \\
E-307 & 36.5 & 1.5 & 34200 \\
E-364 & 38 & 3 & 34200 \\
E-64 & 38 & 3 & 36100 \\
\hline
\end{tabular}

Os pares de pontos resistência-deslocamento, obtidos nas profundidades correspondentes aos metros finais da cravação, permitiram plotar as curvas de carga mobilizada - deslocamento vertical, destas estacas, como mostra a Figura 6.4. A equação da curva interpolada permitiu determinar as resistências de cada sistema estacasolo, definida pelos métodos de Terzaghi, Davisson e NBR 6122, além das análises CAPWAP ${ }^{\circledR}$ realizadas pela PDI Engenharia. Os resultados encontram-se resumidos na Tabela 6.5. Ainda nesta tabela mostra-se $\mathrm{R}_{\text {média ensaio, definida como a média dos valores }}$ pontuais da resistência RMX (Figura 6.4).

Para todas as estacas, os métodos de Terzaghi e Davisson revelaram os valores extremos (máximo e mínimo) da resistência. Comparando-se as solicitações dadas pelas tabelas 6.2 e 6.5 conclui-se que houve semelhança entre os valores médios. 
Tabela 6.5 - Análise dos resultados das provas de carga dinâmica.

\begin{tabular}{|c|c|c|c|c|c|c|c|c|}
\hline Estaca & $\begin{array}{c}\mathrm{R}_{\text {CAPWAP }} \\
(\mathrm{kN})\end{array}$ & $\begin{array}{c}\mathrm{R}_{\text {média ensaio }} \\
(\mathrm{kN})\end{array}$ & $\begin{array}{c}\mathrm{R}_{\text {TERZAGHI }} \\
(\mathrm{kN})\end{array}$ & $\begin{array}{c}\mathrm{R}_{\mathrm{NBR}-6122} \\
(\mathrm{kN})\end{array}$ & $\begin{array}{c}\mathrm{R}_{\text {DAVISSON }} \\
(\mathrm{kN})\end{array}$ & $\begin{array}{c}\mathrm{PP} \\
(\mathrm{kN})\end{array}$ & $\begin{array}{l}\text { PPO } \\
(\mathrm{kN})\end{array}$ & $\begin{array}{l}\text { PPT } \\
(\mathrm{kN})\end{array}$ \\
\hline E-36 & 4699 & 3659 & 5755 & 3608 & 2247 & 728 & 2281 & 2301 \\
\hline E-64 & 5770 & 4767 & 6329 & 4219 & 2880 & 722 & 2076 & 2103 \\
\hline E-307 & 4700 & 4018 & 5297 & 3803 & 2939 & 735 & 2277 & 2277 \\
\hline E-344 & 3904 & 3320 & 4675 & 3098 & 2157 & 824 & 2276 & 2288 \\
\hline E-364 & 5600 & 4282 & 6077 & 3963 & 2604 & 773 & 2099 & 2101 \\
\hline E-397 & 4334 & 3807 & 5811 & 4102 & 3067 & 952 & 2278 & 2263 \\
\hline $\mathbf{m}_{\mathbf{R}}$ & 4835 & 3975 & 5657 & 3798 & 2649 & 789 & 2215 & 2222 \\
\hline$\sigma_{R}$ & 723 & 506 & 592 & 406 & 379 & 89 & 99 & 94 \\
\hline$v_{R}$ & 0.15 & 0.13 & 0.10 & 0.11 & 0.14 & 0.11 & 0.04 & 0.04 \\
\hline $\max$ & 5770 & 4767 & 6329 & 4219 & 3067 & 952 & 2281 & 2301 \\
\hline $\min$ & 3904 & 3320 & 4675 & 3098 & 2157 & 722 & 2076 & 2101 \\
\hline
\end{tabular}

Observação: PP, PPO, PPT referem-se as solicitações do peso próprio, peso próprio mais operação e peso próprio mais tormenta, respectivamente.
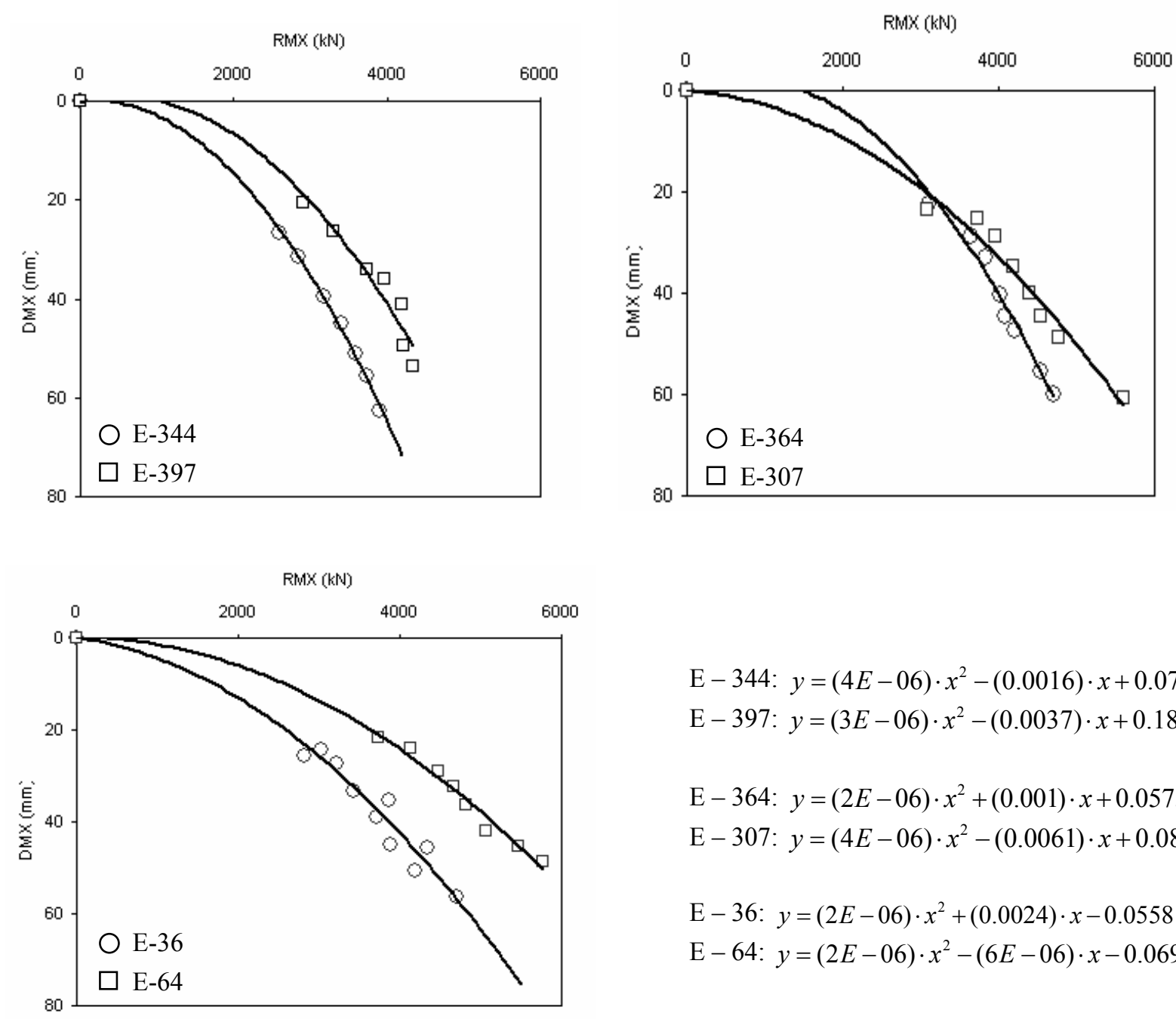

$$
\begin{aligned}
& \mathrm{E}-344: y=(4 E-06) \cdot x^{2}-(0.0016) \cdot x+0.0709 \\
& \mathrm{E}-397: y=(3 E-06) \cdot x^{2}-(0.0037) \cdot x+0.1823 \\
& \mathrm{E}-364: y=(2 E-06) \cdot x^{2}+(0.001) \cdot x+0.0575 \\
& \mathrm{E}-307: y=(4 E-06) \cdot x^{2}-(0.0061) \cdot x+0.0867 \\
& \mathrm{E}-36: y=(2 E-06) \cdot x^{2}+(0.0024) \cdot x-0.0558 \\
& \mathrm{E}-64: y=(2 E-06) \cdot x^{2}-(6 E-06) \cdot x-0.0699
\end{aligned}
$$

Figura 6.4 - Curvas resistência $x$ deslocamento da provas de carga dinâmica para as estacas E-36, E-64, E-307, E-344, E-364 e E-397. 


\subsection{Análise de Segurança e Confiabilidade}

\section{a Previsão}

Os resultados das análises estatísticas referentes à superfície resistente prevista conduziram aos resultados da Tabela 6.6.

Tabela 6.6 - Segurança e confiabilidade da previsão.

\begin{tabular}{c|c|c|c}
\hline Item & Peso Próprio (kN) & Peso Próprio + Operação $(\mathrm{kN})$ & Peso Próprio + Tormenta $(\mathrm{kN})$ \\
\hline$F_{S}$ & 7.41 & 2.50 & 2.44 \\
$\beta_{M S, N}$ & 5.55 & 3.76 & 3.65 \\
$p_{r}$ & $1.44 \mathrm{E}-08$ & $8.52 \mathrm{E}-05$ & $1.30 \mathrm{E}-04$ \\
$\mathrm{~N}=1 / p_{r}$ & 69682685 & 11741 & 7677 \\
\hline
\end{tabular}

Os resultados da Tabela 6.6 levam em consideração a Proposição de Aoki (2002), que torna representativa a amostragem (15 sondagens) dos parâmetros da população finita (450 estacas). Todo o formulário utilizado nesta tabela encontra-se descrito analiticamente no capítulo 4.

Observa-se que o inverso da probabilidade de ruína, entendida como o tamanho da população prevista da fundação, é muito maior que a população real de estacas na obra para todas as condições de solicitações, o que permite afirmar que esta fundação pode ser considerada confiável, ou seja, a probabilidade de ruína é inferior a 1 em 450 estacas e o índice de confiabilidade é maior que 3, valor corrente em obras de fundação.

Quanto à segurança, o fator de segurança global é maior que o mínimo de 2,0 exigido pela norma brasileira NBR 6122/96 Projeto e Execução de Fundações, para obras sem provas de carga.

\section{- PCD de Energia Crescente}

Na Tabela 6.7, 6.8 e 6.9 encontram-se os parâmetros de segurança e confiabilidade obtidos a partir das provas de carga dinâmica de energia crescente para as diversas combinações de solicitações. 
Tabela 6.7 - Segurança e confiabilidade do berço 300 e trecho de transição para a solicitação: peso próprio.

\begin{tabular}{ccccc}
\hline Resistência & $\mathrm{F}_{\mathrm{S}}$ & $\beta_{M S, N}$ & $p_{r}$ & $1 / \mathrm{p}_{\mathrm{r}}$ \\
\hline $\mathrm{R}_{\text {CAPWAP }}$ & 6,40 & 5,62 & $9,70 \mathrm{E}-09$ & $1,03 \mathrm{E}+08$ \\
$\mathrm{R}_{\text {média ensaio }}$ & 5,26 & 6,31 & $1,41 \mathrm{E}-10$ & $7,08 \mathrm{E}+09$ \\
$\mathrm{R}_{\text {TERZAGHI }}$ & 7,49 & 8,22 & $\approx 0$ & \\
$\mathrm{R}_{\text {NBR-6122 }}$ & 5,03 & 7,4 & $6,72 \mathrm{E}-14$ & $1,49 \mathrm{E}+13$ \\
$\mathrm{R}_{\text {DAVISSON }}$ & 3,51 & 4,92 & $4,29 \mathrm{E}-07$ & $2,33 \mathrm{E}+06$ \\
\hline
\end{tabular}

Tabela 6.8 - Segurança e confiabilidade do berço 300 e trecho de transição para a solicitação: peso próprio mais operação.

\begin{tabular}{ccccc}
\hline Resistência & $\mathrm{F}_{\mathrm{S}}$ & $\beta_{M S, N}$ & $p_{r}$ & $1 / \mathrm{p}_{\mathrm{r}}$ \\
\hline $\mathrm{R}_{\text {CAPWAP }}$ & 2,16 & 3,46 & $2,75 \mathrm{E}-04$ & 3641 \\
$\mathrm{R}_{\text {média ensaio }}$ & 1,78 & 3,18 & $7,27 \mathrm{E}-04$ & 1376 \\
$\mathrm{R}_{\text {TERZAGHI }}$ & 2,53 & 5,46 & $2,43 \mathrm{E}-08$ & $4,12 \mathrm{E}+07$ \\
$\mathrm{R}_{\text {NBR-6122 }}$ & 1,7 & 3,44 & $2,94 \mathrm{E}-04$ & 3400 \\
$\mathrm{R}_{\text {DAVISSON }}$ & 1,18 & 0,95 & 0,17 & 6 \\
\hline
\end{tabular}

Tabela 6.9 - Segurança e confiabilidade do berço 300 e trecho de transição para a solicitação: peso próprio mais tormenta.

\begin{tabular}{ccccc}
\hline Resistência & $\mathrm{F}_{\mathrm{S}}$ & $\beta_{M S, N}$ & $p_{r}$ & $1 / \mathrm{p}_{\mathrm{r}}$ \\
\hline $\mathrm{R}_{\text {CAPWAP }}$ & 2,11 & 3,32 & $4,45 \mathrm{E}-04$ & 2247 \\
$\mathrm{R}_{\text {média ensaio }}$ & 1,73 & 2,98 & $1,42 \mathrm{E}-03$ & 702 \\
$\mathrm{R}_{\text {TERZAGHI }}$ & 2,46 & 5,24 & $8,17 \mathrm{E}-08$ & $1,22 \mathrm{E}+07$ \\
$\mathrm{R}_{\text {NBR-6122 }}$ & 1,66 & 3,17 & $7,75 \mathrm{E}-04$ & 1290 \\
$\mathrm{R}_{\text {DAVISSON }}$ & 1,15 & 0,78 & 0,22 & 5 \\
\hline
\end{tabular}

Os resultados das tabelas acima também consideram a Proposição de Aoki (2002) para população finita. Observa-se que como na previsão, as provas de carga dinâmicas também indicam que a fundação é segura e confiável. Segura, pois o fator de segurança global é maior que o mínimo de 1,6 exigido pela norma brasileira NBR 6122/96 Projeto e Execução de Fundações, para obras com provas de carga. Também é confiável, pois a probabilidade de ruína é inferior a 1 em 450 estacas.

Somente no método de Davisson, para as solicitações referentes a ação do peso próprio mais operação e peso próprio mais tormenta as análises levam a uma fundação insegura e não confiável. Porém, este fato vem ressaltar a importância da escolha adequada do critério de ruptura. Nota-se que para esta obra de fundação, a escolha do método de Davison não é uma opção desejável. Vale ressaltar aqui que o método de Davisson foi criado numa época em que as estacas de pequeno diâmetro dominam as atenções de projetistas e executores de fundações por estacas. 
Conclui-se que o trecho de estaqueamento do berço 300 e trecho de transição atende as verificações de segurança (fator de segurança global) e confiabilidade (probabilidade de ruína não condicionada) tanto na fase de projeto quanto na fase de execução. É importante notar que a escolha do método que definirá a ruptura é essencial para uma avaliação adequada do comportamento da fundação.

Vale salientar, também, que nesta obra houve controle de campo a partir das negas das estacas cravadas. Apesar de muitos autores não considerarem uma boa opção para controle na obra, pelas inúmeras fórmulas dinâmicas que existem, ainda é bastante comum a utilização deste procedimento. No caso de estacas pré-moldadas de concreto, geralmente especifica-se uma nega de cravação, usualmente de 10 a 30mm/10 golpes do martelo.

\subsubsection{Estatísticas de Ordem}

Como a medida da dispersão, talvez, seja o item que mais influencia na estimativa da probabilidade de ruína, as estatísticas de ordem são utilizadas a seguir tanto no projeto quanto na execução. Nas solicitações não se utilizou as estatísticas de ordem pois toda a população (450 estacas) é conhecida.

A Tabela 6.10 apresenta a análise de confiabilidade e segurança na fase de projeto utilizando as estatísticas de ordem, nas quais os valores máximo e mínimo da resistência inferida no projeto são, respectivamente, $8000 \mathrm{kN}$ e $3815 \mathrm{kN}$. Comparandose esta tabela com a tabela 6.6 , tem-se que as estatísticas de ordem apresentam fatores de segurança semelhantes aos obtidos pela proposição de Aoki (2002) e superestima a probabilidade de ruína.

Tabela 6.10 - Segurança e Confiabilidade usando estatísticas da ordem.

\begin{tabular}{c|c|c|c}
\hline Item & Peso Próprio (kN) & Peso Próprio + Operação $(\mathrm{kN})$ & Peso Próprio + Tormenta $(\mathrm{kN})$ \\
\hline$F_{S}$ & 7.82 & 2.64 & 2.57 \\
$\beta_{M S, N}$ & 4.27 & 3.00 & 2.94 \\
$p_{r}$ & $9.88 \mathrm{E}-06$ & $1.35 \mathrm{E}-03$ & $1.66 \mathrm{E}-03$ \\
$\mathrm{~N}=1 / p_{r}$ & 101204 & 743 & 601 \\
\hline
\end{tabular}

Para a fase de execução, escolheram-se as resistências pelo CAPWAP e NBR6122. A Tabela 6.11 apresenta os resultados da análise de confiabilidade e resistência também para as duas condições de dispersão: Proposição de Aoki (2002) e estatísticas de ordem. 
As observações a serem feitas na execução, são praticamente, as mesmas na análise de projeto. O que pode ser ressaltado é que no método CAPWAP os valores do inverso da probabilidade de ruína são parecidos.

Tabela 6.11 - Segurança e confiabilidade para a solicitação: peso próprio mais tormenta.

\begin{tabular}{cccccc}
\hline & Resistência & $\mathrm{F}_{\mathrm{S}}$ & $\beta_{M S, N}$ & $p_{r}$ & $1 / \mathrm{p}_{\mathrm{r}}$ \\
\hline Aoki & $\mathrm{R}_{\text {CAPWAP }}$ & 2,11 & 3,32 & $4,45 \mathrm{E}-04$ & 2247 \\
$(2002)$ & $\mathrm{R}_{\text {NBR-6122 }}$ & 1,66 & 3,17 & $7,75 \mathrm{E}-04$ & 1290 \\
\hline Estatíticas & $\mathrm{R}_{\text {CAPWAP }}$ & 2,11 & 3,27 & $5,38 \mathrm{E}-04$ & 1859 \\
de ordem & $\mathrm{R}_{\text {NBR-6122 }}$ & 1,59 & 2,69 & $3,59 \mathrm{E}-03$ & 279 \\
\hline
\end{tabular}

Como comentado no capítulo 4, o método das estatísticas de ordem é um tema interessante para estimar a dispersão (desvio-padrão) e frente a proposição de Aoki (2002) pode ser utilizado na estimativa da probabilidade de ruína. 


\section{Conclusão e Sugestões}

A principal conclusão da dissertação consiste no objetivo desta: incluir $a$ probabilidade de ruína no projeto de fundações por estacas.

Como outras conclusões derivadas do objetivo principal pode-se dizer que:

- Os fatores de segurança global e parciais não devem ser os únicos referenciais para a concepção do projeto de uma fundação;

- É imprescíndivel considerar o tamanho da população finita ou infinita na estimativa da probabilidade de ruína;

- A dispersão (desvio-padrão) da amostragem pode ser avaliada tanto pela proposição de Aoki (2002) quanto pelas estatísticas de ordem, sendo que esta parece sugerir um caminho interessante;

- A escolha adequada do método que avalia a resistência, seja na fase de projeto (baseada em métodos semi-empíricos) ou na fase de execução (provas de carga) é um item bastante influente no sucesso da fundação;

- No estudo de caso referente a uma obra portuária a inclusão da probabilidade de ruína pôde indicar uma importante contribuição no estabelecimento de decisões tomadas por projetistas, executores e, também, pelo proprietário da obra.

De modo geral, o conhecimento da probabilidade de ruína no projeto de uma fundação, além de considerar a dispersão dos valores de resistência e solicitação, pode propiciar uma avaliação do comportamento da obra por pessoas não qualificadas tecnicamente. Isto deve influenciar bastante nas discussões entre cliente, projetistas e executores para a escolha da probabilidade de ruína associada a um fator de segurança e, também, a uma determinada superfície resistente. 
As sugestões para futuras pesquisas passam, em primeiro lugar, pela aplicação desta metodologia nas futuras obras de fundações por estacas.

Como sugestão secundária, pode-se indicar a inclusão da probabilidade de ruína na avaliação dos seguros de risco de engenharia. Estes consideram o histórico da ruína em períodos anteriores e características típicas da obra: tipo e tamanho da obra, localização da obra, conseqüências da ruína, etc.

No entendimento do autor, esta dissertação é um delta $x$ ( $\Delta x$ ) importante na avaliação das fundações por estacas. É claro que assim como o fator de segurança, a abordagem da probabilidade de ruína descrita nesta dissertação ainda é, de certa forma, simplificada, porém essencial para a prática das obras de fundações, sejam elas corriqueiras ou de considerável importância, como foi o estudo de caso relatado no capítulo 6. 


\section{Referências Bibliográficas}

ASSOCIAÇÃO BRASILEIRA DE NORMAS TÉCNICAS (1978). NB 1: Projeto $e$ execução de obras de concreto armado - Procedimento.

. (1992). NBR 12131 - Estacas - Prova de carga estática - Procedimento.

(1994). NBR 13208 - Estacas - Ensaio de carregamento dinâmico. Método de ensaio - Procedimento.

. (1996). NBR 6122 - Projeto e execução de fundações - Procedimento.

. (2003). NBR 6118: Projeto de estruturas de concreto - Procedimento.

. (2003). NBR 8681 - Ações e segurança nas estruturas - Procedimento.

ABCP (1967) - Associação Brasileira de Cimento Portland. Vocabulário de Teoria das Estruturas.

ABEF (1999) - Associação Brasileira de Empresas de Engenharia de Fundações e Geotecnia. Manual de Especializações de Produtos e Procedimentos ABEF, $2^{\mathrm{a}}$ Edição, São Paulo - SP.

ANG, A.H-S \& AMIN, M. (1968). Reliability of structures and structural systems. Journal of the Engineering Mechanics Division, ASCE, Vol. 94, N EM2, April, p.671691.

ANG, A.H-S \& CORNELL, C. A. (1974). Reliability bases of structural safety and design. Journal of the Structural Division, ASCE, Volume 100, No. ST9, September, p.1755-1769.

ANG, A.H-S \& TANG, W. (1984). Probability concepts in engineering planning and design. Volume II: Decision, Risk and Reliability. Jonh Wiley \& Sons. New York. 562p.

AOKI, N. (1976). Considerações sobre a capacidade de carga de estacas isoladas. Curso de Extensão Universitária em Engenharia de Fundações, Universidade Gama Filho, Rio de Janeiro, 44p. 
. (1991). Capacidade admissível de estacas através de ensaios dinâmicos. In: $2^{\circ}$ Seminário de Engenharia de Fundações Especiais (SEFE II), São Paulo, v.2. p.269-292.

(1997). Determinação da capacidade de carga última de estaca cravada em ensaio de carregamento dinâmico de energia crescente. Escola de Engenharia de São Carlos/USP. Tese de doutorado, 111p.

. (2002). Probabilidade de falha e carga admissível de fundação por estacas. Revista Militar de Ciência e Tecnologia, V. XIX, Brasil, p.48-64.

(2003). Sugestões para a revisão da norma de projeto de fundação NBR 6122. Encontro Técnico sobre Normas de Fundações. ABMS. IESP. São Paulo, Brasil, 8p.

AOKI, N. \& CINTRA, J. C. A. (1996). Influência da variabilidade do maciço de solos no comprimento de estacas. In: SEFE III - $3^{\circ}$ Seminário Engenharia Fundações Especiais, São Paulo, 1996. Anais, São Paulo, p.173-183.

(2003). Notas de aula: Segurança e Confiabilidade de Fundações. SGS 817 Engenharia de Fundações. Escola de Engenharia de São Carlos. Universidade de São Paulo.

AOKI, N. \& FALCÃO, (1977). Notas de aula: Fundações Rasas. Seção de Engenharia de Construção. Instituto Militar de Engenharia, Rio de Janeiro. 171p.

AOKI, N. \& VELLOSO, D. A. (1975). An approximate method to estimate the bearing capacity of piles. Proceedings, $5^{\text {th. }}$ Pan American CSMFE, Buenos Aires, vol. 1, p.367376.

ÁVILA, I. A. (2001). Análise do comportamento de estacas metálicas cravadas na Bacia Taubaté através de provas de carga dinâmica de energia crescente. Dissertação (Mestrado). Escola de Engenharia de São Carlos. Universidade de São Paulo, São Carlos - SP, 162p.

BALECH, J. (2000). Análise de transferência de carga de estacas cravadas em argila mole a partir de provas de carga dinâmica de energia crescente. Dissertação (Mestrado). Escola de Engenharia de São Carlos. Universidade de São Paulo, São Carlos - SP, 153p.

BASMA, A. A. (1994). Risk-reduction factor for bearing capacity of shallow foundations. Canadian Geotechnical Journal, Vol. 31, No 1, February, p.12-16

BECKER, D. E. (1996). Eighteenth Canadian geotechnical colloquium: limite states design for foundations. Part I: An overview of the foundation design process. Canadian Geotechnical Journal, vol. 33, p.956-983.

BENJAMIN, J. R. \& CORNELL, C. A. (1970). Probability, Statistics and Decision for Civil Engineers. McGraw-Hill, USA. 684p. 
BILFINGER, W. (2002). Critérios de segurança de fundações em estacas cravadas com consideração de controles executivos. Tese de doutorado.Escola Politécnica da Universidade de São Paulo. São Paulo, 260p.

BOUZON, E. (1976). O código de Hammurabi, introdução, tradução e comentários de E. Bouzon. Petrópolis, Vozes, 116p.

BRZAKALA, W. \& PULA, W. (1996). A probabilistic analysis of foundation settlements. Computers and Geotechnics, Vol. 18, No 4, p.291-309.

BUSSAB, W. O. \& MORETTIN, P. A. (2003). Estatística Básica. 5a edição, Editora Saraiva, São Paulo, 526p.

CAMARINOPOULOS, L. et al. (1999). Assessment of the time-dependent structural reliability of buried water mains. Reliability Engineering \& System Safety. Volume 65, Issue 1, June, p.41-53.

CARDOSO, A. S. \& FERNANDES, M. M. (2001). Characteristic values of ground parameters and probability of failure in design according to Eurocode 7. Géotechnique 51, N ${ }^{\circ}$ 6, p.519-531.

CASAGRANDE, A. (1965). Role of the "calculated risk" in earthwork and foundation engineering. Journal of the Soil Mechanics and Foundations Division, July, No. SM4, p.1-40.

CHERUBINI, C.; GARRASI, A. \& PETROLLA, C. (1992). The reliability of an anchored sheet-pile wall embedded in a cohesionless soil Canadian Geotechnical Journal, vol. 29, p.426-435.

CINTRA, J. C. A. \& AOKI, N. (1999). Carga admissível em fundações profundas. Livro do Projeto Reenge. Escola de Engenharia de São Carlos - USP, São Carlos, SP, $61 p$.

COSTA, T. D. (2001) Análise crítica das metodologias Gerais de Mapeamento Geotécnico visando formulação de Diretrizes para a cartografia geotécnica no trópico ùmido e aplicação na região metropolitana de Belém, escala 1:50.000 Belém. 2v, 256p. Tese de Doutorado - CGIUFPA.

DAVID, H. A. (1980). Order Statistics. John Wiley \& Sons, Inc.

DÉCOURT, L. (1994). Relato Geral da $1^{a}$ Sessão Técnica: Fundações e Interação Solo-Estrutura. In: X COBRAMSEG- Congresso Brasileiro de Mecânica dos Solos e Engenharia Geotécnica, Foz do Iguaçu, 1994. Anais, p.179-2005.

DÉCOURT, L. (1996). Análise e Projeto de Fundações Profundas: Estacas. In: Fundações: Teoria e Prática, Hachich et al. (eds.), Ed. Pini Ltda., São Paulo, Cap. 8.1, p.265-301.

DÉCOURT, L \& QUARESMA, A. R. (1978). Capacidade de carga de estacas a partir de valores de SPT. Anais, VI CBMSEF, Rio de Janeiro, vol. 1, p.45-53. 
DE COCK, F. \& LEGRAND, C. (1997). Design of axially loaded piles - European Practice. Proceeding of the ErtC3 Seminar Brussels/Belgium. April.

DER KIUREGHIAN, A. (1989). Measures of structural safety under imperfect states of knowledge. Journal of Structural Engineering, ASCE, Vol. 115, No. 5, May, p.11191140 .

DITLEVSEN, O. (1997). Structural Reliability Codes for Probabilistic Design - a Debate Paper based on Elementary Reliability and Decision Analysis Concepts. Structural Safety. Vol. 19, No. 3. p.253-270.

ELLINGWOOD, B. R. (1996). Reliability-based condition assessment and LRFD for existing structures. Structural Safety. Volume 18, Issues 2-3, 1996. p.67-80.

ESPINOSA, M. M., CALIL Jr., C. \& STAMATO, G. C. (2004). Uma introdução à confiabilidade em elementos estruturais, IX Encontro Brasileiro em Madeiras e em Estruturas de Madeira, Julho, Brasil.

EUROCODE 0 (2001). Basis of Structural Design. CEN - European Committee for Standardization.

FERREIRA, M. D.; COSTA, T. C. D. (2004) Mapa de Materiais Inconsolidados e Viabilidade de Usos Como Materiais Naturais de Construção da Região de Aurá Região Metropolitana de Belém (PA). In: Simpósio Brasileiro de Cartografia Geotécnica e Geoambiental, São Carlos, Suprema Gráfica e Editora, Vol. 1, p.75-85.

FOLSE, M. D. (1989). Reliability analysis for laterally loaded piles. Journal of Structural Engineering, ASCE, Vol. 115, No. 5, May, p.1011-1020.

FREUDENTHAL, A. M. (1947). The Safety of Structural. Transactions of ASCE. Vol. 112, p.125-180.

(1956). Safety and the Probability of Structural Failure. Transactions of ASCE. Vol. 121, p.1337-1397.

FREUDENTHAL, A. M.; GARRELTS, J. M.; SHINOZUKA, M. (1966). The Analysis of Structural Safety. Journal of the Structural Division, ASCE. Vol. 92, No ST1, February, p.267-325.

FUSCO, P. B. (1976). Estruturas de concreto. Editora McGraw-Hill do Brasil, Editora da Universidade de São Paulo, São Paulo.

GENEVOIS, B. B. P. (1991). Efeito da variabilidade especial dos parâmetros do solo na capacidade de carga de uma fundação superficial. Revista Solos e Rochas, Vol. 14(1), p.55-58, São Paulo.

GIMENES, E. A. (1988). Contribuição à obtenção de parâmetros estatísticos de medições geotécnicas irregularmente espaçadas. Dissertação (Mestrado), Escola Politécnica da Universidade de São Paulo, Brasil. 
GUEDES, M. C. S. (1997). Considerações sobre análises probabilísticas de estabilidade de taludes. PUC - Rio. Dissertação de Mestrado.

GRIGORIU, M.; VENEZIANO, D. \& CORNELL, C. A. (1979). Probabilistic modeling as decision making. Journal of the Engineering Mechanics Division, ASCE, Vol. 105, No. EM4, August, p.585-596.

HACHICH, W. C. (1978). Sobre a Segurança nos Projetos de Geotecnia. EPUSP. Dissertação de Mestrado.

HANSEN, J. B. (1956). The Philosophy of Foundation Design: Criteria, Safety Factors and Settlements Limits. Lecture 2, p.9-13.

HARBITZ, A. (1983). Efficient and accurate probability of failure calculation by use of the importance sampling technique. In: Proceedings of the Fourth International Conference on Applications of Statistics and Probability in Soil and Structural Engineering, ICASP, Firenze, Italy, p.825-836.

HASOFER, A. M. \& LIND, N. C. (1974). Exact and invariant second-moment code format. Journal of the Engineering Mechanics Division, ASCE, Vol. 100. No EM1, February.

HOLEYMAN, A. E. (2001). Screw piles - installation and design in stiff clay. Proceedings of the Symposium on Screw Piles. Brussels, Belgium.

LACASSE, S. \& GOULOIS, A. (1989). Reliability analysis of axial pile capacity. Proceedings of the Twelfth International Conference on Soil Mechanics and Foundation Engineering, Vol. 2, Balkema, Rio de Janeiro.

LANGEJAN, A. (1965). Some aspects of the safety factor in soil mechanics, considered as a problem of probability. VI ICSMFE $-6^{\text {th }}$ International Conference on Soil Mechanics and Foundation Engineering. Montreal, 1965. Anais, Rotterdam. p.500-502.

LI, C. Q. (1995). Computation of the failure probability of deteriorating structural systems. Computers \& Structures. Volume 56, Issue 6, p.1073-1079.

LIMA, L. S. A. (1991). Uma Metodologia para Análise Probabilística de Estabilidade de Taludes. COPPE/Universidade Federal do Rio de Janeiro. Dissertação de Mestrado. 265p.

LIMA, E. C. P.; OLIVEIRA, R. A.; ELLWANGER, F. B. \& MEDEIROS Jr., C. J. (1994). Análise da confiabilidade de estacas de estruturas offshore por determinação direta do ponto de máxima densidade de probabilidade. XV CILAMCE - Congresso Ibero Latino-Americano sobre Métodos Computacionais para Engenharia, UFMG, AMC p.796-803.

MARANHA DAS NEVES, E. (1994). Estados limites e segurança em Geotecnia. Revista Geotecnia, n ${ }^{\circ}$ 72, p.5-62. 
MAREK, P. et al. (1999). Transition from partial factors method to Simulation-Based Reliability Assessment in structural design. Probabilistic Engineering Mechanics, Volume 14, Issues 1-2, January, p.105-118.

MELCHERS, R. E. (2001). Rational optimization of reliability and safety policies. Reliability Engineering \& System Safety. Volume 73, Issue 3, September, p.263-268.

MEYERHOF, G. G. (1995). Development of Geotechnical Limit State Design. Canadian Geotechnical Journal. 32, p.128-136.

MORAES, L. S. (2005). Prova de carga dinâmica em placa. Escola de Engenharia de São Carlos/USP. Dissertação de mestrado, 143p.

MOREIRA, J. E. (1989). A philosophic approach to geotechnical engineering. De Mello Volume, Ed. Edgard Blucher Ltda, São Paulo, p.331-358.

NETO, L. R. (2005). Interpretação de deformação e recalque na fase de montagem de estrutura de concreto com fundação em estaca cravada. Escola de Engenharia de São Carlos/USP. Tese de doutorado, 279p.

NEVES, R. A. (2004). Desenvolvimento de modelos mecânico-probabilísticos para estruturas de pavimentos de edifícios. Escola de Engenharia de São Carlos/USP. Tese de doutorado, 20p.

NOGUEIRA, C. G. (2005). Um modelo de confiabilidade e otimização aplicado às estruturas de barras de concreto armado. Escola de Engenharia de São Carlos/USP. Dissertação (Mestrado), 166p.

NOWAK, A. S. \& COLLINS, K. R. (2000). Reliability of Structures. Michigan: McGraw-Hill.

OLIVEIRA, S. K. F. (1998). Contribuição ao estudo da verificação da segurança das fundações profundas. Escola de Engenharia de São Carlos/USP. Dissertação (Mestrado), 106p.

PACHECO, M. (1990). Conceitos de probabilidade e análise de risco em estudo e projetos de geotecnia. Conferencial especial. $6^{\circ}$ CBGE e IX COBRAMSEF, p.36-56.

PACHECO E LIMA (1996). Um critério estatístico para interpretação de ensaios geotécnicos. Revista Solos e Rochas, Vol. 19(3), p.177-188.

PANDEY, M. D. (1998). An effective approximation to evaluate multinormal integrals. Structural Safety, Volume 20, Issue 1, 1998, p.51-67.

PHOON, K-K. \& KULHAWY, F. H. (1999). Characterization of geotechnical variability. Canadian Geotechnical Journal, vol. 36, p.612-624.

(1999). Evaluation of geotechnical property variability. Canadian Geotechnical Journal, vol. 36, p.625-639. 
PHOON, K-K.; KULHAWY, F. H. \& GRIGORIU, M. D. (2000). Reliability-based design for transmission line structure foundations. Computers and Geotechnics, Vol. 26, p.169-185.

RIBEIRO, R. C. H. (2000). Confiabilidade e Probabilidade em Geotecnia de Fundações Superficiais. PUC - Rio. Dissertação de Mestrado, 96p.

ROSENBLUETH, E. (1975). Point estimates for probability moments. Proc. National Academy of Science, U.S.A., 72(10), Mathematics Sections, p.3812-3814.

SANDRONI, S. S. \& SAYÃO, A. S. F. J. (1992). Avaliação estatística do coeficiente de segurança de taludes. $1^{\mathrm{a}}$ Conferência Brasileira sobre Estabilidade de Taludes, ABMS, Vol. 2, p.523-535.

SANTOS, L. M. (1983). Cálculo de concreto armado, segundo a NB-1 e o CEB. São Paulo, Ed. LMS Ltda, Vol. 1, 2ª Edição.

SCHNAID, F. (2000). Ensaios de campo e suas aplicações à engenharia de fundações. Oficina de Textos. 189p.

SEXSMITH, R. G. (1999). Probability-based safety analysis - value and drawbacks. Structural Safety, Volume 21, Issue 4, December, p.303-310.

SHIGLEY, J. E. (1989). Mechanical engineering design. McGraw-Hill Book. $5^{\text {th }}$ ed.

SILVA, F. C. (2003). Análise de Segurança e Confiabilidade de Fundações Profundas em Estacas. Escola de Engenharia de São Carlos/USP. Dissertação de Mestrado, 2 volumes.

SILVA, N. N. (2004). Amostragem Probabilística: Um Curso Introdutório. São Paulo: Editora da Universidade de São Paulo. 2. ed. 1. reimp. 120p.

SILVA, J. L. \& AOKI, N. (2005). Determinação simples da probabilidade de ruína de grupo de pilares de um edifício de concreto armado. Congresso de Pontes e Estruturas. Associação Brasileira de Pontes e Estruturas - ABPE, 12p.

(2006). Tópicos relacionados à estimativa da probabilidade de ruína. XXXII Jornadas Sudamericanas de Ingeniería Estructural. Campinas, São Paulo, Brasil, 10p.

SOARES, R. C. et al. (2002). Reliability analysis of non-linear reinforced concrete frames using the response surface method. Reliability Engineering \& System Safety. Vol. 75, Issue 1, January, p.1-16.

STEENFELT, J. S. (1993). Introduction to closing discussion. In: Proceedings of the International Symposium on Limit State Design in Geotechnical Engineering. Copenhagen, Sponsored by the Danish Geotechnical Society, Vol. 3, p.633-635.

TANDJIRIA, V.; THE, C. I. \& LOW, B. K. (2000). Reliability analysis of laterally loaded piles using response surface methods. Structural Safety, Volume 22, Issue 4. 
VAN DER VEEN (1953). The bearing capacity of a pile. In: III International Conference on Soil Mechanics and Foundation Engineering. Zurich, v.2, p.84-90.

VANMARCKE, (1977). Probabilistic modeling of soil profiles. Journal of the Geotechnical Engineering Division, ASCE, Vol. 103, Nº GT11, p.1237-1246.

WEN, Y. K. (2001). Minimum lifecycle cost design under multiple hazards. Reliability Engineering \& System Safety. Volume 73, Issue 3, September, p.223 - 231.

WHITMAN, R. V. (1984). Evaluating calculated risk in geotechnical engineering. Journal of Geotechnical Engineering, ASCE, Vol. 110, No. 2, February, p.145-188.

WOLLE, C. M. \& HACHICH, V. F. (1998). Requisitos da qualidade das fundações. Fundações: Teoria e Prática, Hachich et al. (eds.), Ed. Pini, São Paulo, Cap. 19, p.693721.

ZAGOTTIS, D. (1974). A Introdução da Segurança no Projeto Estrutural I, II, III e Final. Revista Construção Pesada. São Paulo. 15p.

(1981). Pontes e grandes estruturas: IV Introdução da segurança no projeto estrutural. Departamento de Engenharia de Estruturas e Fundações - USP. São Paulo Brasil, 237p. 


\section{Anexos}

Anexo A - Perfis Geotécnicos

- Perfil de SP-05 a SP-11

- Perfil de SP-12 a SP-18

- Sondagem SP-4

Anexo B - Solicitações Atuantes

Anexo C - Superfície Resistente Prevista 


\section{Anexo A - Perfil de SP-05 a SP-11}
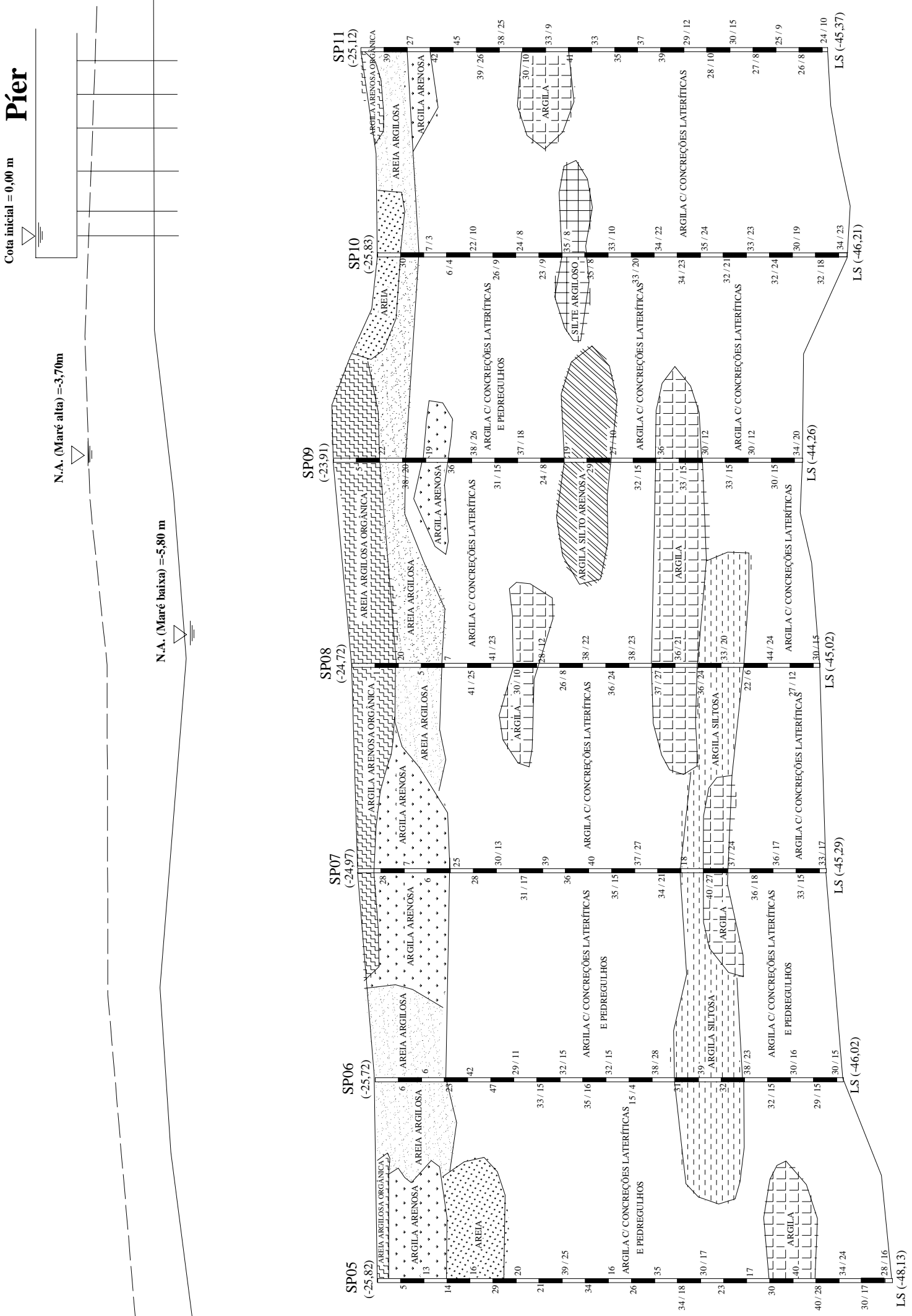
Anexo A - Perfil de SP-12 a SP-18

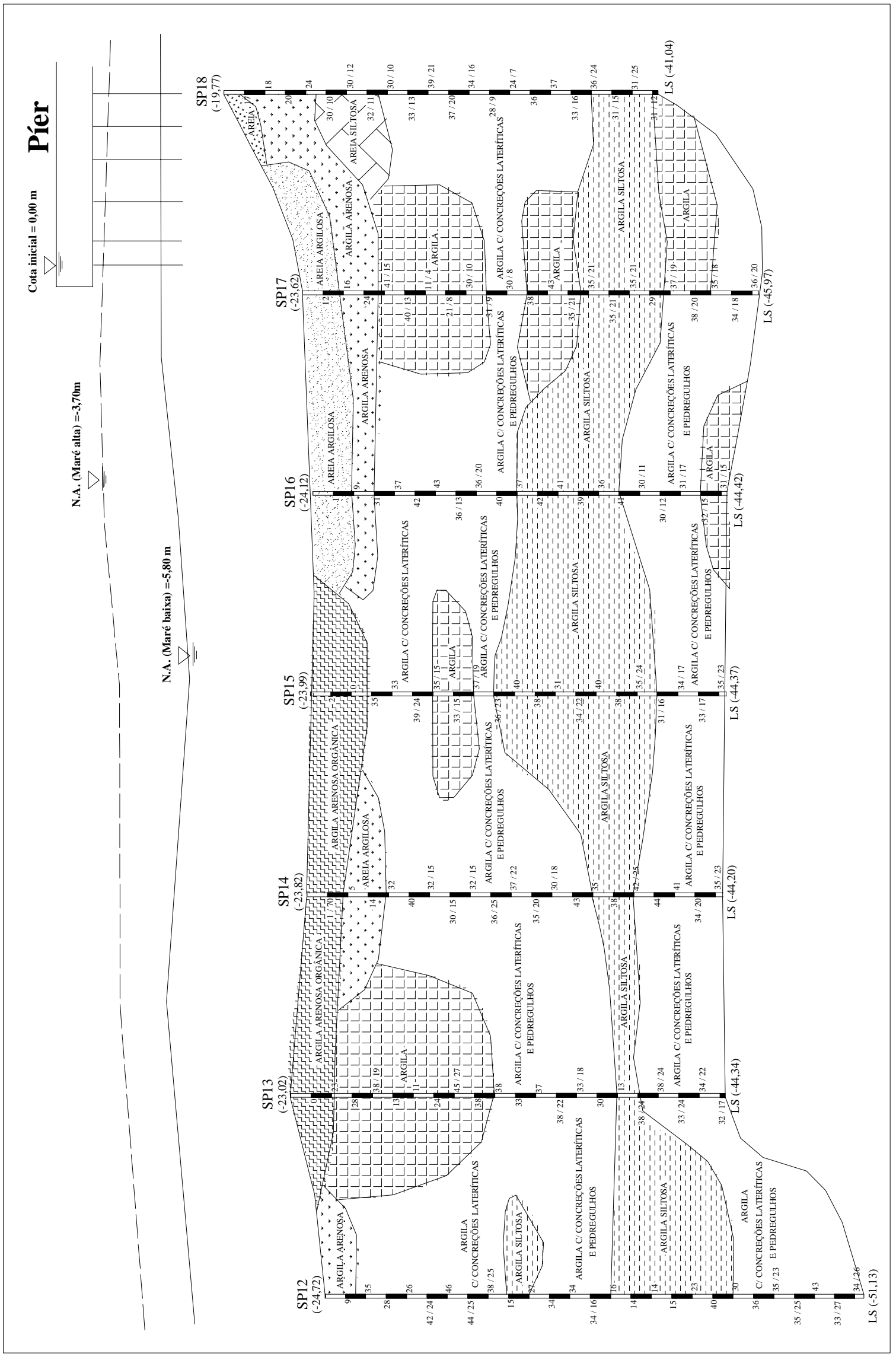


Anexo A - Sondagem SP-4

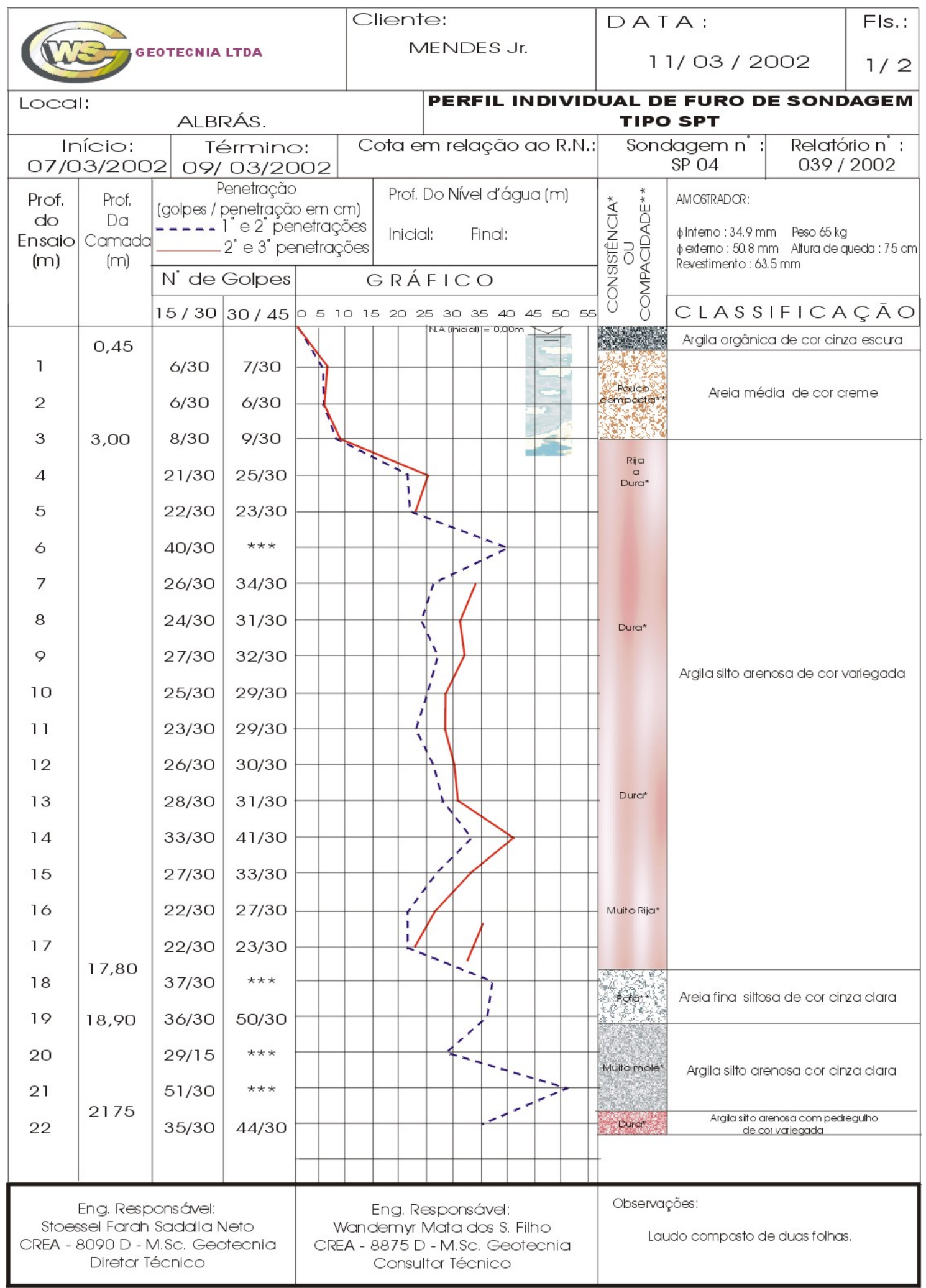




\section{Anexo A - Sondagem SP-4}

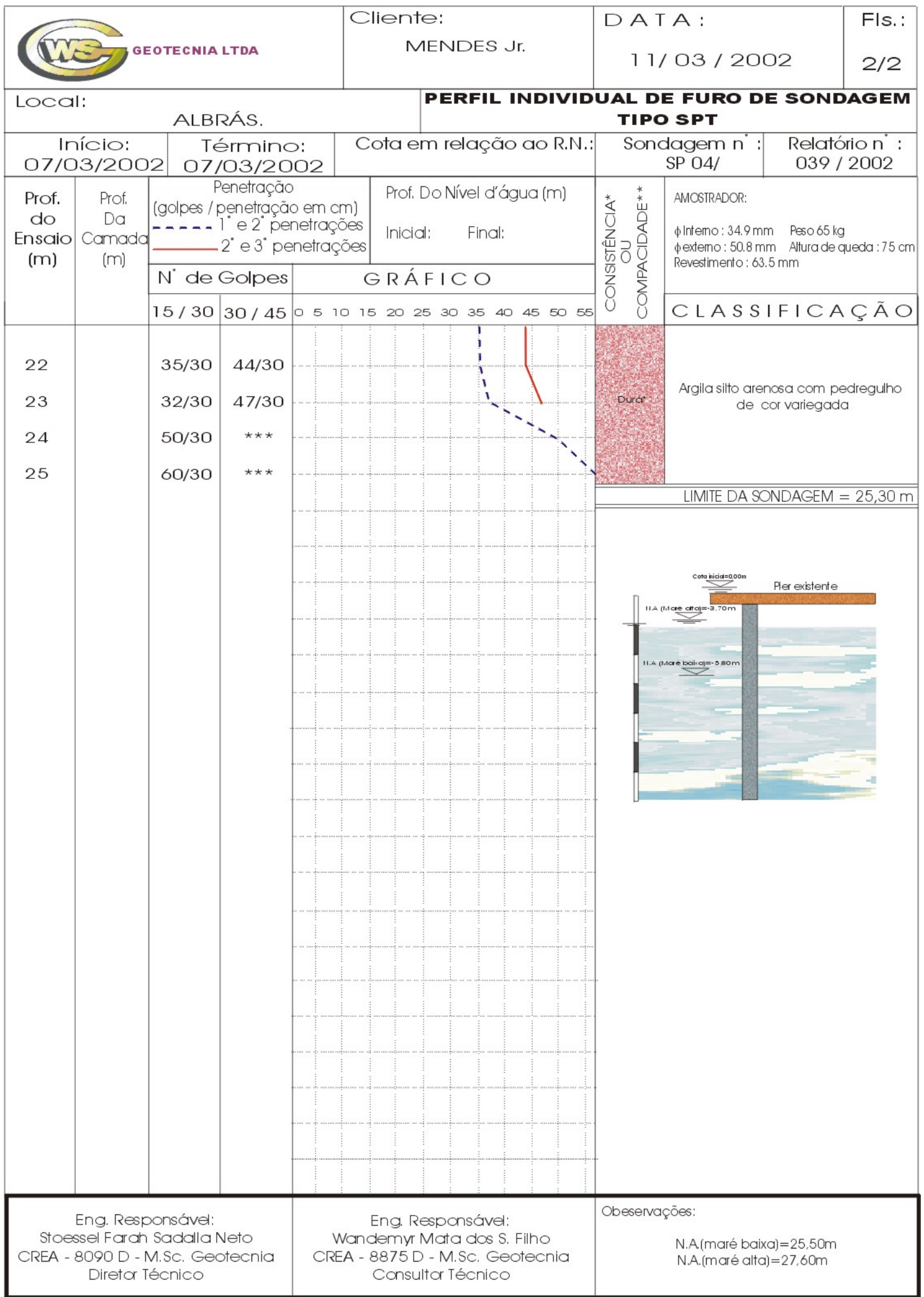


Anexo B - Solicitações Atuantes

\begin{tabular}{|c|c|c|c|c|c|}
\hline \multirow{2}{*}{ ESTACA } & \multirow{2}{*}{$\mathbf{P P}(\mathbf{k N})$} & \multicolumn{2}{|c|}{ PP + OPERAÇÃO (kN) } & \multicolumn{2}{|c|}{ PP + TORMENTA (kN) } \\
\hline & & Compressão & Tração & Compressão & Tração \\
\hline E1 & -545 & -1695 & - & -1703 & - \\
\hline E2 & -616 & -1856 & - & -1886 & - \\
\hline E3 & -668 & -1959 & - & -1998 & - \\
\hline E4 & -692 & -2018 & - & -2057 & - \\
\hline E5 & -742 & -2184 & - & -2215 & - \\
\hline E6 & -754 & -2210 & - & -2231 & - \\
\hline E7 & -746 & -2166 & - & -2184 & - \\
\hline E8 & -737 & -2126 & - & -2146 & - \\
\hline E9 & -729 & -2102 & - & -2128 & - \\
\hline E10 & -724 & -2086 & - & -2115 & - \\
\hline E11 & -722 & -2078 & - & -2107 & - \\
\hline E12 & -721 & -2075 & - & -2101 & - \\
\hline E13 & -721 & -2074 & - & -2093 & - \\
\hline E14 & -721 & -2074 & - & -2090 & - \\
\hline E15 & -722 & -2075 & - & -2092 & - \\
\hline E16 & -722 & -2075 & - & -2098 & - \\
\hline E17 & -722 & -2075 & - & -2104 & - \\
\hline E18 & -722 & -2075 & - & -2105 & - \\
\hline E19 & -722 & -2075 & - & -2105 & - \\
\hline E20 & -722 & -2075 & - & -2099 & - \\
\hline E21 & -722 & -2075 & - & -2093 & - \\
\hline E22 & -722 & -2075 & - & -2092 & - \\
\hline E23 & -722 & -2075 & - & -2096 & - \\
\hline E24 & -722 & -2075 & - & -2102 & - \\
\hline E25 & -722 & -2075 & - & -2105 & - \\
\hline E26 & -722 & -2077 & - & -2107 & - \\
\hline E27 & -722 & -2080 & - & -2106 & - \\
\hline E28 & -722 & -2086 & - & -2105 & - \\
\hline E29 & -722 & -2093 & - & -2108 & - \\
\hline E30 & -722 & -2101 & - & -2117 & - \\
\hline E31 & -722 & -2105 & - & -2127 & - \\
\hline E32 & -723 & -2099 & - & -2129 & - \\
\hline E33 & -725 & -2089 & - & -2122 & - \\
\hline E34 & -727 & -2146 & - & -2181 & - \\
\hline E35 & -729 & -2218 & - & -2246 & - \\
\hline E36 & -728 & -2281 & - & -2301 & - \\
\hline E37 & -726 & -2311 & - & -2328 & - \\
\hline E38 & -720 & -2288 & - & -2310 & - \\
\hline E39 & -714 & -2209 & - & -2243 & - \\
\hline E40 & -708 & -2090 & - & -2133 & - \\
\hline E41 & -706 & -2083 & - & -2125 & - \\
\hline E42 & -707 & -2188 & - & -2221 & - \\
\hline E43 & -712 & -2259 & - & -2281 & - \\
\hline E44 & -717 & -2282 & - & -2298 & - \\
\hline E45 & -721 & -2258 & - & -2277 & - \\
\hline E46 & -724 & -2203 & - & -2231 & - \\
\hline E47 & -725 & -2140 & - & -2174 & - \\
\hline E48 & -725 & -2088 & - & -2122 & - \\
\hline E49 & -724 & -2102 & - & -2132 & - \\
\hline E50 & -724 & -2109 & - & -2132 & - \\
\hline E51 & -723 & -2105 & - & -2121 & - \\
\hline
\end{tabular}




\begin{tabular}{|c|c|c|c|c|c|}
\hline E52 & -722 & -2096 & - & -2111 & - \\
\hline E53 & -722 & -2088 & - & -2107 & - \\
\hline E54 & -722 & -2081 & - & -2108 & - \\
\hline E55 & -722 & -2077 & - & -2108 & - \\
\hline E56 & -722 & -2075 & - & -2106 & - \\
\hline E57 & -722 & -2076 & - & -2104 & - \\
\hline E58 & -722 & -2076 & - & -2098 & - \\
\hline E59 & -722 & -2076 & - & -2095 & - \\
\hline E60 & -722 & -2076 & - & -2098 & - \\
\hline E61 & -722 & -2076 & - & -2103 & - \\
\hline E62 & -722 & -2076 & - & -2106 & - \\
\hline E63 & -722 & -2076 & - & -2106 & - \\
\hline E64 & -722 & -2076 & - & -2103 & - \\
\hline E65 & -722 & -2076 & - & -2096 & - \\
\hline E66 & -722 & -2076 & - & -2092 & - \\
\hline E67 & -722 & -2076 & - & -2093 & - \\
\hline E68 & -722 & -2076 & - & -2098 & - \\
\hline E69 & -722 & -2076 & - & -2104 & - \\
\hline E70 & -722 & -2076 & - & -2105 & - \\
\hline E71 & -722 & -2077 & - & -2106 & - \\
\hline E72 & -723 & -2078 & - & -2103 & - \\
\hline E73 & -725 & -2081 & - & -2102 & - \\
\hline E74 & -727 & -2090 & - & -2111 & - \\
\hline E75 & -728 & -2099 & - & -2126 & - \\
\hline E76 & -725 & -2101 & - & -2137 & - \\
\hline E77 & -715 & -2079 & - & -2121 & - \\
\hline E78 & -691 & -2054 & - & -2085 & - \\
\hline E79 & -646 & -1998 & - & -2003 & - \\
\hline E80 & -578 & -1853 & - & -1852 & - \\
\hline E81 & -721 & -2089 & - & -2197 & - \\
\hline E82 & -718 & -2445 & - & -2429 & 182 \\
\hline E83 & -755 & -2280 & - & -2577 & 23 \\
\hline E84 & -754 & -2693 & 39 & -2661 & 255 \\
\hline E85 & -779 & -2357 & - & -2661 & - \\
\hline E86 & -761 & -2539 & - & -2522 & 72 \\
\hline E87 & -774 & -2300 & - & -2601 & - \\
\hline E88 & -750 & -2493 & - & -2470 & 89 \\
\hline E89 & -768 & -2265 & - & -2558 & - \\
\hline E90 & -743 & -2465 & - & -2440 & 99 \\
\hline E91 & -767 & -2258 & - & -2548 & - \\
\hline E92 & -741 & -2450 & - & -2425 & 85 \\
\hline E93 & -769 & -2262 & - & -2553 & - \\
\hline E94 & -740 & -2439 & - & -2413 & 71 \\
\hline E95 & -771 & -2267 & - & -2554 & - \\
\hline E96 & -739 & -2427 & - & -2401 & 71 \\
\hline E97 & -773 & -2269 & - & -2549 & - \\
\hline E98 & -737 & -2415 & - & -2389 & 68 \\
\hline E99 & -774 & -2271 & - & -2551 & - \\
\hline E100 & -736 & -2404 & - & -2379 & 52 \\
\hline E101 & -776 & -2273 & - & -2555 & - \\
\hline E102 & -734 & -2394 & - & -2370 & 45 \\
\hline E103 & -777 & -2274 & - & -2552 & - \\
\hline E104 & -733 & -2384 & - & -2361 & 48 \\
\hline E105 & -779 & -2273 & - & -2548 & - \\
\hline E106 & -731 & -2376 & - & -2353 & 44 \\
\hline E107 & -780 & -2269 & - & -2549 & - \\
\hline
\end{tabular}




\begin{tabular}{|c|c|c|c|c|c|}
\hline E108 & -730 & -2372 & - & -2347 & 32 \\
\hline E109 & -781 & -2272 & - & -2555 & - \\
\hline E110 & -729 & -2359 & - & -2337 & 23 \\
\hline E111 & -784 & -2294 & - & -2575 & - \\
\hline E112 & -731 & -2400 & 10 & -2377 & 38 \\
\hline E113 & -789 & -2465 & - & -2755 & - \\
\hline E114 & -741 & -2442 & - & -2440 & - \\
\hline E115 & -734 & -2625 & 195 & -2595 & 122 \\
\hline E116 & -733 & -2288 & - & -2286 & - \\
\hline E117 & -717 & -2196 & - & -2194 & - \\
\hline E118 & -693 & -2190 & - & -2189 & - \\
\hline E119 & -669 & -2335 & 99 & -2338 & - \\
\hline E120 & -647 & -2021 & - & -1993 & - \\
\hline E121 & -694 & -2409 & 59 & -2415 & - \\
\hline E122 & -709 & -2246 & - & -2248 & - \\
\hline E123 & -729 & -2238 & - & -2238 & - \\
\hline E124 & -746 & -2332 & - & -2332 & - \\
\hline E125 & -724 & -2606 & 198 & -2576 & 146 \\
\hline E126 & -759 & -2505 & - & -2505 & - \\
\hline E127 & -779 & -2447 & - & -2735 & - \\
\hline E128 & -731 & -2417 & 7 & -2394 & 50 \\
\hline E129 & -780 & -2295 & - & -2574 & - \\
\hline E130 & -733 & -2389 & - & -2358 & 35 \\
\hline E131 & -777 & -2279 & - & -2564 & - \\
\hline E132 & -735 & -2407 & - & -2375 & 46 \\
\hline E133 & -775 & -2276 & - & -2555 & - \\
\hline E134 & -737 & -2416 & - & -2388 & 61 \\
\hline E135 & -772 & -2276 & - & -2549 & - \\
\hline E136 & -739 & -2430 & - & -2403 & 68 \\
\hline E137 & -770 & -2276 & - & -2553 & - \\
\hline E138 & -742 & -2446 & - & -2420 & 68 \\
\hline E139 & -768 & -2274 & - & -2556 & - \\
\hline E140 & -744 & -2463 & 5 & -2438 & 79 \\
\hline E141 & -765 & -2272 & - & -2552 & - \\
\hline E142 & -747 & -2482 & 23 & -2458 & 94 \\
\hline E143 & -762 & -2270 & - & -2553 & - \\
\hline E144 & -750 & -2501 & 17 & -2480 & 95 \\
\hline E145 & -760 & -2266 & - & -2559 & - \\
\hline E146 & -752 & -2520 & 16 & -2502 & 99 \\
\hline E147 & -757 & -2262 & - & -2558 & - \\
\hline E148 & -755 & -2540 & 37 & -2524 & 117 \\
\hline E149 & -754 & -2257 & - & -2555 & - \\
\hline E150 & -758 & -2560 & 50 & -2548 & 130 \\
\hline E151 & -752 & -2256 & - & -2563 & 24 \\
\hline E152 & -763 & -2584 & 36 & -2576 & 123 \\
\hline E153 & -752 & -2262 & - & -2583 & 49 \\
\hline E154 & -770 & -2615 & 31 & -2609 & 121 \\
\hline E155 & -753 & -2271 & - & -2596 & 66 \\
\hline E156 & -773 & -2647 & 69 & -2645 & 156 \\
\hline E157 & -741 & -2218 & - & -2523 & 63 \\
\hline E158 & -755 & -2697 & 199 & -2697 & 295 \\
\hline E159 & -704 & -2104 & - & -2336 & 12 \\
\hline E160 & -656 & -2237 & 50 & -2249 & - \\
\hline E161 & -679 & -2309 & 26 & -2324 & - \\
\hline E162 & -740 & -2255 & - & -2387 & - \\
\hline E163 & -736 & -2651 & - & -2640 & 161 \\
\hline
\end{tabular}




\begin{tabular}{|c|c|c|c|c|c|}
\hline E164 & -764 & -2605 & 126 & -2934 & 280 \\
\hline E165 & -765 & -2699 & - & -2691 & 99 \\
\hline E166 & -780 & -2409 & - & -2721 & - \\
\hline E167 & -757 & -2632 & - & -2615 & 73 \\
\hline E168 & -768 & -2345 & - & -2653 & - \\
\hline E169 & -742 & -2560 & - & -2538 & 72 \\
\hline E170 & -760 & -2314 & - & -2619 & - \\
\hline E171 & -735 & -2526 & - & -2503 & 72 \\
\hline E172 & -760 & -2309 & - & -2610 & - \\
\hline E173 & -734 & -2513 & - & -2489 & 63 \\
\hline E174 & -762 & -2313 & - & -2612 & - \\
\hline E175 & -733 & -2503 & - & -2478 & 53 \\
\hline E176 & -764 & -2317 & - & -2612 & - \\
\hline E177 & -732 & -2491 & - & -2466 & 48 \\
\hline E178 & -766 & -2320 & - & -2611 & - \\
\hline E179 & -730 & -2479 & - & -2454 & 42 \\
\hline E180 & -768 & -2321 & - & -2612 & - \\
\hline E181 & -729 & -2468 & - & -2444 & 33 \\
\hline E182 & -769 & -2323 & - & -2613 & - \\
\hline E183 & -727 & -2458 & - & -2435 & 27 \\
\hline E184 & -771 & -2324 & - & -2612 & - \\
\hline E185 & -726 & -2448 & - & -2426 & 24 \\
\hline E186 & -772 & -2323 & - & -2611 & - \\
\hline E187 & -724 & -2441 & - & -2418 & 19 \\
\hline E188 & -773 & -2320 & - & -2610 & - \\
\hline E189 & -723 & -2436 & - & -2412 & 12 \\
\hline E190 & -774 & -2324 & - & -2614 & - \\
\hline E191 & -722 & -2423 & - & -2402 & 5 \\
\hline E192 & -777 & -2340 & - & -2631 & - \\
\hline E193 & -724 & -2473 & - & -2451 & 21 \\
\hline E194 & -781 & -2492 & - & -2795 & - \\
\hline E195 & -734 & -2502 & - & -2511 & - \\
\hline E196 & -727 & -2723 & 195 & -2694 & 129 \\
\hline E197 & -727 & -2356 & - & -2364 & - \\
\hline E198 & -712 & -2268 & - & -2277 & - \\
\hline E199 & -689 & -2268 & - & -2279 & - \\
\hline E200 & -665 & -2409 & 63 & -2426 & 7 \\
\hline E201 & -643 & -2119 & - & -2092 & - \\
\hline E202 & -690 & -2484 & 42 & -2503 & - \\
\hline E203 & -704 & -2319 & - & -2332 & - \\
\hline E204 & -724 & -2308 & - & -2317 & - \\
\hline E205 & -740 & -2399 & - & -2408 & - \\
\hline E206 & -716 & -2702 & 197 & -2673 & 152 \\
\hline E207 & -753 & -2564 & - & -2574 & - \\
\hline E208 & -772 & -2472 & - & -2773 & - \\
\hline E209 & -724 & -2492 & - & -2471 & 35 \\
\hline E210 & -773 & -2341 & - & -2631 & - \\
\hline E211 & -727 & -2454 & - & -2424 & 18 \\
\hline E212 & -771 & -2332 & - & -2624 & - \\
\hline E213 & -728 & -2472 & - & -2441 & 27 \\
\hline E214 & -768 & -2329 & - & -2617 & - \\
\hline E215 & -730 & -2482 & - & -2454 & 37 \\
\hline E216 & -766 & -2327 & - & -2613 & - \\
\hline E217 & -732 & -2496 & - & -2470 & 44 \\
\hline E218 & -763 & -2327 & - & -2615 & - \\
\hline E219 & -735 & -2512 & - & -2487 & 50 \\
\hline
\end{tabular}




\begin{tabular}{|c|c|c|c|c|c|}
\hline E220 & -761 & -2326 & - & -2616 & - \\
\hline E221 & -737 & -2529 & - & -2505 & 59 \\
\hline E222 & -758 & -2324 & - & -2615 & - \\
\hline E223 & -740 & -2547 & - & -2525 & 69 \\
\hline E224 & -756 & -2322 & - & -2617 & - \\
\hline E225 & -743 & -2567 & - & -2547 & 76 \\
\hline E226 & -753 & -2319 & - & -2619 & - \\
\hline E227 & -745 & -2586 & - & -2569 & 85 \\
\hline E228 & -750 & -2314 & - & -2619 & - \\
\hline E229 & -748 & -2606 & 5 & -2591 & 96 \\
\hline E230 & -747 & -2310 & - & -2619 & 12 \\
\hline E231 & -751 & -2626 & 13 & -2615 & 106 \\
\hline E232 & -745 & -2308 & - & -2626 & 35 \\
\hline E233 & -756 & -2652 & 12 & -2644 & 108 \\
\hline E234 & -746 & -2316 & - & -2644 & 62 \\
\hline E235 & -765 & -2686 & 10 & -2682 & 109 \\
\hline E236 & -747 & -2327 & - & -2661 & 86 \\
\hline E237 & -769 & -2723 & 35 & -2721 & 139 \\
\hline E238 & -736 & -2282 & - & -2601 & 84 \\
\hline E239 & -749 & -2761 & 146 & -2762 & 267 \\
\hline E240 & -694 & -2153 & - & -2404 & 39 \\
\hline E241 & -632 & -2067 & - & -2067 & - \\
\hline E242 & -737 & -2381 & - & -2382 & - \\
\hline E243 & -773 & -2463 & - & -2465 & - \\
\hline E244 & -791 & -2507 & - & -2510 & - \\
\hline E245 & -777 & -2443 & - & -2445 & - \\
\hline E246 & -759 & -2369 & - & -2370 & - \\
\hline E247 & -747 & -2323 & - & -2323 & - \\
\hline E248 & -739 & -2291 & - & -2291 & - \\
\hline E249 & -735 & -2279 & - & -2279 & - \\
\hline E250 & -735 & -2278 & - & -2278 & - \\
\hline E251 & -734 & -2275 & - & -2274 & - \\
\hline E252 & -734 & -2276 & - & -2276 & - \\
\hline E253 & -736 & -2281 & - & -2281 & - \\
\hline E254 & -735 & -2278 & - & -2278 & - \\
\hline E255 & -735 & -2278 & - & -2278 & - \\
\hline E256 & -736 & -2282 & - & -2282 & - \\
\hline E257 & -735 & -2278 & - & -2278 & - \\
\hline E258 & -735 & -2278 & - & -2278 & - \\
\hline E259 & -736 & -2282 & - & -2282 & - \\
\hline E260 & -735 & -2278 & - & -2278 & - \\
\hline E261 & -735 & -2278 & - & -2278 & - \\
\hline E262 & -736 & -2282 & - & -2282 & - \\
\hline E263 & -735 & -2279 & - & -2279 & - \\
\hline E264 & -735 & -2278 & - & -2278 & - \\
\hline E265 & -736 & -2283 & - & -2283 & - \\
\hline E266 & -735 & -2281 & - & -2280 & - \\
\hline E267 & -735 & -2283 & - & -2282 & - \\
\hline E268 & -736 & -2289 & - & -2289 & - \\
\hline E269 & -734 & -2286 & - & -2286 & - \\
\hline E270 & -734 & -2283 & - & -2284 & - \\
\hline E271 & -735 & -2282 & - & -2284 & - \\
\hline E272 & -735 & -2312 & - & -2316 & - \\
\hline E273 & -737 & -2369 & - & -2376 & - \\
\hline E274 & -742 & -2447 & - & -2456 & - \\
\hline E275 & -746 & -2516 & - & -2525 & - \\
\hline
\end{tabular}




\begin{tabular}{|c|c|c|c|c|c|}
\hline E276 & -751 & -2564 & - & -2575 & - \\
\hline E277 & -754 & -2563 & - & -2578 & - \\
\hline E278 & -749 & -2481 & - & -2504 & - \\
\hline E279 & -742 & -2352 & - & -2383 & - \\
\hline E280 & -741 & -2349 & - & -2381 & - \\
\hline E281 & -741 & -2454 & - & -2477 & - \\
\hline E282 & -736 & -2502 & - & -2516 & - \\
\hline E283 & -733 & -2504 & - & -2514 & - \\
\hline E284 & -733 & -2475 & - & -2483 & - \\
\hline E285 & -732 & -2416 & - & -2424 & - \\
\hline E286 & -733 & -2356 & - & -2363 & - \\
\hline E287 & -735 & -2312 & - & -2317 & - \\
\hline E288 & -735 & -2280 & - & -2282 & - \\
\hline E289 & -735 & -2286 & - & -2286 & - \\
\hline E290 & -736 & -2293 & - & -2293 & - \\
\hline E291 & -735 & -2287 & - & -2287 & - \\
\hline E292 & -735 & -2284 & - & -2283 & - \\
\hline E293 & -736 & -2285 & - & -2284 & - \\
\hline E294 & -735 & -2279 & - & -2279 & - \\
\hline E295 & -735 & -2278 & - & -2278 & - \\
\hline E296 & -736 & -2282 & - & -2282 & - \\
\hline E297 & -735 & -2278 & - & -2278 & - \\
\hline E298 & -735 & -2278 & - & -2278 & - \\
\hline E299 & -736 & -2282 & - & -2282 & - \\
\hline E300 & -735 & -2278 & - & -2278 & - \\
\hline E301 & -735 & -2278 & - & -2278 & - \\
\hline E302 & -736 & -2282 & - & -2282 & - \\
\hline E303 & -735 & -2278 & - & -2278 & - \\
\hline E304 & -735 & -2278 & - & -2278 & - \\
\hline E305 & -736 & -2282 & - & -2282 & - \\
\hline E306 & -735 & -2277 & - & -2277 & - \\
\hline E307 & -735 & -2277 & - & -2277 & - \\
\hline E308 & -735 & -2280 & - & -2280 & - \\
\hline E309 & -735 & -2276 & - & -2276 & - \\
\hline E310 & -735 & -2278 & - & -2278 & - \\
\hline E311 & -738 & -2287 & - & -2287 & - \\
\hline E312 & -739 & -2292 & - & -2293 & - \\
\hline E313 & -743 & -2305 & - & -2308 & - \\
\hline E314 & -748 & -2323 & - & -2326 & - \\
\hline E315 & -747 & -2322 & - & -2325 & - \\
\hline E316 & -737 & -2292 & - & -2292 & - \\
\hline E317 & -709 & -2225 & - & -2226 & - \\
\hline E318 & -647 & -2077 & - & -2080 & - \\
\hline E319 & -552 & -1801 & - & -1805 & - \\
\hline E320 & -596 & -1620 & - & -1622 & - \\
\hline E321 & -766 & -2128 & - & -2130 & - \\
\hline E322 & -801 & -2222 & - & -2224 & - \\
\hline E323 & -804 & -2217 & - & -2218 & - \\
\hline E324 & -793 & -2169 & - & -2171 & - \\
\hline E325 & -777 & -2114 & - & -2115 & - \\
\hline E326 & -774 & -2102 & - & -2103 & - \\
\hline E327 & -772 & -2099 & - & -2099 & - \\
\hline E328 & -773 & -2100 & - & -2101 & - \\
\hline E329 & -773 & -2102 & - & -2102 & - \\
\hline E330 & -774 & -2103 & - & -2103 & - \\
\hline E331 & -774 & -2102 & - & -2103 & - \\
\hline
\end{tabular}




\begin{tabular}{|c|c|c|c|c|c|}
\hline E332 & -774 & -2103 & - & -2103 & - \\
\hline E333 & -774 & -2102 & - & -2103 & - \\
\hline E334 & -774 & -2102 & - & -2103 & - \\
\hline E335 & -774 & -2103 & - & -2103 & . \\
\hline E336 & -774 & -2102 & - & -2103 & . \\
\hline E337 & -773 & -2103 & - & -2103 & . \\
\hline E338 & -773 & -2103 & - & -2103 & . \\
\hline E339 & -772 & -2103 & - & -2105 & . \\
\hline E340 & -771 & -2102 & - & -2105 & . \\
\hline E341 & -771 & -2101 & - & -2104 & . \\
\hline E342 & -774 & -2104 & - & -2109 & . \\
\hline E343 & -798 & -2187 & - & -2196 & . \\
\hline E344 & -824 & -2276 & - & -2288 & . \\
\hline E345 & -847 & -2322 & - & -2349 & . \\
\hline E346 & -847 & -2301 & - & -2333 & . \\
\hline E347 & -822 & -2268 & - & -2283 & . \\
\hline E348 & -797 & -2189 & - & -2200 & . \\
\hline E349 & -775 & -2107 & - & -2114 & - \\
\hline E350 & -772 & -2097 & - & -2102 & . \\
\hline E351 & -772 & -2107 & - & -2109 & . \\
\hline E352 & -773 & -2108 & - & -2110 & . \\
\hline E353 & -773 & -2105 & - & -2106 & . \\
\hline E354 & -774 & -2103 & - & -2104 & . \\
\hline E355 & -774 & -2101 & - & -2103 & . \\
\hline E356 & -774 & -2101 & - & -2103 & . \\
\hline E357 & -774 & -2102 & - & -2103 & . \\
\hline E358 & -774 & -2101 & - & -2103 & . \\
\hline E359 & -774 & -2101 & - & -2103 & . \\
\hline E360 & -774 & -2101 & - & -2103 & . \\
\hline E361 & -773 & -2101 & - & -2103 & . \\
\hline E362 & -773 & -2101 & - & -2102 & . \\
\hline E363 & -773 & -2100 & - & -2102 & . \\
\hline E364 & -773 & -2099 & - & -2101 & . \\
\hline E365 & -773 & -2100 & - & -2101 & . \\
\hline E366 & -774 & -2102 & - & -2103 & . \\
\hline E367 & -780 & -2120 & - & -2123 & . \\
\hline E368 & -785 & -2137 & - & -2140 & . \\
\hline E369 & -789 & -2154 & - & -2159 & . \\
\hline E370 & -773 & -2109 & - & -2115 & . \\
\hline E371 & -638 & -1707 & - & -1708 & \\
\hline E372 & -479 & -1212 & - & -1212 & . \\
\hline E373 & -645 & -1438 & - & -1402 & . \\
\hline E374 & -828 & -1937 & - & -1910 & . \\
\hline E375 & -869 & -2048 & - & -2019 & . \\
\hline E376 & -886 & -2077 & - & -2056 & . \\
\hline E377 & -881 & -2058 & - & -2041 & . \\
\hline E378 & -871 & -2048 & - & -2022 & . \\
\hline E379 & -869 & -2040 & - & -2017 & . \\
\hline E380 & -868 & -2038 & - & -2012 & . \\
\hline E381 & -868 & -2030 & - & -2008 & . \\
\hline E382 & -869 & -2027 & - & -2008 & . \\
\hline E383 & -869 & -2038 & - & -2013 & . \\
\hline E384 & -869 & -2037 & - & -2017 & . \\
\hline E385 & -869 & -2043 & - & -2017 & . \\
\hline E386 & -869 & -2029 & - & -2010 & . \\
\hline E387 & -869 & -2025 & - & -2009 & . \\
\hline
\end{tabular}




\begin{tabular}{|c|c|c|c|c|c|}
\hline E388 & -869 & -2042 & - & -2016 & - \\
\hline E389 & -870 & -2041 & - & -2018 & - \\
\hline E390 & -869 & -2042 & - & -2016 & - \\
\hline E391 & -869 & -2032 & - & -2010 & - \\
\hline E392 & -867 & -2026 & - & -2008 & - \\
\hline E393 & -866 & -2035 & - & -2013 & - \\
\hline E394 & -868 & -2050 & - & -2031 & - \\
\hline E395 & -875 & -2080 & - & -2053 & - \\
\hline E396 & -914 & -2180 & - & -2160 & - \\
\hline E397 & -952 & -2278 & - & -2263 & - \\
\hline E398 & -994 & -2405 & - & -2380 & - \\
\hline E399 & -994 & -2397 & - & -2374 & - \\
\hline E400 & -953 & -2286 & - & -2265 & - \\
\hline E401 & -915 & -2174 & - & -2160 & - \\
\hline E402 & -876 & -2069 & - & -2054 & - \\
\hline E403 & -869 & -2055 & - & -2036 & - \\
\hline E404 & -867 & -2041 & - & -2022 & - \\
\hline E405 & -868 & -2033 & - & -2016 & - \\
\hline E406 & -869 & -2024 & - & -2009 & - \\
\hline E407 & -869 & -2028 & - & -2011 & - \\
\hline E408 & -869 & -2039 & - & -2019 & - \\
\hline E409 & -869 & -2039 & - & -2019 & - \\
\hline E410 & -869 & -2031 & - & -2014 & - \\
\hline E411 & -869 & -2028 & - & -2012 & - \\
\hline E412 & -869 & -2035 & - & -2016 & - \\
\hline E413 & -869 & -2038 & - & -2018 & - \\
\hline E414 & -869 & -2033 & - & -2015 & - \\
\hline E415 & -869 & -2026 & - & -2010 & - \\
\hline E416 & -869 & -2023 & - & -2007 & - \\
\hline E417 & -869 & -2028 & - & -2011 & - \\
\hline E418 & -869 & -2036 & - & -2017 & - \\
\hline E419 & -871 & -2040 & - & -2021 & - \\
\hline E420 & -880 & -2051 & - & -2036 & - \\
\hline E421 & -886 & -2067 & - & -2053 & - \\
\hline E422 & -887 & -2082 & - & -2064 & - \\
\hline E423 & -864 & -2025 & - & -2003 & - \\
\hline E424 & -699 & -1564 & - & -1542 & - \\
\hline E425 & -530 & -1082 & - & -1066 & - \\
\hline E61 & -1098 & -2198 & & -2206 & - \\
\hline E69 & -488 & -1933 & & -2664 & - \\
\hline E67 & -721 & -2524 & & -2825 & 523 \\
\hline E68 & -766 & -2210 & & -2867 & 130 \\
\hline E65 & -766 & -2340 & & -3019 & 320 \\
\hline E66 & -721 & -2360 & & -3053 & 557 \\
\hline E64 & -488 & -1656 & & -1933 & 45 \\
\hline E75 & -649 & -1982 & & -2192 & - \\
\hline E73 & -783 & -2387 & & -2703 & - \\
\hline E74 & -605 & -2037 & & -2489 & - \\
\hline E72 & -729 & -2236 & & -2576 & - \\
\hline E71 & -790 & -2269 & & -2730 & 317 \\
\hline E78 & -828 & -2232 & & -2238 & - \\
\hline E77 & -804 & -2232 & & -2244 & - \\
\hline E76 & -759 & -2220 & & -2230 & - \\
\hline E82 & -1117 & -2317 & & -2326 & - \\
\hline E81 & -861 & -2120 & & -2126 & - \\
\hline
\end{tabular}




\section{Anexo C - Superfície Resistente Prevista}

Eixo transversal: $\quad$ Face de ligação entre o final do Berço 200 e a Transição

Eixo longitudinal: $\quad$ Face SUL do Berço 300

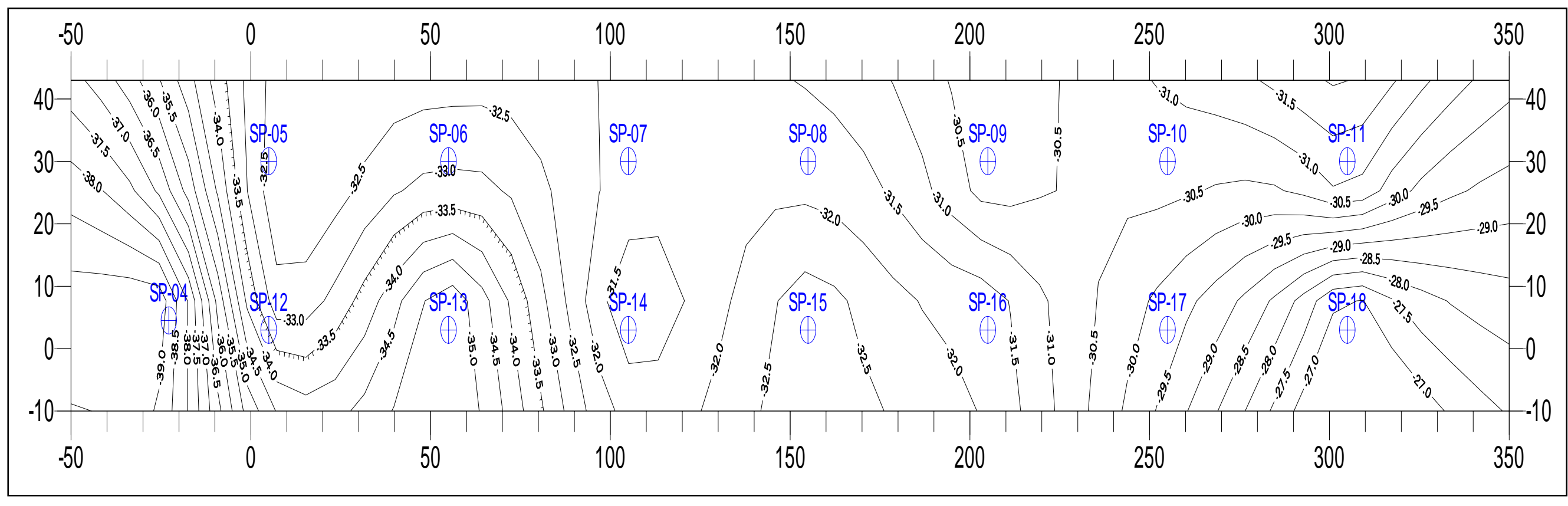

